FOR THE PEOPLE FOR EDVCATION FOR SCIENCE

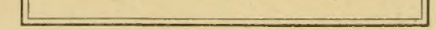

LIBRARY
OF
THE AMERICAN MUSEUM

NATURAL HISTORY 





\section{BRITISH REPTILES.}




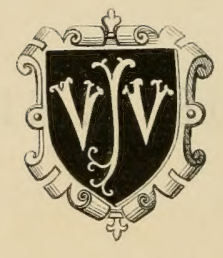




\title{
HISTORY
}

OF

\section{BRITISH REPTILES.}

BY

\author{
THOMAS BELL, SEC. R.S. F.L.S. F.G.S.
}

CORRESPONDING MEMBER OF THE PHILOMATHIC AND NATURAL HISTORY

SOCYETIES OF PARIS, OF THE ACADEMY OF SCIENCES OF PHILADELPHIA, OF THE BOSTON SOCIETY OF NATURAL history, ETC., ETC. PROFESSOR OF ZOOLOGY IN KING'S COLLEGE, LONDON.

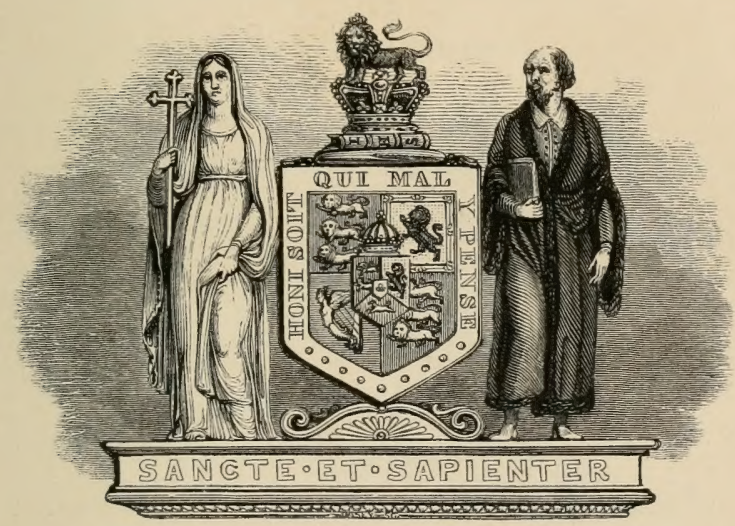

ILLUSTRATED BY 50 WOOD-ENGRAVINGS. SECOND EDITION.

L O N D O :

JOHN VAN VOORST, 1, PATERNOSTER ROW. M.DCCC.XLIX. 


$$
2+93991 \times \text { our } 24
$$

LONDON :

Printed by S, \& J. BeNTLEY and HENRY FLEY, Bangor House, Shoe Lane. 
WVILLIAM YARRELL, ESQ. V.P.L.S. V.P.Z.S.

THIS LITTLE VOLUME,

FORMING A HUMBLE PORTION OF THAT SERIES OF WORKS

ILLUSTRATIVE OF

B R I T I S H Z O O L 0 G Y, WHICH DERIVES ITS PRINCIPAL

ATTRACTION AND VALUE

FROM HIS EXTENSIVE INFORMATION

AND HAPPY METHOD OF COMMUNICATING IT,

IS INSCRIBED

AS A CORDIAL BUT INADEQUATE OFFERING

OF REGARD AND RESPECT, BY HIS SINCERE FRIEND,

THE AUTHOR. 



\section{IN'TRODUCTION.}

The Reptilia constitute a class of vertebrated animals of which the structural characters are as follow:-They have cold blood, - that is to say, their power of producing animal heat is so limited as scarcely to be appreciable, and not sufficient, therefore, to keep up any standard temperature of the body, nor to prevent it from following all the thermal variations of the atmosphere or water by which they are surrounded.

The integument is covered with hard and dry cuticle in various modifications of form, in some constituting broad plates, in others imbricated scales. The heart is in all cases trilocular, - that is to say, it is composed of two auricles and a single ventricle; the respiration is exclusively pulmonary throughout life, and their reproduction is oviparous. The Amplibia, or Batrachia, which are included in the Reptilia by Cuvier and many other naturalists, differ from them, however, in various essential and important characters. The heart particularly is bilo. cular: the integument is naked, and the respiration is carried on by means of branchiæ during the earlier period of life, changing - in some totally, and in others partially - to the pulmonary character in the adult condition. 
The Reptilia, according to most naturalists, include five orders: the Testudinata, or Tortoises and Turtles; the Enaliosauria of Conybeare, to which the gigantic fossil genera, the Ichthyosaurus and Plesiosaurus belong; the Loricata, or Crocodiles and Alligators; the Sauria, or Lizard tribe, and the Ophidia, or Serpents.

There is no other class of vertebrated animals, the different groups of which are formed upon types of structure differing so essentially from each other as these. The eagle and the humming-bird, the ostrich and the petrel, widely as they appear to be separated from each other, not by size only, but by form and habits, still exhibit the same general structure of the skeleton, of the organs of digestion and motion, of the integument, and, in fact, of the whole organization of the body, the various systems of which differ only amongst the different groups by comparative degrees of developement. Even amongst the Mammalia, the whale with its enormous and almost mountainous bulk, paddled through the deepest retreats of ocean by its short fins, which are modifications of the anterior extremities, and by that broad expanded oar, its fleshy tail,-is still formed upon the same general plan of organization as the little light and aërial bat, which flits so rapidly through the regions of air, supported by its thin membranous wings, which are expanded upon slight and linear fingers, the representatives of the same bones which in the former animal are contracted into a massive and shapeless fin. Nor is there in the other organs of the body any more considerable difference of developement. But in the present class, the discrepancies are far more conspicuous, particularly in the whole constitution of the skeleton, in the organs of motion, in the integuments, and many other 
important portions of their organization. If, with Cuvier, and most other Zoologists, we include the amphibious group in this class, these discrepancies are still more remarkable; but even restricting our view to the Reptilia proper, they are sufficiently striking; and a slight glance at the general structure of two of the orders will exhibit them in a very obvious point of view.

In the Chelonians, or Tortoises, and in the Ophidians, or Serpent tribe, the extremes of these different types of organization are exhibited. In the common European land Tortoise, Testudo Graca, which may be selected as a familiar example of the former group, the whole structure of the skeleton is brought into the most compact and solid state. The bones of the cranium and face are consolidated into a single and immovable case, with scarcely the vestige of sutures showing the separation of the different centres of ossification upon which it has been formed; there are no teeth, but the margins of the upper and of the lower jaw are covered by a horny beak, the latter being received into a groove of the former, and thus closing like the lid of a box; then the whole of the dorsal vertebræ, the ribs, the bones representing the sterno-costal cartilages, and the broad united sternum, are altogether compacted into a case of bone, without any separation between the parts of which it is composed. The anterior and posterior extremities are fully developed, but, instead of being placed exterior to the thorax, they are all of them contained within its cavity, and even the bones of the feet are only extended beyond the horny box which protects them, when the animal is employing them in progression.

What a contrast to this solid and compact structure is exhibited by the form of the lithe and tortuous Ser- 
pent! Most of the bones of the head are permanently separate; those of the upper and lower jaw particularly being capable of great extension; there are perfect teeth ; the vertebræ, which are extremely numerous, are susceptible of the most extensive lateral motion; and the ribs, slencler and but slightly attached, compensate for the absence of both anterior and posterior extremities, by being themselves the instruments of the animal's progression. It is unnecessary here to enter more particularly into the detail of these curious diversities of structure; enough has been said to show low far these two groups are separated from each other in their general organization; and it needs scarcely to be adder that the diversity of their habits is not less remarkable.

The relations of these groups seem almost to set all the established principles of classification at defiance; nor is there any one system hitherto promulgated which appears to me satisfactorily to solve the difficulty. Those who have made the most philosophical attempts to ascertain the natural system, the grand and harmonious plan upon which all organic creation is believed to have been formed, have concurred in considering the Reptilia as constituting a group of equal value in the vertebrate division of the animal kingdom, with the Mammalia and birds. It may be safely predicated that, if the system to which I more particularly refer be true, all the groups of equal rank must be founded upon characters of equal value and importance. That if, for instance, the group of Mammalia and that of birds, be equal to each other, each of the other classes - that is to say, every other group of the same rank, - must be equal to each other; and also, that the subordinate groups in each of these classes must exhibit the same mutual relations in every case. But if it can be shown that in one class, so 
called, two ordinal groups exhibit as great a discrepancy in their relative plan of organization as any two classes do, then the relation of the former to either of the latter is not, and cannot be, the same as that which exists between the latter two. Yet in this predicament stand the three first classes of the Vertebrata; the relations of the Mammalia and birds being much stronger and more obvious than those of the Reptilia to either, and the two groups of the latter, which I have just sketched, the Tortoises and the Serpents, being nearly or quite as far removed by their structure from each other as the birds are from the Mammalia. The mode of reproduction is the sole exception of consequence to this view of their relations; and here we have, on the other hand, a close approximation between the Reptilia and the birds themselves.

These considerations appear to me to exhibit insurmountable objections to the consistency and unity of the quinary arrangement, as representing an uniform and perfect plan or system upon which the animal kingdom was created; and I cannot believe that the occasional occurrence of even striking and important coincidences, which appear on a partial view to prove its truth, are sufficient to counterbalance the evidence of its inconsistency which I have just adduced.

I shall now enter into a more particular description of the structure of these animals, commencing with the organs of circulation and respiration. The heart, which is formed of three cavities,-namely, of two distinct auricles opening into one common ventricle, sends to the lungs, on each contraction, a portion only of the blood which it has received from the different parts of the body by the veins, so that the blood which, by the heart's contraction, is distributed to the body through the arteries, is of a mixed 
nature, consisting of a portion of the impure blood just retumed from thence, with that which has been aërated in the lungs. It is clear that the blood is by this mechanism but partially changed by the action of oxygen; in other words, that the quantity of respiration, speaking with reference to the physiological meaning of the term, is comparatively small. Hence arises the circumstance that these animals have what is called cold blood; for as it is from respiration that the blood derives its heat, and the temperature of the body is thereby sustained in animals which have more perfect respiration, it follows that where this function is but imperfectly performed, the animal heat, muscular force, and all the other functions dependent upon respiration, will be diminished. In the fishes the same effect is produced by different means. These are likewise cold-blooded animals; and in these, also, this peculiarity arises from the small quantity of respiration which they enjoy; but the phenomenon which in the reptiles is produced by the transmission of a part only of the blood through the respiratory organ at each contraction of the heart, is in the fishes effected by the different medium through which the oxygen is presented to the blood; for in the latter, although the whole of the blood is sent through the branclice, or gills, the quantity of oxygen, leld in solution in the water which bathes them, is so small as to effect but a partial change in the condition of the blood. In one case the circulation is complete, but the respiration is aquatic, and therefore imperfect; in the other, the application of the air to the blood is immediate, but the circulation is incomplete. In the Mammalia, on the contrary, where the heart is double, and the circulation consequently complete, combined with atmospheric respiration, the animal heat is considerable; and in birds 
it is even higher still, from the increased quantity of respiration produced by numerous air-sacs and cells pervading all parts of the borly, and communicating with the lungs.

From the structure of the Reptilia, it follows that they possess but little power of sustaining muscular action ; and although capable in many instances of moving rapidly for a short time, it is only when they are supplied with that degree of temperature externally which is denied them from au interual source, that they are capable of exerting any energy at all; and if deprived of external heat to a certain extent, they pass into a state of torpidity or hibernation.

The respiratory and sanguiferous systems being thus circumscribed in their extent, and the nervous and muscular powers in a corresponding degree limited, we are prepared to find that the other functions of the body are no less tardy in their operation. Digestion is carried on only in proportion to the degree of temperature of the surrounding atmosphere; and even under the most favourable circumstances is extremely slow. Many Serpents are more than a fortnight after taking their food before the undigested remains are voided, during which period they usually fast. If the temperature in which they are placed be very low, it is greatly retarded, and during hibernation it ceases altogether; for I have known a Tortoise which had fed largely upon grass immediately before it became torpid, retain the grass unchanged in the stomach during the whole of the winter, so that on opening the body after its death, which took place immediately on its avaking in the spring, and before it had any access to food, the stomach was found filled with a large quantity of grass wholly undigested. 
The phenomena of hibernation are amongst the most remarkable and interesting which occur in the history of animals. That the cold-blooded creatures of which we are now treating, with their limited respiration and circulation, their entire dependence upon external heat to carry on their functions, and the consequent diminution of all their powers, and of their expenditure also, during a low degree of external temperature, should be able to sustain life for an almost indefinite period, under peculiar circumstances, is not, perhaps, so surprising. But this simple torpidity is very different from that true hibernation to which many of the warm-blooded animals are liable. The bats, the squirrel, the dormouse, the marmots, and many others, may be cited as examples. It is sufficient in reference to the present class to observe, that in temperate or cool climates, the whole of them retire during the winter to some place of concealment; the land Tortoises to excavations which they often dig for themselves; the freshwater Tortoises to holes in the muddy banlis, or to the mud at the bottom, of their native lakes or rivers; the Lizards and Serpents to holes in trees, under stones, beneath dead leaves, or in similar hiding-places, where many species, especially of the latter order, congregate in large numbers, and are found closely entwined together. Here they pass the winter in a state of almost lifeless repose, the functions of life so nearly suspended, that none of the external signs of its existence are visible. The circulation is extremely slow, the respiration apparently altogether stopped, digestion absolutely suspended. The return of the genial warmth of spring calls them again into action. The circulation is restored, the blood is again fitted for its various offices by the return of regular respiration, the functions of the digestive organs are again 
performed, and the animal resumes its former habits, without having undergone any material change.

I have already hinted at the difficulties which exist in forming a consistent and unobjectionable arrangement of these animals. The order of Testudinata and that of Loricata,-the former comprising the Tortoises and Turtles, the latter the Crocodiles and their congeners, - are natural and well defined; nor is there any sufficient ground for identifying the latter group with the true Saurians. On the other hand, the Saurians and the Ophidians are so nearly related in all important points of their structure, and pass into each other by such insensible gradations, that I camnot but think that Merrem was correct in viewing them as constituting a single order, to which he gave the name $S$ quamata, from the nature of their dermal covering. If the true Ophidians, or Serpents, be considered as ordinally distinct from the Lizards, the intermediate group to which Mr. Gray has given the name Saurophidic, must also constitute a distinct order; but I am rather disposed to follow Merrem's arrangement. Adding, therefore, the Enaliosaurians of Conybeare, including the great fossil reptiles, the Ichthyosauri and Plesiosauri, as a group probably intermediate between the Tortoises and Crocodiles, we have the following orders of this class; - namely, Testudinata, Enaliosauria, Loricata, and Squamata, the last including the true Saurians, the true Serpents, and the intermediate group, the Saurophiclia of Gray. For convenience sake, however, and because the present work is scarcely a fit arena for the discussion of disputed methods of arrangement, I prefer adopting, for the present popular purpose, the more usual one to which I have before alluded. 
The first of the orders, the Testudinata, includes the Tortoises and Turtles. Although we have no species of this order inhabiting the British islands, yet as there have been occasionally stray individuals of the marine forms brought to our coasts, and even taken alive, and as many species of the land and fresh-water forms are often kept living in our gardens and ponds, it may not be uninteresting or inappropriate to offer a short account of their general organization and habits. Their structure, as has been already observed, differs in a very remarkable manner from that of the rest of the class. The arrangement of the osseous system has already been glanced at; and it offers the most remarkable tendency to consolidation and strength, to the sacrifice of facility and variety of motion. In the terrestrial forms especially this character is carried to an extreme degree; the vertebræ, the ribs, and the sternum are all closely and inseparably united into a compact solid case, in which the whole of the viscera, and, during rest, the head, limbs, and tail are covered and protected. So strong is this shell, both from the thickness and solidity of its parietes, and from the arched form of the superior portion, that in many species it will bear immense pressure without injury. In certain genera, however, this bony box, although still exceedingly strong, has certain parts which are rendered moveable, for the still more complete protection of the enclosed organs. Thus in the genus Kinixys, a terrestrial form, the lumbar portion of the carapace, or upper part of the case, is moveable, so that the animal has the power, when the limbs and tail are withdrawn within it, to close that moveable piece against the posterior part of the sternum; and in the genus Pyxis the anterior portion of the sternum exhibits this peculiarity in a still more remarkable degree. 
But it is in the genera Terrapene, Kinosternon, and Sternothconus, all of them aquatic or palustrine forms, that this peculiarity is the most obvious. In the first-named genus especially, the sternum is formed of two distinct valves, moveable upon a single cartilaginous hinge, and capable of completely closing the bony box, of which it thus forms a double lid; within this admirable shelter the animal is wholly included, and, if disturbed, resists, by means of its powerful muscles, every attempt to open it. The general form of the carapace, or upper part of the shell, is also admirably adapted to the habits of the different groups of which this order is composed. In the land Tortoises it is strong, compact, elevated, and regularly arched, for the purpose of resisting the numerous injuries to which their localities, and especially their extreme slowness of movement, must otherwise expose them. In the aquatic species, on the contrary, it is remarkably flattened, especially in the genus Trionyx, which has also the margins of the ribs free towards their extremities, and the whole body covered with a coriaceous skin, which is free at the edges, and serves the same purpose as the flattened lateral fins of the flat fishes, such as the sole and plaice,-namely, to enable them to scuttle themselves under the mud or sand at the bottom of the rivers or lakes in which they reside. These last have also a very long and retractile neck, by which they are able, when thus concealed, to seize fish which pass immediately above them, by suddenly stretching out the neck, and then as suddenly withdrawing it. The land Tortoises, which are exclusively vegetable feeders, are slow in their motions, the limbs being clumsy and club-shaped. The fresh-water forms are all of them carnivorous; the neck is therefore long, the legs lax and flexible, and the feet palmated to enable them to pursue their prey with con- 
siderable rapidity; whilst the marine Turtles have them morlified into true paddles, the toes being entirely concealed by hard scaled skin. These modifications of form are very interesting, as evincing an admirable adaptation of a general plan of structure to the varied habits of the different groups.

The jaws of all these different forms are covered with a hard, sharp, horny beak, the lower portion of which shuts within the upper, and the portions of food are cut or snapped off, as it were, on the principle of shears. The aquatic species aid the separation of their food, which they seize with their jaws, by tearing it by means of their long and sharp claws. They thus pursue, seize, and tear in pieces living frogs, and other aquatic reptiles, fish, and even young water birds; and so forcible and violent is their bite, that I have known a stick of half an inch in diameter at once snapped asunder by the jaws of a snapping Turtle, Chelydra serpentina; and a specimen of Trionyx, lately in the possession of Mr. Cross, of the Surrey Zoological Gardens, snapped off the finger of a sailor when on his voyage to this country.

The whole of the Testudinata are strictly oviparous, and the egg is covered by a calcareous shell, like that of birds; the eggs of the land Tortoises, as well as those of the marine Turtles, are generally round; but those of the fresh-water genera are usually more or less oval or elliptical. The multitudes of fresh-water Tortoises in some districts is astonishingly great, and their eggs form a lucrative article of commerce from the quantity of oil which is obtained from them.

It has been already stated that we have no indigenous species of this order. There are, however, on record several well-authenticated instances of marine Turtles, of two 
distinct species, having found their way to our consts, one of them probably from the Mediterranean, and the other from the American shores across the Atlantic. The former is the Coriaceous Turtle, Spargis Coriacea, called by Merrem by the specific name of Mercurialis, on account of its having been in ancient times dedicated to Mercury, by whom its shell was believed to have been employed in the construction of the lyre. Of this species two specimens are recorded by Borlase in his History of Cornwall, as having been caught in the mackerel nets off that coast in July 1756, the detail of which is given in the description of the species.

I have been induced to enter thus at large into the history of this tribe of reptiles, because, although we do not possess any British species, there is every reason to believe that several of the fresh-water species, both of Europe and North America, might be naturalized in the southern parts of England. The Terrapene Europaca, the common lacustrine Tortoise of the Continent, is found in Portugal, Spain, Italy, and Greece, in France, and even in Prussia. These Tortoises are eaten by the inhabitants of all the countries in which they are found; and as they live principally upon small fish, the air-bags of which they reject, it is said that the people are wont to judge of the quantity of 'Tortoises to be found in a lake or pond, by the number of air-bags which are seen swimming on the surface of the water. I once placed in a small pond, in which were some of these fresh-water Tortoises, six small living fish; and on the following morning I found the air-bags of five of them floating on the surface of the water, and the sixth fish still alive. In some parts they are fed upon grains, and on other nourishing food, and fattened for the table. There are also several American species of $\boldsymbol{E} m y s$, or fresh-water 
'Tortoise, which will bear a greater degree of cold than that of most of our winters, without perishing; and it is certainly desirable that a wholesome and agreeable food, like that afforded by some of these, should not be lost to us, if the species can be easily perpetuated and multiplied in our climate.

Of the third order of Reptiles, to which the term Loricate has been given, on account of the peculiar coat of hard mail with which all the species are covered, we have happily no indigenous example, nor would any of them bear the cold of our climate. The Crocodiles and Alligators of both worlds, and the Gavials of India, constitute this order. They are distinguished from the true Saurians, or Lizard tribe, by several important characters. Of these, the most tangible and obvious is that upon which the name of the order is founded; the covering of the whole of the back part of the neck, body, and tail, with distinct series of bones, of moderate size, embedded, as it were, in the substance of the skin, and covered externally with a thick cuticle. These dermal bones are usually furnished with a crest, which renders them exceedingly strong, and they altogether form a panoply of defence which can resist the attacks of the most powerful enemies of whatever kind. These animals are carnivorous, taking their prey generally in the water, but retiring to the shore to devour it, which they often defer until it has become half putrid. For the reasons given above, I do not think it necessary to enter into particulars respecting the structure and history of these animals. They can never become of local interest to us, as they are not made subservient to any purpose of utility to man, nor can they be naturalized in our latitude.

The true Saurians are characterized by the existence of both anterior and posterior extremities, and of a moderate. 
number of perfect and moveable ribs, by an entire covering of scales, which in most families are imbricated, in others flat and with their margins in mutual contact. The eyes are furnished with eyelids; the ear in some protected by a simple valve, in others by scales rather larger than the surrounding ones, and in others the tympanum is on a level with the surface of the skin.

In this group are found some of the most active, and certainly the most beautiful of the reptile class. Many of them are tinctured with the most brilliant colours; and as they are called into the greatest activity in the bright sunshine, nothing can surpass the splendour of their everchanging hues. Most of the Saurians are insectivorous; but there are some, as the Iguanas, which live principally on fruit. The activity of the smaller insectivorous Lizards, when in pursuit of their food, is exceedingly curious and interesting. They watch with all the caution of a cat, and dart upon their prey with the quickness of lightning.

In the act of seizing their food, however, they must necessarily be exposed to some danger from the noxious qualities of the insects which they indiscriminately attack. The following fact would seem to indicate that even in our own temperate climate, an insect not generally recognized as poisonous may inflict a fatal injury upon its Saurian enemy:-Some years since, I had in my possession two living specimens of the beautiful little green anolis of the West Indies, a Lizard about the size of our own smallest species. I was in the habit of feeding them with flies and other insects, and having one day placed in the cage with them a very large garden spider, Epeira Diadema, one of the Lizards darted at it, but seized it only by the leg. The spider instantly ran round and round the creature's mouth, weaving a very thick web around both jaws, and 
then gave it a severe bite in the lip, just as this species of spider usually does with any large insect which it has taken. The lizard was greatly distressed, and I removed the spider, and rubbed off the web, the confinement of which appeared to give it great annoyance; but in a few days it died, though previously in as perfect health as its companion, which lived for a long time afterwards.

It has been already observed that the passage from the Lizard tribe to the Serpents is by a succession of very gradual modifications of developement. In the lower forms of the Surrian group, the body becomes gradually elongated and serpentiform: its ribs increase in number, the anterior and posterior limbs are removed farther and farther from each other, and diminish in size and power, exhibiting in some forms the anterior, and in others the posterior only, external to the integument, until at length they cease to appear, being merely rudimentary, and wholly covered by the skin. Of this transition state we have an example in the common Slow-worm, Anguis fragitis, which, though completely Serpentiform in its external appearance, yet possesses the minute rudiments of limbs entirely concealed under the integuments. Notwithstanding this general form of the Serpent, they have not the expansible jaws of the true Serpents: nor is the character of the ears the same, the tympanic membrane not being superficial, nor the auditory passage covered by integument; the eyes, also, like those of the Lizards, are furnished with moveable eyelids, which are wholly wanting in the true Serpents.

Upon these characters, and several others of minor importance, Mr. Gray founded his intermediate order of Saurophidians, to comprehend all the transition forms; but it may, perhajs, be objected that the group is not sufficiently defined to sanction such a distinction. On the 
other hand, it must be confessed that it is difficult to reconcile the separation of the Ophidians from the Saurians, according to the arrangement of Cuvier, who, to effect this, has been obliged to place some of these intermediate genera in the former, whilst he retains others in the latter group. Upon the whole, as I have before observed, it appears more consonant with nature to consider, with Merrem, that the whole of these three groups constitute but a single order.

The movements of the Saurian reptiles are effected principally by means of their feet, and in some of the higher forms, exclusively so; but as they descend towards the more elongated forms of the Scinks, and other genera, in which these organs become more and more subordinate, they are greatly assisted by the lateral motion of the borlies, different parts of which are brought into alternate contact with and pressure upon either the roughness of the ground, or the shrubs and herbage through which they pass. A comparison of the progression of these, however, and even of the Slow-worm, with that of the true Snakes, will show that the latter only employ the free terminations of their ribs as organs of locomotion. In these the ribs serve absolutely and perfectly the function of feet, and with the exception of their being covered with integument, their action is exactly that of the multitudinous feet in the Scolopendra or Julus, the whole series of ribs coning into contact in succession. At the same time, it is upon the lateral motion of the body and the alternate lateral pressure of successive portions of it, that the Serpents mainly depend for the rapidity of their progression.

It appears almost necessary to apologise for offering this sketch of some of the most important phenomena in the structure and habits of the different groups of existing 
Reptilia. I have been induced to do so by the consideration that very little is popularly known respecting them, and by the eagermess with which information of this nature is sought by many, whose habits and opportunities forbid any personal investigation into the depths of anatomical and physiological science.

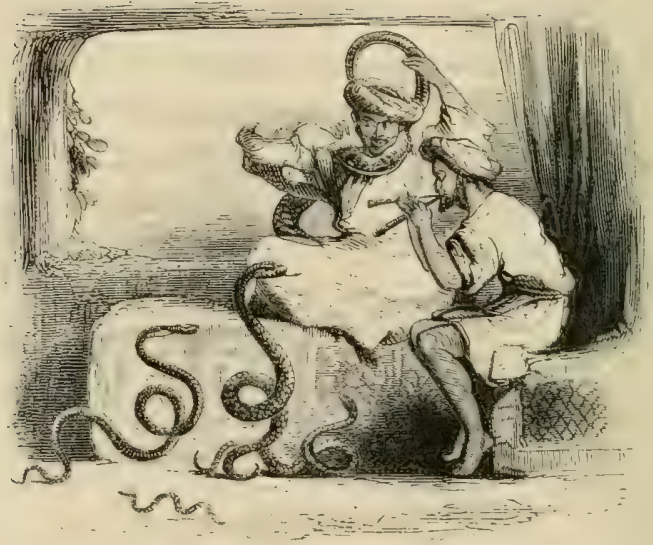




\section{N D E X.}

\section{The systematic names are printed in italics.}

Adder, 61.

Anguis fragilis, 41.

Blind-worm, $i b$.

Bufo calamita, 126.

" mephitica, $i b$.

, Rubeta, $i b$.

, terrestris, 115.

" $"$ fretidus, 126.

"vulgaris, 117.

Chelonia imbricata, 1.

Coluber Berus, 62.

" cœruleus, 59-69.

" chersea?, 62 .

"Dumfrisiensis, 60 .

"natrix, 50 .

"torquatus, $i b$.

Coriaceous Tortoise, 12.

Coriudo coriacea, $i b$.

Couleuvre à Collier, 50.

Crapaud commun, 115.

Dermatochelys porcata, 12.

Eft, 143.

Evet, $i b$.

Frog, common, 89.

, edible, 110.

, green, $i b$.

, Scottish, 102.

Grenouille rousse, 89.

Lacerta agilis, 18-35.

, aquatica, 143.

" anguiformis, 18.

, arenicola $i b$.
Lacerta di Simeo, 18.

, maculata, 34, 144.

, odura, 35.

" palustris, 129.

" stirpium, 18.

"vivipara, 35 .

Lacertus vulgaris, 34 .

LEzard des Souches, 18.

Lissotriton palmipes, 154. , punctatus, 143.

Lizard, brown, 144.

" common, 34 .

" nimble, $i b$.

" sand, 18.

"scaly, 35.

"viviparous, 34 .

" warty, 129.

Molge palustris, $i b$.

"punctata, 144.

Natrix torquata, 49 .

„vulgaris, 50 .

Natter-Jack, 126.

Newt, greater, 129.

"small, 143.

" (smooth), palmated, 154.

" $\quad$ common, 143 .

" (warty), common, 129.

$" \quad$ " strait-lipped 140.

Orvet commun, 41.

Pelias Berus, 61.

Rana aquatica, 89.

,Bufo, 115, 126. 
Rana esculenta, 110.

" fusca, 89.

"Rubeta, 126.

"Scotica, 89.

" temporaria, ib.

" viridis, 110.

Salamandra aquatica, 129.

" cristata, $i b$.

" palmipes, 154.

" punctata, 144.

" vittata, 153.

Salamandre Suisse, 154.

Slow-worm, 41 . palmipède, it.

Snake, common, 49.

" Dumfries, 60.

"ringed, 49.

Sphargis coriacea, 12.

" Mercurialis, $i b$.

Testudo coriacea, 12.

" imbricata, $]$.

"Mercurii, 12.

Toad, common, 115.
Toad, Natter-Jack, 126.

Triton aquaticus, 144.

"Bibronii, 140.

" cristatus, 129.

" marmoratus, 140.

" palmipes, 154.

" palustris, 129-144.

"punctatus, 144.

" vittatus, 152.

Tropidonolus Natrix, 50.

Turtle, coriaceous, 12.

" hawksbill, 1 .

" lenthery, 12.

" trunk, $i b$.

Viper, black, 62-74.

" blue-bellied, 62--69.

" common, 61 .

"red, 62,71 .

Vipera Berus, 62.

" chersea, 59-67.

" communis, 62 .

" vulgaris, $i b$.

Zootoca vivipara, 34 . 


\section{BRITISH REPTILES.}

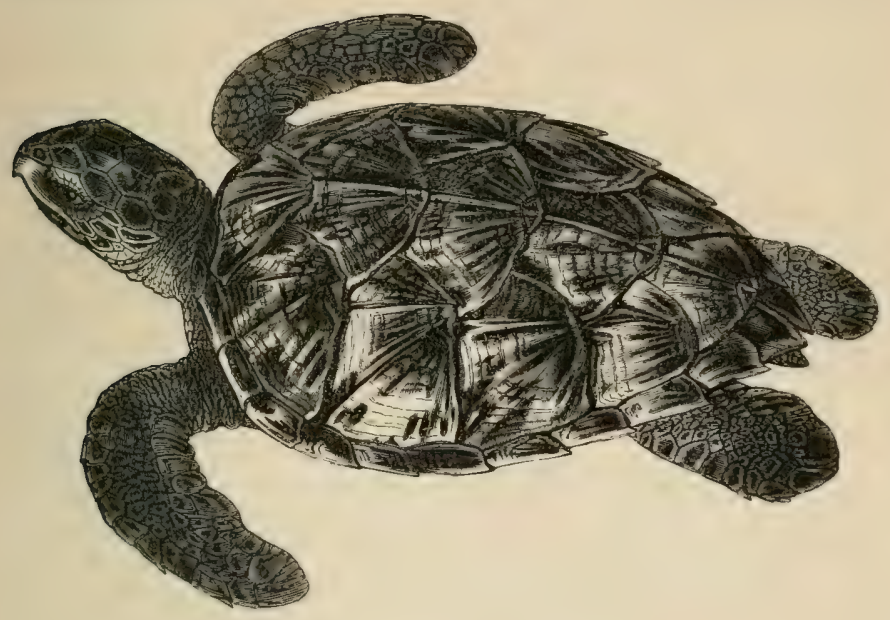

Genus, Chelonia. Brongn.

Generic Character. -Dorsum large, depressed, somewhat heart-shaped, covered with horny plates; feet depressed, fin-shaped.

\section{HAWK'S-BILL TURTLE. \\ Chelonia imbricata. Schweig.}

Specifuc Character.-Dorsal plates thirteen, free at the margins, imbricated.

Testudo indricata, Linn. Syst. Nat. p. 350, sp. 2. Schneid. Schildkr. p. 509. Penn. Faun. Ind. p. 87. Latr. Hist. Rept. I. p. 50. DAUD. Hist. Rept. II. p. 39.

Chelonia imbricata, Scuweig. Prod. in Archiv. Kœnigsb. I. p. 291, et 408. Gray, Syn. Rept. p. 52, sp. 1. Briron, Hist. Rept. II. p. 548, t. xxv. f. 2. Bonap. (Pr. Musign.) Syn. Chelon.

ITaukstill Turtle, Brown, Jamaic. p. 463. CatesB. Nat. Hist. Carol. II. p. 39, t. lix. 
Trre single and purely accidental occurrence of a bird or of a fish within the range of our guns or our nets, has always been deemed sufficient warrant to constitute the wanderer fair game to our native Faunists. It may, perhaps, be doubted whether the important and interesting subject of the geographical distribution of animals can receive much illustration from thus swelling the catalogue of local species by the addition of such as owe their place in our Fauna rather to the caprice of the winds or the waves, to the violence of a storm, or the temptation of an unusual chase after their food, than to any regular and voluntary migration: nor does there appear any very sufficiont reason for distinguishing between those species of birds, for example, which are driven over to our coasts by the immediate force of the tempest, and those which are brought from the same countries, and wafted hither by the same impelling power, but through the medium of the sails of a ship, and secured by the safeguard of a cage. However, as such is now the established custom of naturalists, I have determined on availing myself of the means thus offered me, of adding to the interest of this little work, by admitting, as all previous British Faunists have done, the two species of stray Turtles which have accidentally been found on our coasts, although certainly neither the one nor the other can claim to be considered as indigenous.

The family of Cheloniade, to which both the species which have thus obtruded themselves into our Fauna belong, is composed exclusively of marine Turtles. The most generally interesting species are the common esculent Turtle, Chelonia Mrydas, well known as a delicious article of food, and the present species, which furnishes the beautiful substance linown by the name of Tortoiseshell. 
The structure of the whole family is admirably adapted to their marine habits. The body is flattened so as greatly to facilitate their progress through the water; the feet are formed into the most perfect oars, by means of which they are propelled with considerable force and velocity; "the Green and Hawk-billed in particular," says Audubon, "remind you, by their celerity, and the ease of their motions, of the progress of a bird in the air." The head is so placed upon the neck as to allow of the nostrils being readily raised above the surface for the purpose of occasional respiration. The nostrils, also, are furnished with a fleshy valve, which is closed when the animal is submerged, but opens when required for respiration.

The food of the Green Turtle consists of marine plants, especially the sea-wrack, Zostera marina; and they graze at the bottom of the water, coming at intervals to the surface to breathe. As this mode of taking their food renders them very liable to swallow, with their aliment, a considerable quantity of sea-water, there is a beautiful structure lining the interior of the osophagus, by which this circumstance is effectually obviated. 'This consists of a great number of horny pyramidal bodies, with which the whole interior of the csophagus is furnished, all of them directed backwards towards the stomach; by which means, although the food and the water together can be readily swallowed, yet, when the stomach is contracted for the purpose of regurgitating the water, the food itself is retained. "The Hawk-billed species feeds on sea-weeds, crabs, various kinds of shell-fish, and fishes; the Loggerhead mostly on the fish of conch shells of large size, which they are enabled, by means of their powerful beak, to crush to pieces with apparently as much ease as a man cracks a walnut. The Trunk Turtle feeds 
on mollusca, fish, crustacea, sea-urchins, and various marine plants." *

Their jaws are strong, and firmly articulated. The horny beak, which so much resembles that of some birds as to have led to the application of the name of Hawk'sbilled Turtle to the species about to be described, is very hard, but the edge is sharp, in most cases toothed, and that of the lower jaw is received into a groove of the upper; so that the food taken between them is not only cut by the external sharp edges passing each other, but bruised by the pressure of the lower mandible against this upper groove and its internal margin. When not engaged in feeding, they are often seen floating without the slightest movement on the surface of the sea, sometimes at considerable distance from the land, apparently asleep; for they are at such times easily approached and taken.

The annual resort of the various species of marine Turtles to the land for the purpose of depositing their eggs, is one of the most interesting points of their history. On the Island of Ascension, on the shores of the Gulf of Florida, and in many other places, inmumerable multitudes of Turtles arrive at a period of the year differing somewhat in the different species, but in all during the early part of the summer. They resort to their favourite breeding-places from various parts, some even from a great distance; and there is reason to believe that each individual returns year after year to the same place. The following details of this operation, from the graphic pen of my friend Audubon, are so interesting that $\mathrm{I}$ offer no apology for inserting them without mutilation.

" On first nearing the shore, and mostly on fine calm moonlight nights, the Turtle raises her head above the

* Audub. Amer. Ornith. Biog. II. p. 374. 
water, being still distant thirty or forty yards from the beach, looks around her, and attentively examines the objects on shore. Should she observe nothing likely to disturb her intended operations, she emits a loud hissing sound, by which such of her many enemies as are unaccustomed to it are startled, and so are apt to remove to another place, although unseen by her. Should she hear any noise, or perceive any indications of danger, she instantly sinks, and goes off to a considerable distance; but should everything be quiet, she advances slowly towards the beach, crawls over it, her head raised to the full stretch of her neck, and when she has reached a place fitted for her purpose, she gazes all around in silence. Finding ' all well,' she proceeds to form a hole in the sand, which she effects by removing it from under her body with her hind flappers, scooping it out with so much dexterity that the sides seldom if ever fall in. The sand is raised alternately with each flapper, as with a large ladle, until it has accumulated behind her, when, supporting herself with her head and fore part on the ground fronting her body, she, with a spring from each flapper, sends the sand around her, scattering it to the distance of several feet. In this manner the hole is dug to the depth of eighteen inches, or sometimes more than two feet. This labour I have seen performed in the short period of nine minutes. The eggs are then dropped one by one, and disposed in regular layers, to the number of a hundred and fifty, or sometimes nearly two hundred. The whole time spent in this part of the operation may be about twenty minutes. She now scrapes the loose sand back over the eggs, and so levels and smooths the surface, that few persons on seeing' the spot could imagine anything had been done to it. This accomplished to her mind, she retreats to the water with 
all possible dispatch, leaving the hatching of the eggs to the heat of the sand. When a Turtle, a Loggerhead for example, is in the act of dropping her eggs, she will not move although one should go up to her, or even seat himself on her back; for it seems at this moment she finds it necessary to proceed at all events, and is unable to intermit her labour. The moment it is finished, however, off she starts; nor would it then be possible for one, unless he were as strong as a Hercules, to turn her over and secure her." *

Each Turtle has generally three layings in the season, at intervals of two or three weeks. The eggs are perfectly round, varying from two to three inches in diameter. The external membrane is flexible, very white, and contains a considerable quantity of calcareous matter. The yolk forms in general an exceedingly delicate article of food; but that of the Loggerhead Turtle has a somerwat musliy flavour.

When the young ones are hatched, which takes place from a fortnight to three weeks after the eggs are deposited, according to the temperature, they have only that central part of each scale or plate formed which is termed the areola; and all the concentric layers which in advanced age are seen to constitute the principal part of the plates are added afterwards at their margins. The shell is soft, and affords them but little protection from the attacks of their numerous enemies. In their attempts to gain the water for the first time, number's of them fall a prey to birds of varions kinds; and of those which are fortunate enough to escape from this danger, probably the greater part are seized and devoured by shoals of fish and of crocodiles.

* Audub. Amer. Ornith. Biog. II. 
The different species of marine 'Turtles are found in all the seas of hot climates, and they are only seen in considerable numbers within a certain distance from the land. About the shores of several of the West India Islands, "Cuba, Jamaica, St. Domingo; in the Atlantic, at the Cape de Verde and Ascension Islands; again, in the Inclian Ocean, at the Isle of France, Madagascar, the Seychelles, \&c.; at Vera Cruz, in the Gulf of Mexico, and at the Sandwich and Gallapagos Islands, in the Pacific," * they are found in the greatest abundance.

It is unnecessary, and it would be out of place here, to enter at large upon the particular history of the different species. Every one knows the value of the Green Turtle, as it is commonly called, as an article of luxurious and most nutritious food; and all the species afford a large quantity of oil, which is employed for various purposes. But it may not be uninteresting to offer a few observations on the particular utility of the species which is now to be described.

The Hawk's-billed Turtle, Chelonic imbricata, is not generally used in food, as its flesh is far from being either so wholesome or agreeable as that of the Green Turtle; but the large scales with which it is covered are so much cmployed in the arts, both for purposes of ornament and utility, as to constitute no unimportant object of merchandize. It is the substance commonly called Tortoiseshell. For the following short account of the mode of obtaining and preparing it, I am principally indebted to the admirable History of Reptiles by my excellent friends M. Dumeril and M. Bibron.†

Although the greater number of the whole order of 'Tes-

* Dumeril et Bibron, Hist. des Rept. II. p. 520.

+ Hist. des Rept. II. p. 524, et seq. 
tudinata have the back and sternum covered with horny plates, or scales, it is almost exclusively those of the present species which are applicable to the purposes just named. The thirteen plates with which the whole upper part of the shell is covered, are in fact much thicker and stronger, as well as more beautifully clouded in colour, than those of any other species; and as they lie one over the other like the tiles of a house, so that at least one-third of each overlaps the one behind it, they are much larger in comparison with the size of the individual. The scales, or plates, are in the first place separated by the application of heat. They are sold to the manufacturers in the rough state, in which they are uneven, fragile, opaque, and dirty; and it is the first object of the artificer to obviate these defects. The uneven surface, the irregular curvature, the unequal thickness of different parts, have all to be corrected; and not only can these objects be readily effected, but the substance can be rentiered ductile, compressible, capable of receiving any impression, of being carved, moulded and polished, and even extended by soldering pieces together by means of their own substance reduced to powder. The whole of these processes are performed by means of heat.

The uneven curvature is first of all to be removed, and the plate rendered perfectly flat. This is effected by immersing it in hot water, and then allowing it to cool under heavy pressure between smooth blocks of wood, or metallic plates. The surface is then rendered smooth, and the thickness equal, by scraping and filing away the rough and prominent parts. In this way each plate receives an equal and smooth surface. But it is in many cases desirable to employ larger pieces than can be obtained from single plates, and two pieces are then united together in the 
following manner :-The edges are bevelled off to the space of two or three lines, and the margins when placed together overlap each other to that extent. They are then pressed together by a metallic press, and the whole is submitted to the action of boiling water; and by this means the two pieces are so perfectly soldered together, as to leave no indication of the line of union. By the application of heat, also, the tortoise-shell may be made to receive any impression by being pressed between metallic moulds.

No portion of this precious substance is lost or useless. The filings and powder, which remain after these and the other processes to which the shell is submitted, are placed with any small fragments in metallic moulds, and by means of pressure, exercised whilst they are exposed to the heat of boiling water, they are formed into plates of any thickness which may be required.

Such is a very hasty and general sketch of the manner in which this beautiful substance is rendered available to the many purposes of oruament and use in which it is constantly employed.

The history of this species as a British visitant is confiner to the mere notice of its accidental occurrence on three different occasions on the shores of Great Britain. Sibbald states that he received the shell of one which "came into Orkney;" Dr. Fleming says, "I have credible testimony of its having been taken at Papa Stour, one of the West Zetland Islands;" and the late Dr. Turton has mentioned an instance of one which " in the year 1774 was taken in the Severn, and placed in the fish-ponds of the author's father, where it lived till winter."

It is found about the islands and coasts both of the Indian and Atlantic Oceans, where it occurs in considerable abundance; its flesh is said to be unpalatable, but 
the eggs are considered a great delicacy. It does not generally attain to more than one-third the size of the Green Turtle.

The shell of this species is depressed, rather longer in proportion to its breadth than the other species, and somewhat heart-shaped. It is covered with thirteen imbrieated plates, each of which in the young state has the apex pointed; but in older individuals this is entirely worm away. The margin has plates, which are prominent at the posterior and exterior angle, especially those towards the hinder part, so as to form sharp and strong denticulations. The under side, or sternum, has twelve plates; and there are two carine which run through its whole length from the anterior to the posterior margin; these ridges, however, are worn off by age; but they were very evident in the individnal from which the present figures were taken, and which I had alive for a short time in my possession. The heal is rather elongated, flattened above, and compressed at the sides in front of the eyes, so that the beak is less arched than in any other species of the genus. The head is covered with fourteen seales, to which, in zoological language, different names are given from their situation. The upper and lower jaws are covered with a horny beak, as before described; they are not denticulated at the edges; they are sharp, and scarcely sinuous; and the apex, both in the upper and lower, is sharp and hooked, that of the under shutting within that of the upper. The feet do not materially differ from those of the species generally, of the marine form, as before described. The tail is conical, and is so short, that it does not extend beyond the posterior margin of the shell.

The colour of the upper parts is yellow, marbled or splashed with a deep rich brown; the plates of the head 
are brown, often margined with yellow; the under parts of the whole animal are yellowish white; and in the young individual there is a spot of black occupying the areola, or nucleal spot of the four posterior pairs of sternal plates.

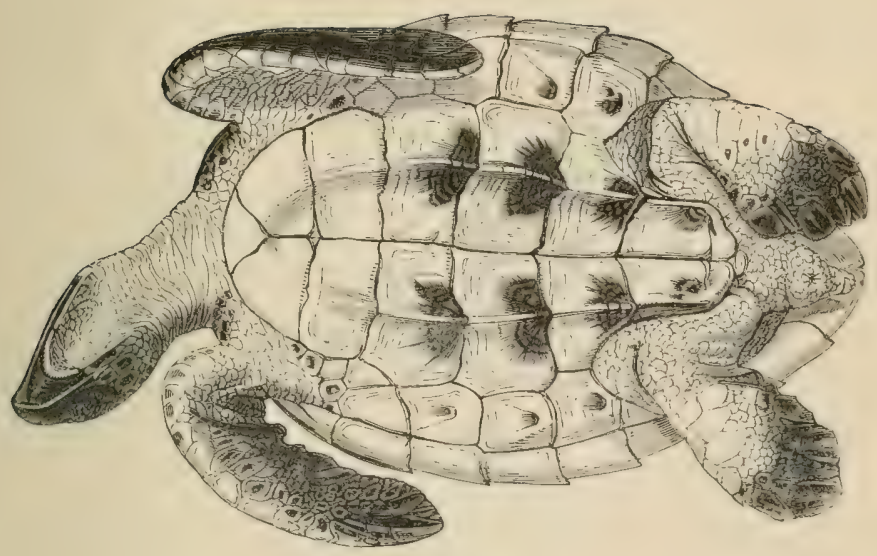




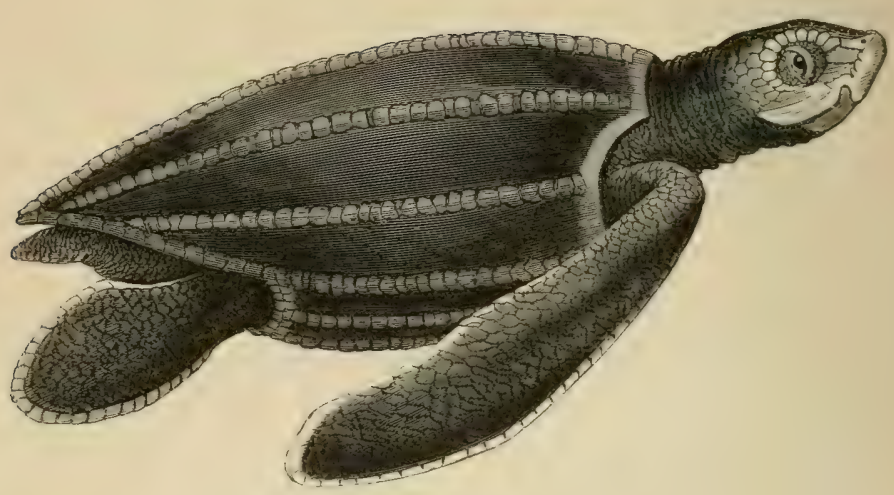

Genus, Sphargis. Merr.

Generic Character.-Body wholly without scales; covered with a leathery skin. Feet without nails.

\section{LEATHERY TURTLE.}

\section{TRUNK TURTLE.}

\section{Sphargis coriacea.}

Testudo Mercurii, Gesn. Aquat. II. p. 1134.

" coriaced, Linn. Syst. Nat. I. p. 350, sp. 1. Schneid. Schildk. p. 512. DAUD. Hist. Rept. II. p. 62, t. xviii. f. 1. TurT. Brit. Faun. p. 78.

Sphargis " Gray, Syn. Rept. p. 51. Dumer. et Bibron, Hist. Rept. II. p. 560, t. xxiv. fo 2. Bonap. Faun. Ital. JENYNS, Brit. Vert. p. 290.

" Mercurialis, Merr. Amph. p. 19. Risso, Hist. Nat. Eur. Merid. III. p. 85. Schleg. Faun. Japon. Chelon. p. 6, t. 1, 2, 3.

Coriudo coriacea, Flem. Brit. Anim. p. 149.

Coriaceous Tortoise, Pennant, Brit. Zool. III. p. 7, t. i.

Turtle, Borlase, Nat. Hist。 of Cornw. p. 285, t. xxvii. f. 4. Dermatochelys porcata, WAGL. Syst. Amph. p. 133, t. i. f. 1-23. 
Turs remarkable species is distinguished from all the other marine Turtles by the absence of horny plates upon the body, head, and limbs; which, instead of them, are covered by a tough leathery shin. In this respect it bears the same relation to the family to which it belongs, that the different species of Trionyx do to the fresh-water Tortoises most nearly allied to them. This skin is perfectly smooth in the adult; but in young specimens it is covered with hard tubercles. The head is more acute than in the other marine species: it is somewhat triangular when viewed from above, the part anterior to the eyes being narrowed; the jaws are of immense strength, and the edges very sharp; the upper one has three remarkable notches, one in the centre, which is angular, and one on each side at a short distance from the former, which are rounded. The lower jaw is scarcely sinuated at the margin, and the point is very acute, and somewhat hooked, corresponding with the central notch of the upper. The nostrils are small, and perfectly circular. The eyes rather large, opening nearly vertically, particularly in the younger specimens. The view of the head here given is
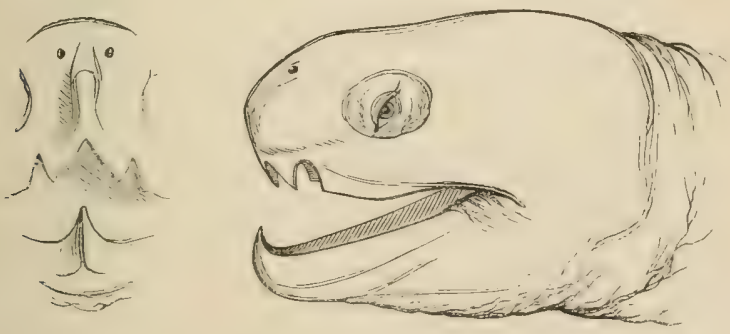

from a very large individual, of which the head and extremities are in my collection. The carapace, or dorsal shell, has seven distinct raised carinæ, or ridges, which in the adult are sharp, and slightly toothed: in the young they 
are rounded, and composed of a number of round obtuse tubercles. These seven ridges are equidistant, and consist of one along the median line of the back, one on each margin of the shell, and two on each side between the dorsal and the marginal one. The anterior paddles are remarkably long, being more than twice the length of the hinder ones, and somewhat falcate; the latter, however, are generally broader than the former. They are covered with a perfectly smooth skin. The tail is acute, much compressed at the sides, and extends only to the extreme point of the dorsal shell. The following figures of these parts are from the specimen above mentioned.

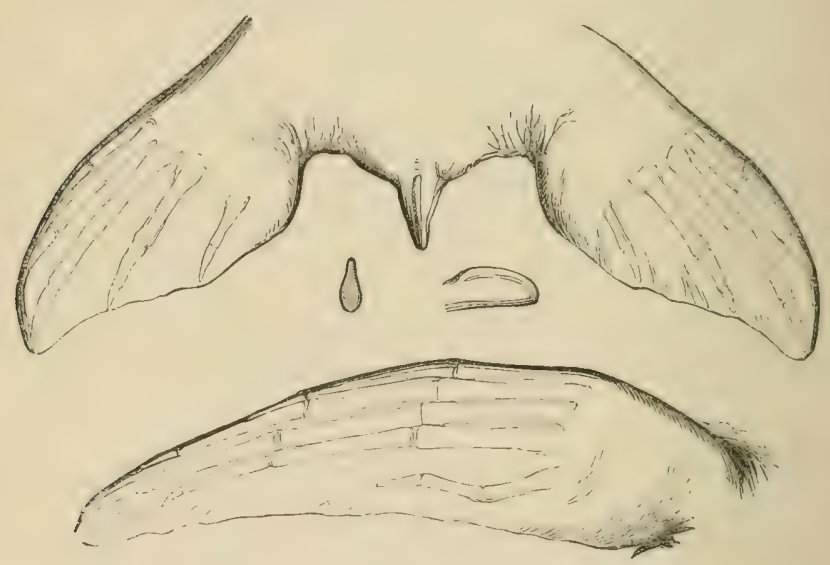

The young individual differs from the adult more considerably in this species than in any other species of the order with which I am acquainted. Some of the peculiarities of the former age have already been alluded to; in addition to which may be mentioned the more full and rounded form, the larger head, the larger and more expanded eye, and the existence of five ridges on the sternum. The eye opens almost vertically, which gives a 
peculiar and strange aspect to the young animal. The figure at the head of this description is from the plate in the Prince of Musignano's "Fauna Italica;" and was taken from a very young individual.

The colour of the adult is generally a full brown, with numerous pale yellowish spots; in the very fine specimen in my collection, the under side of the extremities and throat are white, with black irregular spots, rendering them, in fact, pied.

This species, which is stated by Mr. Audubon to resort to the Tortugas, or Turtle Islands of Florida, is later than the other species in arriving thither for the purpose of depositing its eggs. The average number laid by it, according to the same authority, may be three hundred and fifty in two sets. It is less cautious than the other species in choosing the places for this important operation. "Its foor consists of molluser, fish, crustacea, sea-urchins, and various marine plants."

"The lyre," says Sir John Hawkins, "is the prototype of the fidicinal or stringed species" of instruments, "and is said to have been invented about the year of the world 200 by Mercury, who, finding on the bank of the river Nile a shell-fish of the Tortoise kind, which an inundation of the river had left there, and observing that the fish was already consumed, he took up the back-shell, and, hollowing it, applied strings to it." * This application of the dorsal shell of a Tortoise to the construction of a musical instrument by Mercury is of very general reception amongst the classical writers, and is even mentioned by Homer in his Hymn to Mercury. To what species of Tortoise the individual belonged, which was destined to be the means of so much enjoyment to mankind in all subse- 
quent ages of the world, it would be useless now to inquire: but it is not improbable that the seven ridges on the back of the present species may have given rise to the belief that it may have been the favoured animal; particularly as seven strings are by some of the ancient writers assigned to the lyre; for Amphion is said to have "built the seven gates of Thebes in compliment to the seven strings of his lyre." This legend is neither overstrained, nor improbable; for the margin of the shell would afford a very good fastening for the strings, and the arched vault of the back would answer the purpose of a good reverberating cavity.

This species is found in the Mediterranean, in the Atlantic, the Pacific, and the Indian Oceans. My own specimen, above referred to, was from the latter locality.

The history of its occurrence on the shores of Great Britain is as follows: - Borlase, in his History of Cornwall, mentions "two of a vast size which were caught in the mackerel nets off the coast of Cornwall, a little after Midsummer 1756. The larger weighed eight hundred pounds, the lesser nearly seven hundred." Pennant states that "a third, of equal weight with the first, was caught on the coast of Dorsetshire, and deposited in the Leverian Museum." This specimen, if I mistake not, is the one now in the British Museum. "The late Bishop of Carlisle informs me," proceeds Pennant, "that a Tortoise was taken off the coast of Scarborough in 1748 or 1749. It was purchased by a family then resident there, and several persons were invited to partake of it. A gentleman, who was one of the guests, told them it was a Mediterranean Turtle, and not wholesome; only one of the company ate of it, who suffered severely, being seized with dreadful vomiting and purging." 
The following are the dimensions of the parts in my possession of the large specimen to which I have before referred, the total length of which was eight feet.

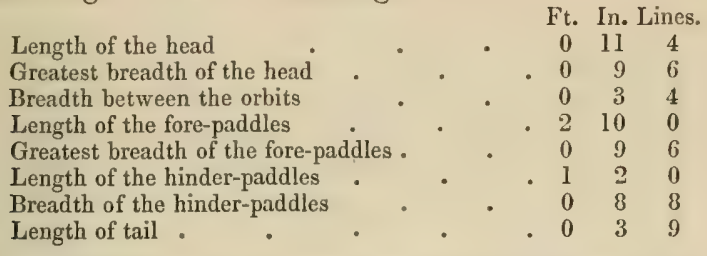

Supposing the neck to have been eight inches, the upper shell would have been nearly six feet and a half in length.

Although such is the meagre total of our clain to indigenous species of the Testudinata, there appears to be no obvious reason why many of the land and fresh-water species should not be naturalized, or at least bred in a domesticated state, in our southern counties. Every one knows that the Testudo Graca, or common land Tortoise, will live for a great number of years in this country without any particular care; nor do I doubt that the common fresh-water species of Europe, Terrapene Europaa, might be readily introduced here, as well as several species of Emys from the United States. They would probably require some little attention for the first few winters; but I believe they may in a short time be completely acclimated.

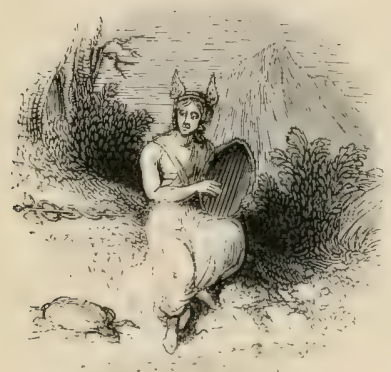




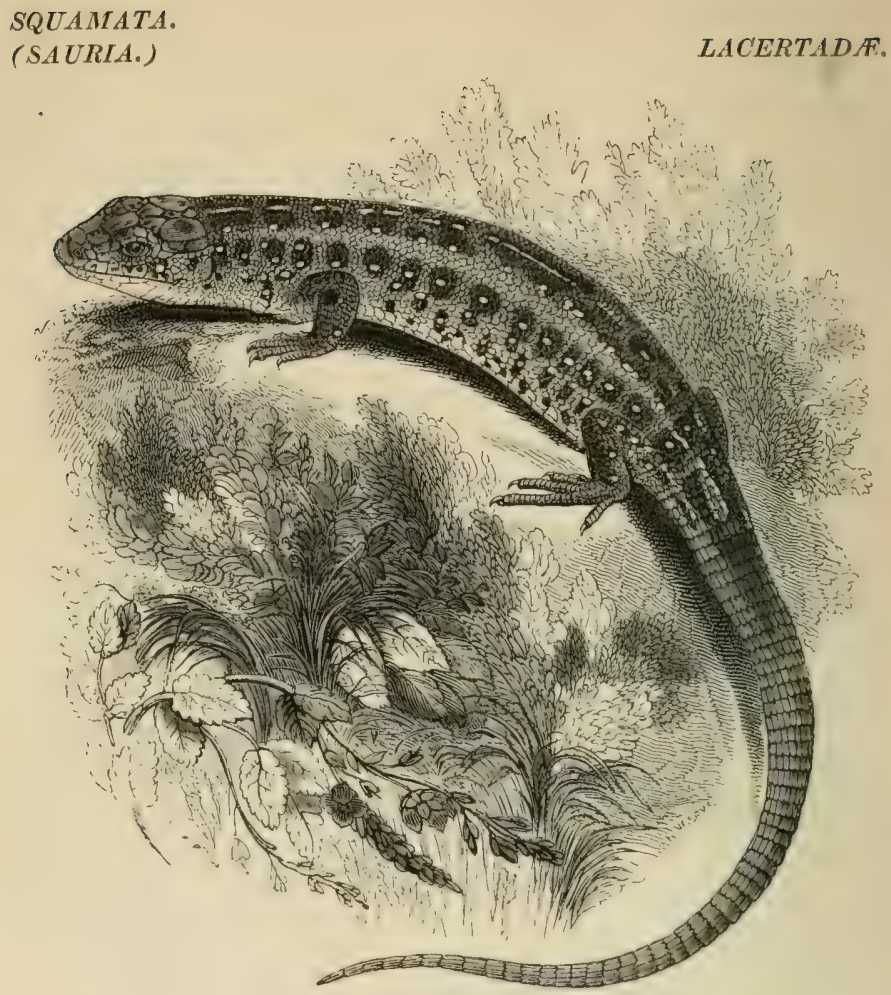

\section{Genus, Lacerta. Linn.}

Generic Character.-Throat with a distinct collar. Nostrils situated towards the outer and inferior margin of the nasal scuta. An osseous superorbital lamina. Tomples covered with scuta. Scales of the back, orbiculo-polygonal, slightly carinated. Palate toothed.

\section{SAND LIZARD.}

\section{Lacerta agilis. Linn.}

2. Lacertus terrestris anguiformis, Mzknet, Pinax, p. 161. RAY, Syn. Qund. p. 264.

Lacerta agilis, Linn. Fn. Suec. 284.-1 I . curâ RETz. 239.-Syst. Nat. I. p. 363, n. 15. MulL. Zool. Dan. Prod. p. 36, n. 299. Merr. Syst. Amph.p. 66, sp. 13. C. L. Bonar. Faun. Ital. cum Icon. 
Lacerta stirpium, Daud. Rept. III. p. 155, t. xxxv. f. 2. Dugés in An. des Sc. Nat. XVI. p. 376, sp. 3, t. Ixxvi. f. 1, 2. JENYNS, Brit. Vert. p. 291.

" arenicola, DAUD. 1. c. p. 230, t. xxxviii. f. 2.

" anguiformis, SHePpakD, in Linn. Trans. XVI. p. 51.

LEzard des Souches, Daud. 1. c. M. EDw. in An. des Sc. Nat. XVI. p. 65. 83. t. v. f. 4 , et t. viii. f. 1.2 .

\section{Lacerta di Linneo, C. L. Bonap. l. c.}

Because it may appear to many persons not accustomed to the use of what are commonly termed essential generic or specific characters, that many of those phrases by which such characters are expressed are confined in their signification, and the characters themselves of slight value and importance, it may not, perhaps, be useless, before we proceed to describe the species, to offer a few words explanatory of their employment, especially with reference to those groups of animals on which the present work professes to treat. It has always appeared to me that generic distinctions should, as far as possible, be limited to such differences of structure as indicate a difference in the habits of the animals. Thus, the absence in one species, and the presence in another, of an organ or part of an organ, the application of which is of obvious or probable moment in any of the habits of life, - as, for example, the degree of development of the thumb in some genera of monkeys, or the modification of the carnivorous propensity in allied groups of carnivora, evidenced by the greater or less degree of acuteness in the tubercles of certain teeth, - will form good grounds for such a distinction. Now it is evident here that what is called the generic character is merely the phrase expressive of some point of structure belonging to the whole group in which a certain habit obtains. In many cases even, the most convenient, or the only tangible characters of the group may have no reference whatever to the peculiarity of habit which forms the legitimate founda- 
tion for the generic distinction. This will be found to be the case, for instance, in some of the genera of saurian reptiles, and even in the generic distinction of our only two native species; the genus Zootoca, to which our common Lizard belongs, being characterized, as regards habit, by the circumstance that the species of which it is composed are ovo-viviparous. This is a character to which the structure of any of its external organs bears no possible relation; but as it is found that the species having this habit is externally characterized by some peculiarity in the form and situation of certain little scales about the head, having, however, no possible reference to the habit in question, such peculiarities are employed as convenient and permanent artificial characters by which it may be distinguished.

It must, however, be acknowledged that there are cases in which a numerous group is found to consist of several divisions, each of them distinguished by some point of form or structure, the use or object of which is absolutely unknown or unintelligible to us, and in which the habits, as far as we know them, are not conspicuously different. For the sake of convenience in some cases, and of consistency and harmony of system in others, these groups may, notwithstanding this uncertainty, receive with propriety a distinctive generic appellation; but, wherever it is possible, generic groups ought only to be formed where Nature has herself pointed out their distinction.

The generic and specific characters of the Lacertine group have only of late years received the degree of attention which they deserved. The divisions and subdivisions of this numerous family had been either overlooked, or so arbitrarily defined as to be detected with difficulty, and their value had been greatly misunderstood. The employ- 
ment of minute characters in the structure and proportions of the different parts of the body, the relative dimensions of the limbs, and the form and size of certain important scales, has, however, of late produced a greater degree of certainty, and more accurate definition, not only in the relation of the groups, but also in the characters of the species. One of the most useful attempts to reduce the characters of the Lizards to a tangible and certain rule, dependent upon differences which, though apparently trifling in themselves, are of great value as being constant and easily detected, was made by my friend Dr. Milne Edwards, in a valuable paper in the sixteenth volume of the "Annales des Sciences Naturelles;" and Wagler has since that carried the principles of generic subdivision to an extent perhaps scarcely warranted by nature. U uon this point, however, it would be out of place here to dwell.

The external parts from which the artificial characters of the present group of reptiles are founded, are principally the plates covering the head, the scales of the collar, the præ-anal scale, those in which the femoral pores are placed, the abdominal plates, and the scales of the back and tail. In order to comprehend these characters, I here introduce an outline of most of these parts. In the first figure, the plates of the upper part of the head of the species about to be described are

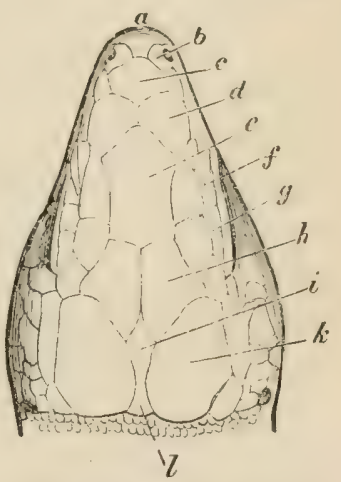
exhibited, and they are thus designated: — $a$, rostral; $b$, nasal; $c$, internasal ; $d$, fronto-nasal; $e$, frontal ; $f$, anterior palpebral ; $g$, posterior palpebral ; $h$, fronto-parietal; $i$, inter-parietal; $k$, parietal; $l$, occipital. 
In the next figure, the under parts of a variety of the same species are exhibited in outline, to shew the collar, the abdominal plates, the præ-anal plate, those which are perforated by the femoral pores, and the scales of the tail.

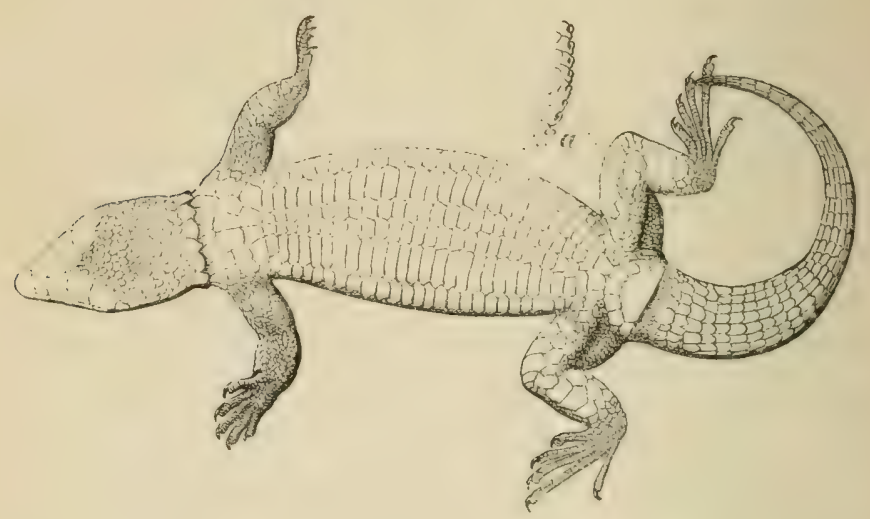

In the whole of the sub-family of Lacertina the head is covered by the number of plates designated above, differing only in some very trifling modifications of form. The abdomen is covered by broad plates, as seen in the figure, not imbricated, or lying one over another, as are the scales of the back and tail, but applied to each other at the margins; and these are arranged in longitudinal rows. There is in all the species a distinct collar, composed of several scales, larger than those which cover the throat, and quite detached from the plates which cover the breast, which they loosely overlay. The scales of the back and sides are small, and imbricated. Those of the tail are always arranged in distinct and even whorls, are elongated and narrow, becoming more so towards the termination of the tail. The femoral pores, as they are termed, exist also in all the family. They consist, probably, of very small follicular 
glands, each placed in a scale, the middle of which is pierced by the opening of the follicle. In some the scale is very little larger than the pore, and appears almost like a minute tube; in others the scale is larger and triangular. The use of these pores is not known. They vary exceedingly in number, even in the same species: in this respect, therefore, they afford no distinctive characters.

In some species, in addition to the teeth which are placed in the margins of the upper and lower jaws, there are also a few very minute ones in the back part of the palate, which may be readily felt by a pin or the point of a penknife. The existence or absence of these palatine teeth would, perhaps, scarcely be admissible alone as a generic distinction; but when combined with others, and associated also with a marked difference of habit, it may be ardmitted as a valuable, because a tangible and permanent character. It is on this account that $I$ have employed it as one of the means of generic discrimination between our two English Lizards.

I now proceed to the consideration of our first species.

It has been well remarked by the Prince of Musignano, whose knowledge of the European Vertebrata in general, and of the Reptilia in particular, is undoubtedly superior to that of any other naturalist, that the Linnean term agilis has been applied by the Zoologists of different countries to that species of Lizard which is best known or most common in their own. Thus the Podarcis muralis, the common Lizard of Italy and of France, has been so called by Italian and French writers; and our own little indigenous species, so frequent in almost all parts of England, which I shall presently describe under its proper appellation of Zootoca vivipara, has hitherto received the same name from every British naturalist who has written on the subject. 
Not even when the present handsome species was distinguished as indigenous to this country, was it suspected that the name applied to the former was erroneous as so applied, and still less that it might, in fact, appertain to this new addition to our Fauna.

The slender knowledge possessed by Limneus of the species of Reptilia, and his total ignorance, consequently, of the value of specific characters in this class, led him to include amongst the supposed varieties of his Lacerta agilis several which have since been ascertained to be not specifically only, but generically distinct; - at least, according to the rigid principles of subdivision adopted by several of our more distinguished modern Erpetologists. As, however, the typical form of his species thus named was indigenous to Sweden,-for he refers in his great standard work, the "Systema Nature," to the "Fauma Suecica" to fix its identity,-it only remains for us to ascertain what is the common species of that country, to fix this doubtful and obscure synonymy.

It appears quite clear that neither of the two species which I have before mentioned as having erroneously received the name of Lacerta agilis can possibly be the one originally intended by the great Swedish naturalist, as neither of them appears to be indigenous to that country. But it is not only highly probable, but becomes a demonstrated fact, that the present species is the type of the $L$. agilis of Limneus, when it is considered that it is a native of Sweden, and that the short allusion-for it is nothing more-in the "Fauna Suecica" is perfectly applicable to it. The specific character given by Limnens both in the "Fauna Suecica" and the "Systema Naturex" is vague, and equally applicable to the whole of the genus Lacertr as now constituted; but he proceeds to name two varieties 
in the following manner:- " $\beta$ Lacertus viridis Aldrovand. $\gamma$ Lacertus dorso punctis albis duplici serie. Var. $\beta$ rarissima, nec mili ipsi obvia." Here we have the common and the rarer green varieties of our own species indicated, at least, with great probability. But in the more recent edition of the same work by Retzius, the characters are still more decidedly applicable; and the expression "laterum ocellis nigris, pupillâ albâ," is decisive. This opinion is also corroborated by the short description given by Otho Frederick Müller, in his "Prodromus Zoologire Danicæ," of two varieties of the indigenous Lacerta of Denmark, which he also terms $L$. agilis. The following are his words :- "b. suprà maculis nigris punctis linearibus [albis*] inscriptis, subtus absque maculis. c. Suprà cinereofusca, punctis albis nigrisque contiguis." These are very accurate descriptions of the markings of different individuals of the present species; even the green variety, which occurs also in this country, was not unknown to Müller, who adds, "viridem quoque in sylva Frederichsdalensi reperi."

From these considerations it becomes necessary to reform the nomenclature and synonymy of our English Lizards, by restoring the name of agilis to the present species, to which it originally belonged,-by abolishing altogether that of stirpium, adopted by Mr. Jenyns from the French writers, by whom it had been applied to this species,- and in the case of the other and more common indigenous species, by substituting for the name $L$. agilis, hitherto applied, that of Zootoca vivipara, which really belongs to it. The first naturalist who has demonstrater that the species now under consideration is the true Lin-

* The word here is originally "nigris;" but this is evidently a misprint. Spots of black could not be said to be marked with llack dots. 
nean agitis, is the Prince of Musignano, who, in his beautiful "Fauna Italica," has thus restored its true name, with the additional Italian appellation of Lacerto di Linneo. I have lately examined many specimens of both species in company with that distinguished naturalist, and have thus had the views now stated amply confirmed.

As a British species, there appear to be on record several more or less obscure allusions to it amongst former writers. Merrett, in his "Pinax," mentions the common or viviparous species as " $L$. terrestris vulg. ventro nigro maculato ;" and the present one is probably intended by the phrase "L. terrestris anguiformis, in ericetis." These words, with the enumeration of the different species of Newts, are copied verbatim by Ray without acknowledgment. This, however, is but an obseure and uncertain allusion. The first description of the species by any British Zoologist is that by the Rev. Revett Sheppard, in the sixteenth volume of the Linnean Transactions, in the year 1802. This gentleman adopts the specific name anguiformis from Ray, with whom he appears to believe it to have been original, as he was probably unacquainted with the "Pinax" of Merrett. The Lizard to which his description refers could not have been a variety of the common species, as the latter never acquires half the length of one specimen seen by Mr. Sheppard, which, he says, was upwards of a foot long; and this, although certainly an extraordinary, is not an incredible length for an individual of this species, as I have myself occasionally seen them approaching that length, measured from the nose to the extremity of the tail. Even the general length of $\mathrm{Mr}$. Sheppard's specimens was "seven inches and upwards." It is true that the characters and descriptions given by this author are vague and unsatisfactory, as they refer merely to colour; but the 
dimensions can scarcely admit of a reasonable doubt on the subject. The locality mentioned by him as its most usual resort,-namely, on heaths, -is also, as far as it goes, a confirmatory fact.

It is to Mr. Jenyns, however, that we owe the only clear and satisfactory published description of this species as a native of Britain; and his account of its characters is as admirable for its correctness and perspicuity as any of the other descriptions of that accomplished author.

It is from the immediate vicinity of my own native place that the specimens which have hitherto formed the subjects of more recent observation have been obtained. I have been familiar with it from my childhood; and its frequency in various parts of the sandy heaths around Poole and its neighbourhood gave me, when young, numerous opportunities of observing the remarkable difference of size between this and the other native species;-from which circumstance I had, even then, often suspected that they were distinct. Subsequently, when the prosecution of the study of Erpetology might perhaps have enabled me to distinguish them, the opportunity of observing them had ceased, until Mr. Jenyns, having, through Mr. Yarrell, obtained specimens from Poole, seized, with his usual acumen, upon the point of distinction, and speedily discovered the identity of this species with the $L$. stirpium of Daudin, of Milne Edwards, and of Dugés.

I shall be readily pardoned this long and somewhat dry investigation of the synonymy of this species by every systematic Zoologist who appreciates the importance of precision on this subject; and I now proceed to give a short history of its habits, as far as I have had an opportunity of observing them.

This beautiful species is found in the neighbourhood of 
Poole in somewhat different situations. Its general abode is on sandy leaths, where it is frequently seen crossing the small bye-paths with considerable swiftness, although it is certainly less rapid in its movements than the smaller and more common species. The transient glance which is thus obtained of it, "together with its viperine appearance and colours," and the size and length of its body and tail, may easily have deceived Mr. Sheppard, who says that he has often mistaken it for the Viper when hastily passing it. But it is also occasionally seen on the sunny sides of green banks, basking in the sun's rays, and retreating quickly upon the approach of any intruder. Mr. Sheppard mentions that he had "once or twice observed it near marshes;" and it is occasionally seen in the small village of Hamworthy, near Poole, in moist situations. It has been stated by a gentleman of my acquaintance, that the brown varieties are confined to the sandy heaths, the colours of which are closely imitated by the surface of the body, and that the green variety, which I have already slightly alluded to, frequents the more verdant localities just mentioned. Be this as it may, - and it is a statement which at present I can neither confirm nor refute,-it is certain that these varieties, mentioned by Linneus and seen by Miiller, do exist in the place I have named, and within a comparatively short distance.

It is more timid and far less easily rendered familiar than the beautiful Green Lizard ( $L$. viridis) of Guernsey and the South of Europe. This latter species may be readily tamed, and taught to come to the hand for its food, and to drink from the hollow of the palm of any one to whom it is accustomed. It will lie coiled up between the two hands, enjoying the warmth, and not offering to escape. But it is very different with the present species, 
which appears not to be susceptible of any such attachment. It will indeed attempt to bite any one who handles it, which I have never known to occur with the $L$. viridis. When in confinement, it ceases to feed, conceals itself with extreme timidity when approached, and ultimately pines and dies.

The female lays her eggs, to the number of twelve or fourteen, in hollows in the sand, which she excavates for the purpose, and having covered them carefully with sand, she leaves them to be hatched by the solar heat. It is probable that the eggs are laid a considerable time before they are hatched, as I have found the female containing numerous eggs of the full size, and apparently ready to be deposited, and yet without the vestige of an embryo within any of them: there is, therefore, every reason to conclude that this species never brings forth her young alive, as is always the case with the common Lizard.

It is a northern species, rarely occurring so far south as Italy, but sufficiently common in the northern parts of France and the middle districts of the European Continent, and extending, as we have seen, as far north as Sweden and Denmark.

It varies exceedingly, like most others of the Lacertine group, in colour and marking. The most common colour of the upper parts is a sandy brown, with obscure longitudinal fascir of a darker brown, and a lateral series of black rounded spots, each marked with a yellowish-white dot or line in the centre. There is often in this most common variety more or less of green on the sides. The following figure is of a very beautiful individual in my collection, which was taken in the neighbourhood of Poole by my relative, Dr. Bell Salter, of Ryde : it is of a rich brown colour above, with a rather lighter fascia on each side near 
the mesial line, and a number of black ocellated spots. arranged almost continuously in somewhat irregular oblique fascix, each of these spots having a white pupil. There

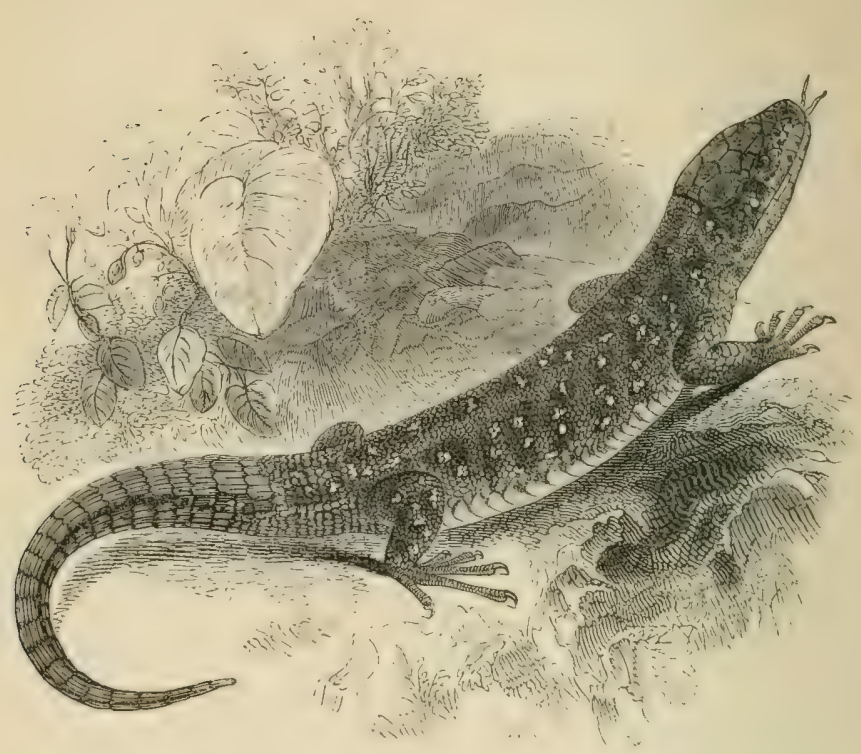

are in this, as in the one described by Mr. Sheppard, about four black spots on the head. This specimen has a remarkably short tail, and some other structural peculiarities, which led me at first to suppose that it belonged to a different species; but I am now satisfied that it is merely a variety of the present one. The comparative shortness of the tail probably arises from its having been mutilated and restored.

Another variety is that to which I have before alluclerl, in which the upper parts are more or less of a green hue. In some this colour is brighter and lighter than in others; but the usual colour is a rather dull brownish-green. Not 
only is it very probable that the passages which I have quoted from Linnens and Müller indicate this variety, but I cannot help believing that all the accomts we have on record of the supposed occurrence of the Green Lizard, $L$. viridis, in Ireland and in England, are to be referred to individuals of the same variety of our present species; which were probably of unusually vivid hues, and observed under all the advantages of bright sunshine. Such may doubtless be the explanation of the "beautiful green Lacerte" seen by Gilbert White, "on the sunny sand-banks near Farnham." * The Prince of Musignano, in his " Fauna Italica," figures a variety with the whole of the back of a dull brick-red colour. The under side is usually of a whitish or greyish colour, varied with light green towards the sides, about the collar, and under the tail, and a few black dots scattered about those parts.

In its general form this Lizard is much thicker and less gracile than the more common species. The head is rather: more obtuse, the body more rounded, and the limbs stronger and shorter. The relative proportions of the tail and the body vary exceedingly in different individuals. As a general rule, it may be stated that the length of the head and body together is to that of the tail as three to four nearly; but in one specimen in my collection the proportions are nearly equal, and in that which is figured above, page 30 , the tail is even considerably shorter than the head and body; but, as has been observed before, this may have occurred from the mutilation and reproduction of that part. The legs are so short, that when the posterior ones are

* I find, by referring to my lamented friend Mr. Bennett's edition of the "Natural History of Selborne," that I have appended the following note to page 114:- "These were probably unusually large and bright individuals of the $L$. stirrium, now ascertained to be indigenous to this country." 
brought forwards and the anterior placed backwards, parrallel to the side of the body, the hinder toes do not extend further than to the wrist of the anterior ones; in which respect it differs remarkably from the other species. In this, as in others, however, the abdomen of the female is proportionally larger than that of the male. The third and fourth toe of the fore foot are nearly of equal length; Mr. Jenyns says the former is the longer, but in some specimens the reverse is the case. The plates of the head ${ }^{*}$ are similar in their general form and proportions to those of most others of the genus. The nostrils are placed near the outer or inferior margin of the nasal plates, and nearly half-way between the anterior and posterior margins. The frontal plate is elongate pentagonal; the anterior angle obtuse; the lateral margins parallel, but slightly contracted about the middle; the inter-parietal pentagonal, and with a depressed point in the centre; the occipital very small. The upper eyelid with a series of very minute scales, and the whole surface of the lower covered by similar ones; the space between the eye and the auditory passage covered with plates, of which the two superior, lying immediately under the parietal, are much the largest. The scales of the upper parts of the body are round or polygonal, and slightly, though distinctly, carinated. The abdominal plates in six rows, the middle series narrower than the adjoining ones. Pre-anal plate single, of a broad pentagonal form; the anterior margin bordered by four pairs of plates. Femoral pores varying in number from eight to fifteen on each side. In the specimen figured at page 30, there are eight on one side, and nine on the other. The pores are in this species placed in flat triangular scales; whilst in 
Zootoca vivipara the scales are so round and small as almost to form tubes. The tail is covered with numerous distinct whorls, according to Dugés from fifty to eighty, of elongated scales, which are longer, narrower, and more distinctly carinated towards the extremity. The number of whorls varies considerably in different individuals.

The following are the dimensions of one of moderate size :-
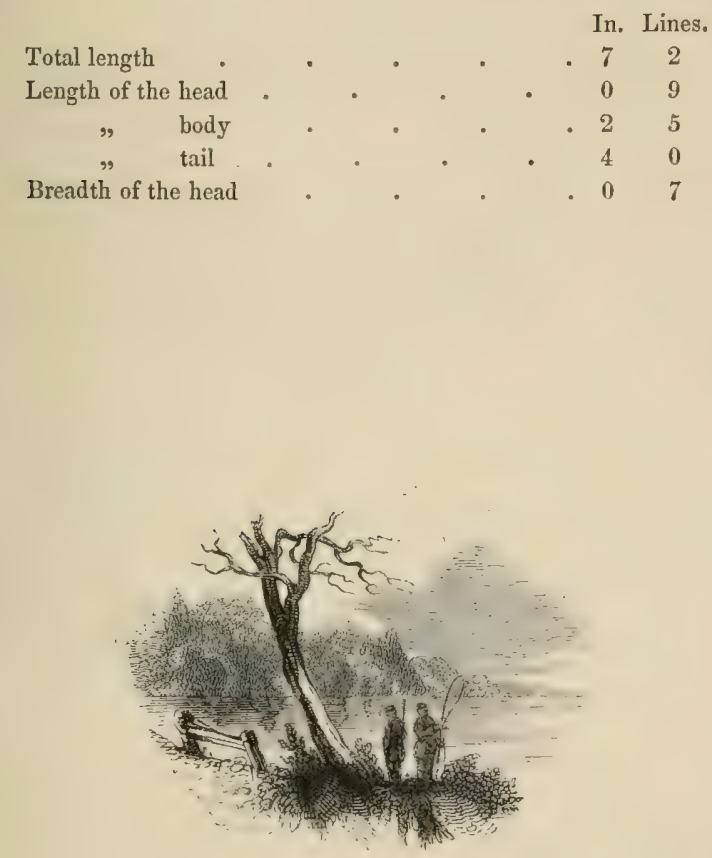


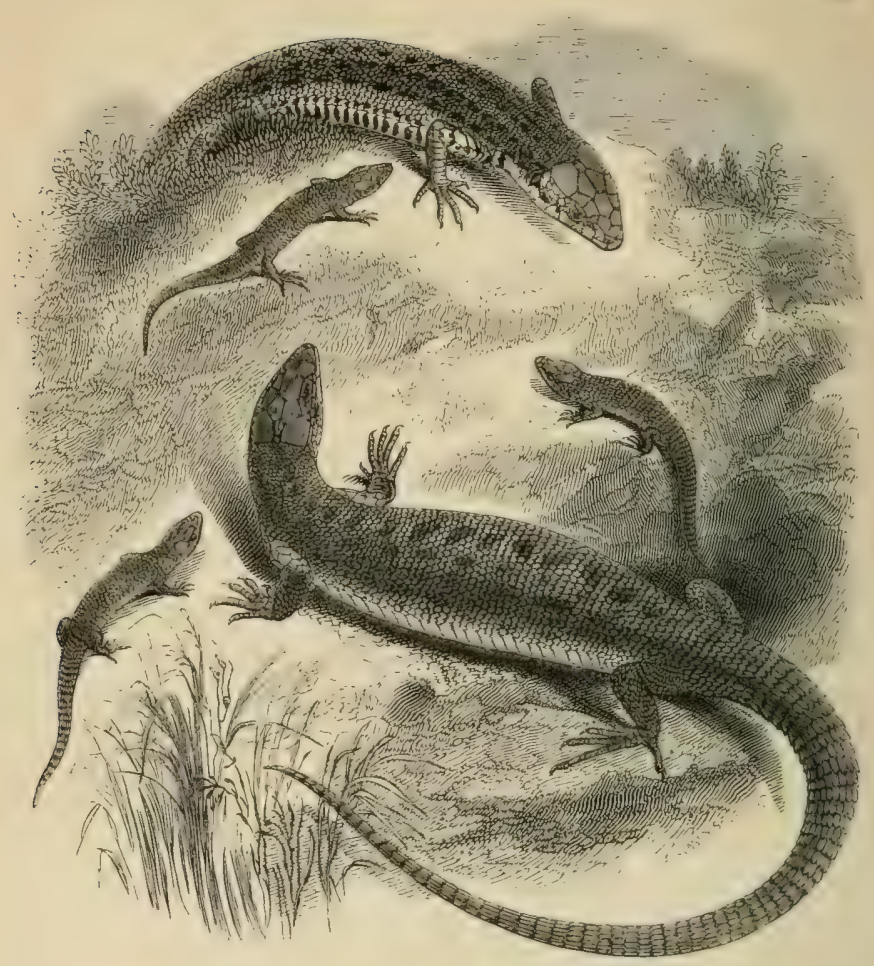

Genus, Zootoca. Wagl.

Generic Character. - Nostrils, collar, superorbital lamina, as in the genus Lacerta. Temples covered with adpressed scales. Scales of the back elongated and hexagonal. Palate toothless.

\section{VIVIPAROUS LIZARD.}

NIMBLE LIZARD. COMMON LIZARD.

\section{Zootoca vivipara.}

Lacertus terrestris vulgaris ventre nigro maculato, Merrett, Pinax, p. 169. RAY, Syn. Quad. p. 264. 
Lacerta agilis, Berkenir. Syn. 1. p. 56. Sheppard, in Linn. Trans. VIT. p. 49. Flem. Brit. An. p. 150. JENYNS, Brit. Vert. p. 292.

"vivipara, JACQ. Nov. Act. Helv. I. p. 33, t. i.

Zootoca " WAGL. Syst. Amph.p. 155.

Scaly Lizard, PEN. Brit. Zool, MI. p. 21, to ii.

MAS.

Lacerta odura, Sheppard, l. c. p. 50.

Evough has been said in the account of the former species on the subject of the nomenclature and synonymy both of that and of the present subject. I have there attempted to shew that the Linnean name agilis has been hitherto improperly applied to this common species, and that it belongs to our other indigenous Lizard. It remains now only to say a few words on the identity of the present one with the Lacerta vivipara of the younger Jacquin. An examination of the figure in that author's paper will shew that this synonymy is correct; and it is entirely confirmed by the fact of the ovo-viviparous character of our species. The following graphic and interesting account I copy from the paper referred to; and as the work is comparatively little known in this country, I make no apology for thus giving it in detail. It is an additionally interesting circumstance that this worthy son of so distinguished a father was only eleven years old when these observations were made.

"In excursu botanico in Alpes vicinas, cum parente optimo, circa finem Julii præteriti instituto, obtulit sese mihi forte fortuna in monte Schneeberg, Lacerta prægnans, quam prehensam, ut servarem, capsulæ inclusi: præterlapso duorum dierum spatio cum hane iterum aperirem, en ! apparet illa onere, quod gestaverat, liberata, ac editis sex lacertis juvenculis stipata; ovorum in capsula reliquorum vestigia ne minima quidem hac licet sollicite excussa, deprehendere licuit! quod eo magis mirabar, quo ì 
Cl. Mullero, S'ystem. Nat. t. iii. p. 77, traditam noveram, (quasi res esset in omnibus lacertarum generibus constanter observata) lacertas ova, eaque cute seu membrana vestita, magno numero excludere solere; cum autem neutiquam omnino vero sit simile, tam exiguo duorum dierum spatio, non ova tantum deponi, sed et ipsas ex his excludi potnisse lacertulas, non sine ratione concludere pesse mili videbar, hasce vivas it matre in lucem editas fuisse." Mr. Gray, in his Synopsis of Reptiles in Griffith's Animal Kingdom, refers Jacquin's Lacerta vivipara to the $L$. muralis of Daudin and Merrem (Podarsis muralis of Wagler): this mistake, however, Mr. Gray has subsequently corrected.

It is in consonance with the remarks which I have ventured to make on the real value of generic characters, and the legitimate grounds for generic distinctions, that I have followed Wagler in assigning a distinct appellation to the present animal. Choosing minute and unimportant points of external structure as what may be termed its artificial character, it is in the peculiarity of its habits and pliysiology that I rest its claim for separation from the forms most nearly allied to it. But for this interesting peculiarity, - I mean the fact of its being ovo-viviparous, - I should certainly have retained it as a species of Lacerta, as Mr. Gray has done. Although, therefore, I have adopted Wagler's division of the Lacertine group as far as regards our own indigenous species, I have done so upon very different grounds; and should not be disposed to follow him in many of the artificial divisions which he has made throughout the whole class of Reptilia.

This agile and pretty little creature is the common inhabitant of almost all our heaths and banks in most of the districts of England, and extending even into Scotland: it is also one of the few reptiles found in Ireland. On the 
Continent its range does not appear to be very extensive: it is not found in Italy, nor, I believe, in France, and is very probably confined in a great measure to our own latitude. Its movements are beautifully graceful as well as rapid; it comes out of its hiding-place during the warm parts of the day from the early spring till autumn has far advanced, basking in the sun, and turning its head with a sudden motion the instant that an insect comes within its view, and darting like lightning upon its prey, it seizes it with its little sharp teeth and speedily swallows it. Thus it will often take a great number of the smaller insects, preferring those of the dipterous order; though it will not refuse many of the coleoptera or orthoptera, if they be not too large.

Instead of depositing her eggs in the sand to be hatched by the warmth of the sun, as is the case with the former, the female of the present species retains the eggs within the oviduct until the young are ready to leave them, and thus they are produced alive. $A s$ in all the ovo-viviparous reptiles, the covering of the egg is very thin, and merely membranous. In this respect they differ from those which deposit their eggs before the embryo is formed. In the latter case a more efficient protection is necessary, and the covering is either calcareous, as in the Tortoises and Crocodiles, or of a substance resembling parchment, as those of the Snakes and most Lizards. In the Viper, which also produces its young alive, the covering, as in the present animal, is extremely thin and very easily torn; and there is reason to believe that the laceration of this membrane and the emancipation of the young take place in and are occasioned by the very act of parturition.

As the young ones are occasionally found with the mother, there is some reason to believe that these little 
animals are not wholly devoid of the instinct of parental care and tendance; but it is scarcely probable that the exercise of this feeling is ever very powerful, or that it endures for any considerable period. The young when brought forth are fully formed, and capable of running about, and very shortly afterwards of taking their own food. They vary in number from three to six.

Although I have alluded to the sun's influence as being the means of hastening the evolution of the embryo in the oviparous reptiles, it is not to be concluded that the same source of warmth is unnecessary in the present and similar instances. The only difference is, that in the ovo-viviparous species the solar heat is communicated to the embryo through the medium of the mother; and hence we often see the pregnant female about the month of June constantly basking in the sun, and lying in such a position as to expose the body most fully to his influence. Every one who has watched the habits of our native reptiles must have seen the same circumstance in the gravid female of the Common Viper; and may have observed how much more reluctantly and tardily she leares the genial spot than the male.

This little Lizard is much smaller and more gracile in its form than the L agilis. The head is more depressed, rather narrower, and the muzzle more acute. The arrangement and relative size of the plates on the head do not differ very considerably; but those of the temples are much smaller and more numerous in the present than in the former. The collar consists of nine plates, which are nearly equal; the abdominal plates in six rows, the middle and outer ones narrower than the intermediate. The dorsal seales are narrower, more angular, and the carina less distinct than in $L$. agilis: those of the tail are 
nearly similar. The feet are more slender, and the toes longer in proportion. The femoral pores, which vary less in number than in the other, being generally nine or ten, are placed in scales which are very different from the corresponding ones in $L$. agilis. Instead of being broad, flat, and triangular, and much larger than the orifice of the pores, as in that species, they are small, rounded, and so little larger than the pores, as to appear merely as the sides of a tube. This is a very tangible character, though, I believe, not before observed. "The following," says Mr. Jenyus, "are sexual distinctions:-In the male, the tail and legs are longer in proportion to the body; the former is nearly (in some specimens quite) two-thirds of the entire length : the hind-leg applied to the side of the abdomen reaches to, or passes beyond, the carpus of the fore-foot; the ante-anal lamella is shorter, and broader, or more transverse; the under side of the base of the tail is flattened with a slight longitudinal depression of the middle just behind the vent; during the season of sexual excitement, the base of the tail is much dilated at the sides, appearing swollen.* In the female, the abdomen is longer and the tail shorter, the latter being often not more than half the entire length: the hind-Jeg barely reaches to the tips of the claws of the fore-foot; the ante-anal lamella is longer in proportion to its breadth, and of a more decided hexagonal or pentagonal form; the base of the tail is rounded, and never dilated at the sides." +

The colours and markings of this species vary greatly. The general ground colour of the upper parts is a greenish

* It is in this state undoubtedly the Lacerta cedura described by Mr. Sheppard in the seventh volume of the Linnean Transactions, as having the tail bulging out a little below the base, as if it had been cut off and set on again. This was first detected by Mr. Gray, and published in the Proceedings of the Zoological Society for 1834 .

+ Jenyns, Brit. Vert. p. 293. 
brown, with a dark brown line down the middle of the back, which is often somewhat interrupted; a broad fascia extends parallel with this on each side, commencing behind the eyes, and extending to a greater or less length down the tail; between these and the former are often one or more rows of black dots, and similar ones occur in many individuals in the broad lateral fascia. The under side of the body and base of the tail in the male are bright orange, spotted with black: in the female these parts, as well as the tail, pale greyish green, without spots.

The usual length is from five inches and a half to six and a half: the head usually about five lines.

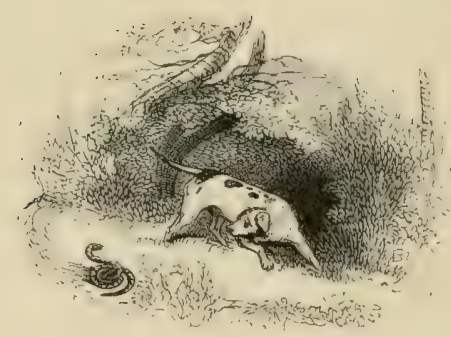




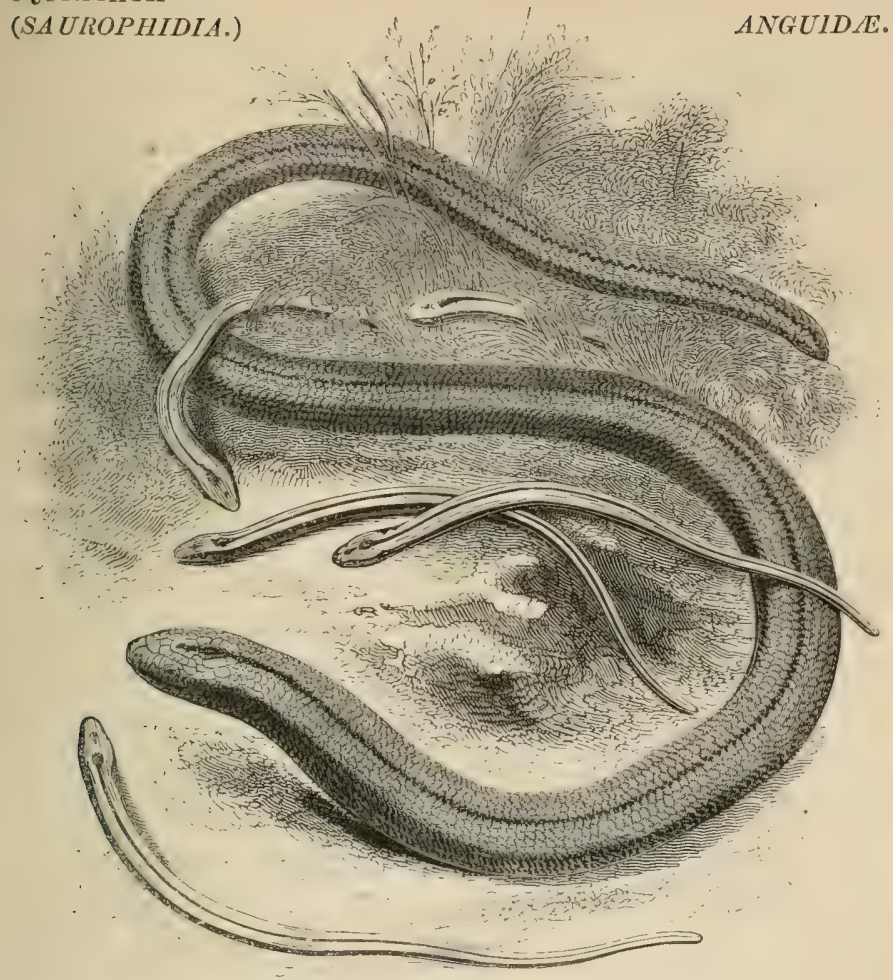

Genus, Anguis, Linn.

Generic Character,-Body and tail cylindrical, obtuse; scales smooth, imbricate, nearly equal above and beneath; head covered with about nine larger plates; tympanum concealed; legs none; bones of the shoulder, the sternum, and pelvis rudimentary, and wholly concealed.

\section{BLIND-WORM. SLOW-WORM. Anguis fragilis. Linn.}

Specific Character.-Silvery grey, a black longitudinal line extending down the back. Scales rounded and plain.

Anguis fragilis, Linn. Syst. Nat. I. p. 392. Muld. Zool. Dan. Prod.p. 36 , sp. 306. Latr. Rept. IV. p. 209. DaUd. Rept. VII. p. 327, t. lxxxvii. f. 2. Merr. Syst. Amph. p. 79. WaGL. Syst. Amph. p. 159. Gndy, Syn. Rept. in Griff. An. Kingd. p. 74. Flem. Brit. An. p. 155. Jenyes, Brit. Vert. p. 295. CiI. L. Bonar. Faun. Ital, c. icon.

Orret commun, Cuv, Règ. An. 2 Edit. 11. p. 70.

Blind-worm, PenN. Brit. Zool. III. p. 36, t. iv. No. 15. 
The group to which the genus Anguis belongs is one of the most interesting in its relations of all the forms of Reptilia. Under external characters considerably differing from each other,- some possessing the limbs and locomotion of true Lizards, and others wholly devoid of external members and moving like true Serpents,--there are in Mr. Gray's order Saurophidia many points of mutual affinity which prevent the possibility of separating them from each other. From the well-known family of the Scinks, or Scincida, with their true legs and five-toed feet, down to the present species and its immediate congeners, every possible gradation is to be found in the development of the anterior and posterior extremities. Agreeing, as they all do, in the Saurian character of the structure of the head, the consolidation of the bones of the cranium and jaws, and the narrow and confined gape, so different from these parts in the true Serpents, they yet approach the latter in the comparative length of the bodies and in the gradual diminution and ultimate disappearance of the extremities. In the genus Scincus, for instance, the limbs are already less robust than those of the true Saurians; the two pairs are also more distant from each other, in consequence of the greater comparative elongation of the body. There are as yet five perfect toes on each foot, which, however, are shorter and more even in their relative proportions than in the Lizards. These deviations become increased in the genus Chalcides, and still more in Seps, which has a very elongated body, the limbs extremely small, and the toes only four or three on each foot. In Monodactylus a further reduction takes place in the development of the limbs, which have dwindled to a mere little undivided finger; they are still, however, four in number; but in the genus Bipes the anterior 
ones have wholly disappeared, and are found in a rudimentary state under the integument, the posterior ones constituting only small undivided processes. These also being removed, the Ophidian form of the present genus, and those of Tortrix, Typhlops, and others, with all the Amphisbcrida, succeed, in which the bones of the shoulder, the sternum, and the pelvis exist in a more or less rudimentary condition; and lead us towards the true Snakes, in which all these parts are lost excepting the rudiment of a posterior extremity, which in the Boc appears externally in the form of a small horny hook, or holder, on each side of the vent. In the Serpents, the gape, too, has assumed its extreme power of extension, from the bones of the jaws and other parts of the face being separate; and in most of them the scales, which in the former groups were similar on the upper and under parts of the body and tail, are small and imbricated above, whilst beneath they assume the form of broad transverse plates. Such is a very brief account of the beautiful gradations by which these reptiles pass fiom the true or typical Samrian to the Ophidian form; and although, perhaps, it would be more consistent with analogy to consider, with Merrem, the whole of the scaled Reptilia as constituting one great orler, yet the union of this interesting intermediate group, to which Mr. Gray has given the name Saurophidia from that relation, is a legitimate and important improvement upon the confusion in which they were left by Cuvier, who separated animals even of the same family, and placed some in his order "Saurions," and others in his "Ophidiens."

The structure of the common Slow-worm, then, necessarily removes it from the Suakes, to which, indeed, it bears a less close affinity than to some of the Saurians. This 
structure, and the relations which it indicates, form an unanswerable argument of the fallacy of the position, that external characters are in all cases sufficient to indicate affinities; and shew of how much importance, or rather how essential, is the anatomical investigation of internal structure, to enable us to arrive at the true relations of individual species or of groups.

The Blind-worm, or Slow-worm, by which names this species is known indifferently in this country, is found in alnost every part of Europe, excepting the extreme north, and is capable of enduring a much colder climate than most other reptiles even of our own country. It is found in Russia, in Poland, in Denmark, Sweden, and Scotland, as well as throughont the whole of the more temperate parts of Europe, and as far south as the South of France, and Italy; but it has not, I believe, been seen in any part of Africa. It makes its appearance also at an earlier season than any other of our scaled reptiles. It retires in the autumn under masses of decayed wood or leaves, or into soft dry soil where it is covered with heath or brushwood, and penetrates to a considerable depth in such situations by means of its smooth rounded muzzle, and even polished body.

Its habits are extremely gentle and inoffensive. Even when handled roughly, it rarely attempts to bite; and when it is irritated so as to induce it to seize upon the finger, the teeth are so small as scarcely to make an impression. Of course the opinion that it is venomous is a mere vulgar error. There are no poison-fangs in the jaw, either of this or of any other species of the group to which it belongs. It is so timid, that on being laid hold of or pursued, it contracts itself so forcibly as to become perfeetly stift; : and it is then so fiagile as to be easily broken 
in two either by a blow or an attempt to bend it. Hence it acquired the specific name of fragitis, applied to it by Linneus. This property, however, is not peculiar to the present species: the Glass-snake, as it is called, an American species, has derived its name from a similar circumstance. Lilie the Viper, and, in a less degree, also the Common Snake, this species is not easily induced to feed in a state of confinement. I have kept them repeatedly, and have offered them young frogs and insects, but without being able to induce them to take them. That this failure, however, was rather due to my ignorance of their favourite food than to any disinclination on their parts to feed in captivity, the following note by Mr. George Daniel in Mr. Bennett's edition of White's Selborne sufficiently testifies.

"A Blind-worm that I kept alive for nine weeks, would, when touched, turn and bite, although not very sharply; its bite was not sufficient to draw blood, but it always retainerl its hold until released. It drank sparingly of milk, raising the head when drinking. It fed upon the little white slug (Limax agrestis, Linn.) so common in fields and gardens, eating six or seven of them, one after the other; but it did not eat every day. It invariably took them in one position. Elevating its head slowly above its victim, it would suddenly seize the slug by the middle, in the same way that a ferret or dog will generally take a rat by the loins; it would then hold it thus sometimes for more than a minute, when it would pass its prey through its jaws, and swallow the slug head foremost. It refused the larger slugs, and would not touch either young frogs or mice. Snakes kept in the same cage took both frogs and mice. The Blind-worn avoided the water; the Snakes, on the contrary, coiled themselves in the pan containing water 
which was put into the cage, and appeared to delight in it. The Blind-worm was a remarkably fine one, measuring fifteen inches in length. It cast its slough whilst in my keeping. The slin came off in separate pieces, the largest of which was two inches in length; splitting first on the belly, and the peeling from the head being completed the last."

These are interesting particulars; but it is certain that when in a state of liberty they do not exclusively live upon slugs, as I have found the remains of insects in the stomach; and they will also feed readily on earth-worms, even of six or seven inches long, according to the testimony of M. de Sept-Fontaines, as quoted by Lacépède.

The last-mentioned Erpetologist, who, however, like his colleague Buffon, was too credulous of all the stories told him, declares that this reptile would swallow mice, small rats, frogs, and toads. This is the statement of a person who has rather received for granted the assertions of the ignorant, than taken the trouble to observe for himself. The fact is, that the wholly undilatable character of the mouth necessarily restricts it to the deglutition of such prey as can be received within its narrow and circumscribed gape.

One very interesting point in its habits, is its being ovo'viviparous. Like the last-described species, the Zootoca vivipara, the young of this animal are hatched before they come into the world; and it is probable that in this case, as in that of the species just named, as well as in the Viper and the Rattlesnake, the rupture of the membrane of the cgg takes place during the parturition. The female is said to go with young about six weeks or two months: there can be no doubt, however, that the duration of this period must depend upon the temperature to which the animal is exposed. They are produced in June or July. The num- 
ber of young ones produced at one birth varies from seven to twelve or thirteen. When brought forth, they are from eighteen to twenty-two lines in length. The young become very active almost immediately after their birth, and soon learn to feed upon small soft insects, and probably small worms, snails, or slugs.

The shedding of its skin is performed by this species in the same manuer as by most of the true Ophidians. It is, in fact, taken off in one piece, when the animal is at liberty and strong enough to effect this; and, like the others, it leaves the skin, turned inside out, attached to the brushwood, or other substance which it has employed to entangle or secure it as it was coming off. It is, however, stated that in some cases it is inverted only as far as the vent, and that the tail slips out of its covering "like a sword out of its scabbard."

This animal is long, and almost of equal thickness throughout the whole length, but rather tapering posteriorly. The body is slightly tetragonal. The head is short and small; the eyes small, but very brilliant and quick; the eyelids perfect, as in the Lizards; the ears entirely covered with the integument; the teeth are very small, and slightly hooked; the tongue rather broad, not very extensile, notched at the extremity, but not bifid as in the true Snakes. Vertex covered with about nine plates; sides of the head, throat, back, sides, belly, and tail, all covered with small and nearly equal rounded scales, which are not carinated. The tail, which is obtuse, is, in some individuals, not more than half the length of the body, or even less; but in others, reaches to nearly an equal length with the head and body. My own observations would go to prove that this difference in the relative proportion of these parts may in some measure depend on 
sex; as we find in the Common Lizard that the body of the female is longer than that of the male.

The general colour is brownish grey with a silvery glance; and there are generally several parallel longitudinal rows of little dark spots along the sides, and, more constantly, one along the middle of the back. In some individuals the upper part is wholly without spots or lines; the sides only being marked with an obscure band. The belly is of a bluish black colour, with whitish reticulations. The young ones are very light yellowish grey above; the sides and belly quite black; and there is a black dot on the vertex, and another on the occiput, - which latter gives origin to a slender longitudinal black line down the back.

The total length is from ten to twelve, or even fourteen inches: the head half an inch, or a little more. The vignetie gives a representation of the under part of the tail, and of the upper part of the head.

The Anguis Eryx of Linneus, the Aberdeen Snake of Pennant, communicated to them by Dr. David Skene, and said to have been taken in Aberdeenshire, was certainly nothing more than the common Slow-worm; and, from the description, can scarcely be considered even as a variety of it, so little does it differ, if indeed it can be said to differ at all, from its normal appearance.

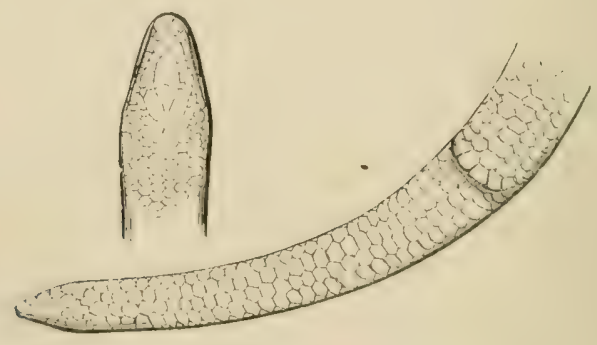




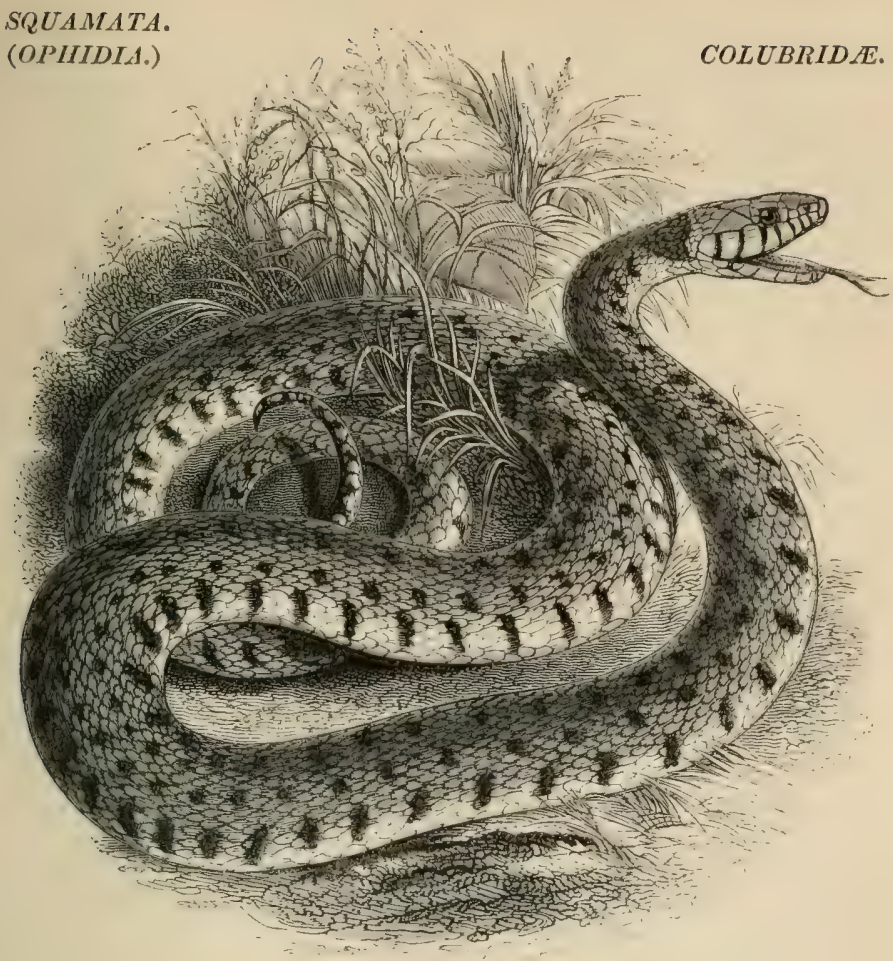

\section{Genus, Natrix. Laur.}

Generic Character.-Head distinct, oblong-ovate, depressed, covered with scuta; gape wide; body very long, nearly cylindrical, slightly depressed; tail cylindrical, slender; scales imbricated, placed in longitudinal series, lanceolate, generally carinated; abdominal shields simple, arched at the margin; caudal shields biserial.

\section{RINGED SNAKE.}

\section{COMMON SNAKE.}

\section{Natrix torquato. Ray.}

Specific Character.-Above greyish olive, with several rows of alternate black spots; beneath greenish yellow, tessellated with black (sometimes almost wholly black); an interrupted yellow fascia across the neck, followed by two black spots; scales lanceolate, acutely carinated; tail about one-fourth the length of the body. 
Natrix torquata, RAy, Syn. Quad. p. 334. Flem. Brit. An. p. 156. Jenyns, Brit. Vert. p. 296. Bonap. Faun. Ital, cum figuris.

Coluber natrix, Linn. Syst. Nat. I. p. 380. SHaw, Gen. Zool. III. p. 519. Latr. Hist. Rept. IV.p. 38. Daud. Hist. Rept. VII. p. 34, t. lix. f. 15 ; t. lxxxii. f. 1. Turt. Brit. Faun. p. 81. $"$ torquatus, IAACEP. Quad. Ovip. et Serp. II. p. 147, t. vi. f. 2.

Natrix vulgaris, LAUR. Spec. Med. p. 75 et 80.

Tropidonotus natrix, Kunц.-Firzings. Prod. Faun. Aust. p. 320. WAGL. Syst. Amph. p. 179. GrdY, in Griff. An. Kingd. IX. p. 85.

Ringed Snake, Penn. Brit. Zool. III. p. 33, t. iv. No. 13.

Couleuvre à Collier, LACEP. ]. c.

The family of Colubrida, to which our Common Snake belongs, is one of the most extensive of all the natural groups of reptiles. It includes a number of generic divisions, some more and some less-strongly marked, which are found in every quarter of the globe. They are, all of them, perfectly free from any poisonous quality, not possessing any of those tubular teeth or poison glands which render some other families of Serpents so formidable. Many of the species which, on account of the broad plates which are found to occupy the upper part of the head, were considered as belonging to the genus Coluber, by Linneus and his immediate followers, are to be referred, not to other genera only, but to other families; as the Cobra di Capello, and the Common Viper, for instance.

To this family, then, belong those Serpents, and those only, which, in addition to the absence of poisonous fangs, have the head covered with broad plates, and the under side of the tail with divided scuta throughout its whole length, as shewn in the following figures, which are taken from the present species.

It is by far the most common of our true reptilia, if we except the little Lizard, Zootoca vivipara. It inhabits all our woods, and heaths, and hedgerows, especially in the neighbourhood of water, feeding upon young birds, and even eggs, or mice, and other small quadrupeds, and 
lizards; but, in preference to all these, upon frogs. I have seen one of these voracious creatures in pursuit of a frog, which appeared perfectly conscious of its approaching fate,
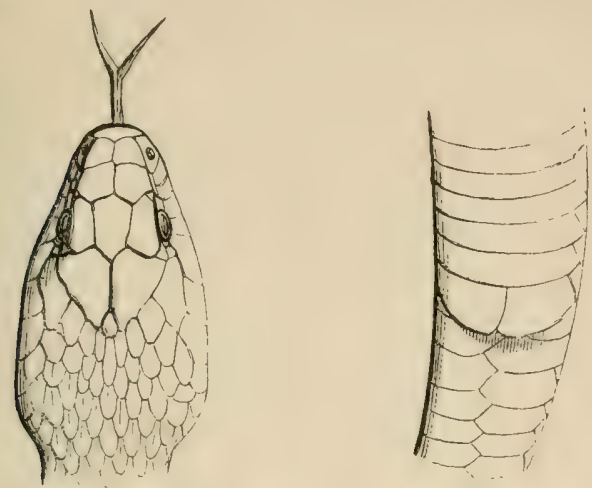

leaping with less and less power as it found its situation more hopeless, and the crisis of its fate approaching, and uttering its peculiar weak cry with more than usual shrillness, until at length it was seized by its pursuer by the hinder leg, and gradually devoured. The manner in which the Snake takes its prey is very curious. If it be a frog, it generally seizes it by the hinder leg, because it is usually taken in pursuit. As soon as this takes place, the frog, in most instances, ceases to make any struggle or attempt to escape. The whole body and the legs are stretched out, as it were, convulsively, and the Snake gradually draws in first the leg he has seized, and afterwards the rest of the animal, portion after portion, by means of the peculiar mechanism of the jaws, so admirably adapted for this purpose. It must be recollected that in the true Serpents, unilike the group to which the Slowworm belongs, the bones of which the upper and lower jaw are composed, are perfectly and loosely distinct from each other, and connected only by ligaments. By this arrange- 
ment not only is great dilatability of the mouth obtained, which is also aided by a peculiarity in the structure of the joint, but one side of either jaw is capable of acting independently of the other; and as the animal is gradually taking its prey, one side of the jaws is extended forwards, and the two rows of teeth of the upper, and the single row of the lower, fixed into the integument; then the opposite side of the jaws is stretched forwards in the same manner, and so on alternately, until the victim is thus gradually and often slowly conveyed into the osophagus, and by the muscular action of this part it is swallowed. When a frog is in the progress of being swallowed in this manner, as soon as the Snake's jaws have reached the body, the other hinder leg becomes turned forwards; and as the body gradually disappears, the three legs and the head are seen standing forwards out of the Snake's mouth in a very singular manner. Should the Snake, however, have taken the Frog by the middle of the body, it invariably turns it by several movements of the jaws, until the head is directed towards the throat of the Snake, and it is then swallowed head foremost. This process will remind all who have witnessed the curious sight of the great Boa taking its food, of the manner in which that enormous reptile effects its deglutition, after it has, by the pressure of its mighty sides, killed and crushed the bones of its victim.

The scene above-described is one which I have often witnessed; and I once saw two Snakes seize upon the same hapless frog. As this circumstance is not unlikely to happen in their native state, it may not be out of place to mention the result. On placing a frog in a large box, in which were several Snakes, one of the latter instantly seized it by one of the hinder legs, and immediately afterwards another of the Snakes took forcible possession of the 
fore-leg of the opposite side. Each continued its inroads upon the poor frog's limb and body until at length the upper jaws of the two Snakes met, and one of them in the course of its progress slightly bit the jaw of the other; this was retaliated, though evidently without any hostile feeling ; but after one or two such accidents, the most powerful of the Snakes commenced shaking the other, which still had hold of the frog, with great violence, from side to side, against the sides of the box. After a few moments' rest, the other returned the attack, and at length the one which had last seized the frog, having a less firm hold, was shaken off, and the victor swallowed the prey in quiet. No sooner was this curious contest over than I put another frog into the box, which was at once seized and swallowed by the unsuccessful combatant.

The frog is generally alive not only during the process of deglutition, but even after it has passed into the stomach. I once saw a very small one, which had been swallowed by a large Snake in my possession, leap again out of the mouth of the latter, which happened to gape, as they frequently do immediately after taking food. And, on another occasion I heard a frog distinctly utter its peculiar cry several minutes after it had been swallowed by the Snake. In taking lizards or birds, it always, as far as my own observation goes, swallows the head foremost. After it has taken its food, it usually remains inactive for many days, not ordinarily seeking a fresh meal until the former one is digested. So exclusively are all Serpents animal feeders, that they not only will not take, but cannot digest, vegetable matters. This is shewn in a very striking manner by a fact which I have witnessed in the case of a Boa which was in the menagerie formerly kept at the Tower. This creature was accustomed to have fowls given to it; 
and after this food was digested, and the remains were voided, any corn which might happen to have been in the crop of the fowl when it was taken, was always found mingled with the excrement, but wholly unchanged.

Snakes are extremely fond of water, taking to it readily, and swimming with great ease and elegance, holding the head and neck above the surface. It is very probable that it resorts to the water in search of frogs.

Snakes, like most other Reptilia, shed their cuticle or outer skin at greater or less intervals. It is a mistake to assign a particular period to this process; some have stated it to occur once, some trice in the summer; but I have found it to depend upon the temperature of the atmosphere, and on the state of health, and the more or less frequent feeding of the animal. I have known the skin shed four or five times during the year. It is always thrown off by reversing it; so that the transparent covering of the eyes, and that of the scales also, are always found concave in the exuviæ. Previously to this curious circumstance taking place, the whole cuticle becomes somewhat opaque, the eyes are dim, and the animal is evidently blind. It also becomes more or less inactive; until at length, when the skin is ready to be removed, being everywhere detached, and the new skin perfectly hard underneath, the animal bursts it at the neck, and creeping through some dense herbage, or low brushwood, leaves it attached, and comes forth in far brighter and clearer colours than before.

Like most Serpents, the Snake has the power of expelling from certain glands, situated within the vent, a most disgusting stinking secretion. This is only done when alarmed or irritated, or when under sexual excitement; in the latter case it is most probably intended as a means of directing the other sex in the pursuit. 
This species, and indeed the whole genus, is truly oviparous, depositing its eggs a considerable time before the young ones are hatched, and leaving them to be vivified and dereloped by the heat of the sun, or of a dung-heap. The eggs are connected together by a glutinous matter, and are generally from sixteen to twenty in number. It is certainly remarkable, considering that the normal character of the whole class of reptiles is truly oviparous, that of our five indigenous species of true Reptilia, the minority only should deposit their eggs before the young are developed and hatched - the present species, and the Lacerta agilis; the latter, too, a recent addition to our known Fauna.

Towards the end of autumn, or earlier, they resort to their place of hibernation, in some sequestered and sheltered corner, as the hollow roots of a tree, under hedges or brushwood, or similar places of security, where they remain, coiled together, sometimes in considerable numbers, throughout the whole of the inclement season; and with the first return of warmth they come forth with all the other tribes which pass the winter in torpidity, and resume all the functions of life.

The Common Snake is easily tamed, and may be made to distinguish those who caress and feed it. I had one many years since, which knew me from all other persons; and, when let out of his box, would immediately come to me, and crawl under the sleeve of my coat, where he was fond of lying perfectly still, and enjoying the warmth. He was accustomed to come to my hand for a draught of milk every morning at breakfast, which he always did of his own accord; but he would fly from strangers, and hiss if they meddled with him.

It inlabits most of the countries of Europe, from Scotland and the corresponding latitude of the Continent, to 
Italy and Sicily. In all parts of England it is exceedingly common; generally frequenting places in which there is ready access to water, and hence it is found in more humid places than the Viper.

So much has been sqid of the inability of reptiles of every kind to exist in Ireland,-or at least of their nonexistence in that island, that I have endeavoured to ascertain exactly to what extent these statements are correct. I have already mentioned the existence of the $L$. agitis there, and with regard to the present species, the following is the result of my inquiries. It would appear not only that the Common Snake is not indigenous to Ireland, but that several attempts to introduce it have totally failed. Mr. Ball some time since informed me of some trials of this kind; and the following letter, which I have recently received from Mr. Thompson, gives a very detailed and clear account of the actual facts.

"In this order (Oplidia) there is not now, nor I believe ever was there, any species indigenous to Ireland. In the Edinburgh New Philosophical Journal for April 1835,* it is remarked, "We have learned from good authority that a recent importation of Snakes has been made into Ireland, and that at present they are multiplying rapidly within a few miles of the tomb of St. Patrick.' I never," proceeds Mr. Thompson, "heard of this circumstance until it was published, and subsequently endeavoured to ascertain its truth, by inquiring of the persons about Downpatrick, (where the tomb of St. Patrick is,) who are best acquainted with these subjects, not one of whom had ever heard of Snakes being in the neighbourhood. Recollecting that about the year 1831 a Suake (Natrix torquata), immediately after being killed at Nilecross, was brought by * Vol. XVIII. p. 373. 
some country people in great consternation to my friend, Dr. J. L. Drummond, I thought this might be one of those alluded to ; and recently made inquiry of James Clealand, Esq. of Ruth Gael House (county Down), twenty-five miles distant in a direct line from Downpatrick, respecting Snakes said to have been turned out by him; I was favoured by that gentleman with the following satisfactory reply:- ' The report of my liaving introduced Snakes into this country is correct. Being curious to ascertain whether the climate of Ireland was destructive to that class of reptiles, about six years ago I purchased half a dozen of them in Covent Garden Market in London; they had been taken some time, and were quite tame and familiar. I turned them out in my garden; they immediately rambled away; one of them was killed at Milecross,* three miles distant, in about a week after its liberation; and three others were shortly afterwards killed within that distance of the place where they were turned out; and it is highly probable that the remaining two met with a similar fate, falling victims to a reward which it appears was offered for their destruction." "

Such is the most accurate and authentic account which I have yet obtained respecting this curious fact in the geographical distribution of these animals; and it certainly does not appear that the failure of these attempts to introduce Snakes into Ireland is to be attributed to anything connected with the climate, or other local circumstances, but rather to the prejudices of the inhabitants which led to their destruction, nor is there reason to believe that their absence from Ireland is other than purely accidental.

That this immunity from reptile infestation was an an-

* This was the one before alluded to, as having been brought to Dr. Drummond. 
cient privilege of the "Land of Saints," is shewn by the following passage from Bede's "Ecclesiastical History:"-

"Hibernia autem et latitudine status, et salubritate ac serenitate aërum multum Brittanniæ præstat, ita ut rarò ibi nix plusquam triduana remaneat: nemo propter hiemem aut fona secet æstate, aut stabula fabricet jumentis: nullum ibi reptile videri soleat, nullus vivere serpens valeat: nam sæpè illo de Brittannia adlati serpentes, mox ut proximante terris navigio, odore aëris illius adtacti intereunt: quin potius omnia penè quæ de eâdem insulâ sunt contra venenum valent. Denique vidimus quibusdam a serpente percussis, rasa folia codicum qui de Hibernia fuerant, et ipsam rasuram aquæ immissam, ac potui datam, talibus protinus totam vim veneni grassantis, totum inflati corporis absumsisse, ac sedasse tumorem." *

This species grows to the length of more than three feet, sometimes, though rarely, of four feet. The head is considerably depressed, of an elegant ovate form, the back part broader than the neck; the gape is of the length of the head, and slightly curved, rising posteriorly. The teeth are small, curved backwards, and, as in all the other innocuous Snakes, arranged in two series on each side of the jaw both above and below. Plates of the head broad and flat; labial plates seven. Tongue long, excessively flexible, bifid to about one-third its length. Body very long; the

* "Ireland, in breadth, and for wholesomeness and serenity of climate, far surpasses Britain, for the snow scarcely ever lies there above three days; no man makes hay in the summer for winter's provision, or builds stables for his beasts of burden. No reptiles are found there, and no snake can live there; for, though often carried thither out of Britain, as soon as the ship comes near the shore, and the scent of the air reaches them, they die. On the contrary, almost all things in the island are good against poison. In short, we have known that, when some persons have been bitten by serpents, the scrapings of leaves of books that were brought out of Ireland being put into water, and given them to drink, have immediately expelled the sprending poison, and assuaged the swelling."-Bede's "Ecclesiastical History," b. i. c. 1, Giles's Translation. 
median line of the back elevated; the neck narrowed; the tail very tapering, moderately pointed at the extremity, occupying generally about one-fifth of the entire length. Scales of the back oval, imbricated, each having a distinct carina, those of the sides broader and with the carina less marked, and becoming almost obsolete. Abdominal plates broad, transverse, in number about one hundred and seventy; subcaudal plates from sixty to sixty-five pairs.

The upper parts of the body and head are of a light brownish grey with a green tinge, sometimes approaching to a dull, pale olive. The labial plates separated by distinct black lines. Behind the head, on the upper part, is a broad collar, or two lunate spots of a bright yellow colour, and immediately bchind these are two broad transverse spots of black, which are also sometimes separate, at others confluent. Two rows of small black spots arranged alternately down the back, and larger ones at the sides; all of which vary in size, as well as in the degree of their approximation to each other. Abdomen of a dull pale bluish, or plumbeous colour, in many specimens marbled with black.

The female, as in all Ophidians, is always much larger than the male.

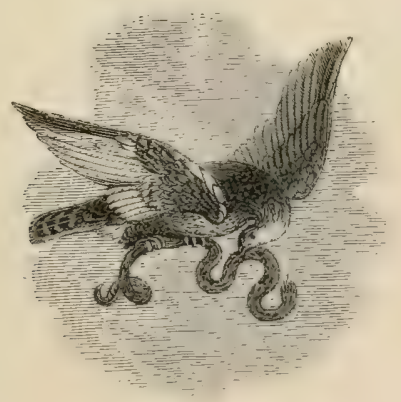


Coluber Dumfrisiensis. Sowerb.

MANY years since a small Snake, having the characters of one of the Colubrida, was taken by Mr. J. W. Simmons, near Dumfries. It was published as a new species by Mr. Sowerby in his British Miscellany, and figured in the third plate of that work. It was there named Coluber Dumfrisiensis. The specimen remained until within the last few years in the possession of Mr. Sowerby's family; but having come into my hands, it was unfortunately lost or mislaid, and I have never since been able to recover it. There is, I think, great reason to believe that it was a very young Natrix torquata, but differing certainly in many respects from the usual appearance and characters of that species. It was about three or four inches in length; "of a pale brown colour, with pairs of reddish brown stripes from side to side, over the back, somewhat zigzag, with intervening spots on the sides." The most remarkable peculiarity mentioned, however, is that "the scales are extremely simple, not carinated." The abdominal plates were one hundred and sixty-two; those under the tail about eighty. This is all the information at present possessed respecting the species, if it be indeerl a species. Mr. Jenyns, in his excellent Manual, expresses the opinion which I have given above, that it is "probably an immature variety of the common species."

See Sowerby's Brit. Miscell. p. 3, t. iii.; also London's Mag. Nat. Hist. II. p. 438, where the original figure is copied. 


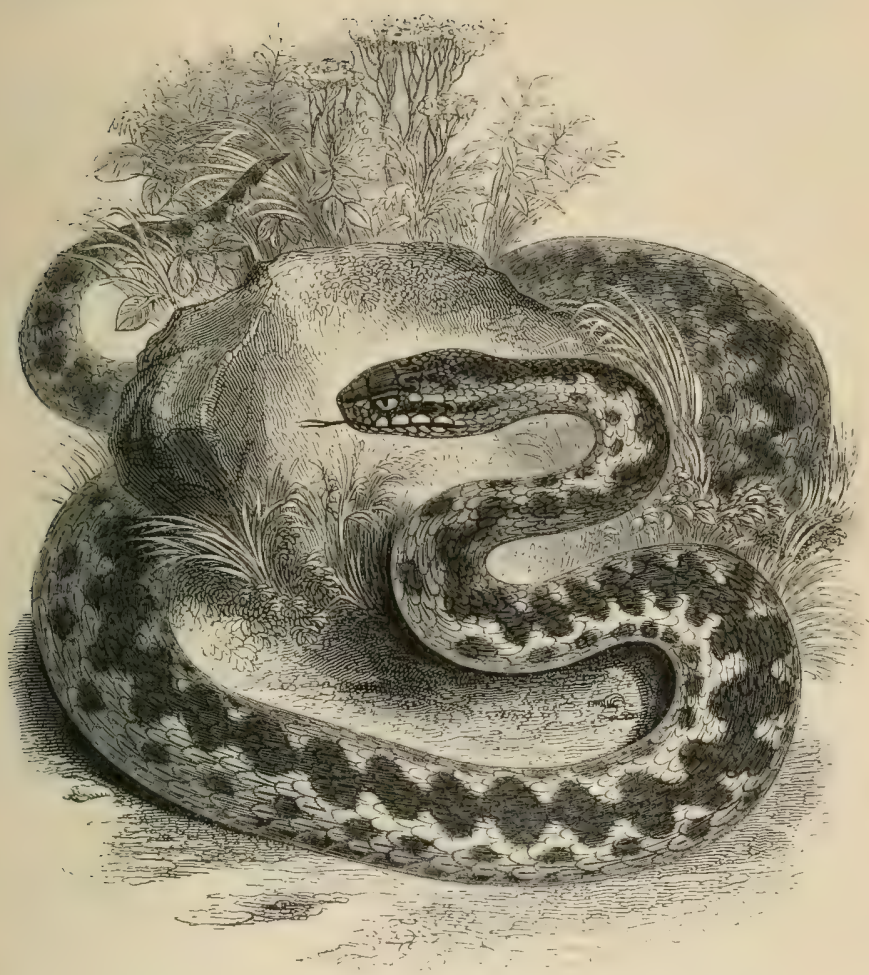

Genus, Pelias. Merr.

Generic Character:-Head depressed, oblong-ovate, somewhat compressed before, and wider behind the eyes; vertex covered with scuta; no pit between the nostrils and eyes; tail with double plates beneath.

\section{COMMON VIPER.}

\section{ADDER.}

\section{Pelias Berus.}

Specific Character,-Brown, with a series of confluent rhomboidal black spots along the back. 
Vipera, $\quad \mathbf{R}_{A \mathrm{Y}}$, Syn. Quad. et Serp. p. 285.

Coluber Berus, Linn. Syst. Nat. I. p. 377. La Ur. Spec. Med. p. 97. Shaiv, Gen. Zool. III. p. 365, t. ci. TurTon, Brit. Faun. p. 80.

Vipera $"$ DAUd. Hist. Rept. VI. p. 89.

"vulgaris, LATR. Rep. III. p. 812.

" communis, LEACH, Zool, Miscell. III. t. vii. Flem. Brit. Anim. p. 156. Jenyes, Brit. Vert. p. 297.

Pelias Berus, Merrem, Syst. Amph. p. 148, sp. 1, $\alpha_{.} \beta_{0} \gamma$. Bonap. Faun. Ital, cum. fig.

Vipère commune, DaUd. l. c. (an Cuv.?)

Viper, Pennant, Brit. Zool. III. p. 26, t. iv.

Var. $\beta$.

Red Viper, $\quad$ RACKeTt, in Linn. Trans. XII. p. 349.

Coluber chersea? LINN. Syst. Nat. p. 337.

Var. $\gamma$.

Blue-bellied Viper, (Coluber caruleus,) SHEPp. in Linn. Trans. VII. p. 56.

Var. $\delta$.

Black Viper, LeAcH, Zool. Misc. loco cit.

The Common Viper is happily the sole British representative of any of the poisonous groups of Serpents, and indeed the only poisonous reptile indigenous to this country. It is far more numerous in Scotland than the Common Snake, and is found in abundance in all parts of England and WVales, frequenting heaths, dry woods, and banks. In Ireland it has never been seen; and it may, almost with certainty, be stated that it does not exist there. On the continent of Europe it is extensively distributed, being found from the northern parts of Russia to the south of Italy and Spain. It is everywhere deservedly feared on account of its venom, which, although less virulent than that of many other species, is yet sufficiently so to produce severe symptoms, and sometimes, in $t_{i_{\ldots}}$. rarmer climates, even fatal results. In this country I have never seen a case which terminated in death, nor have $I$ been able to trace to an authentic source any of the numerous reports of such a termination, which have at varions times been confidently promulgated. At the same time the 
symptoms are frequently so threatening, that I cannot but conclude that in very hot weather, and when not only the reptile is in full activity and power, but the constitution of the victim in a state of great irritability and diminished power, a bite from the Common Viper would very probably prove fatal. The remedies usually employed are the external application of oil, and the internal administration of ammonia.

The poisonous fluid is perfectly innocuous when swallowerl. Dr. Mead, and others, have made this experiment, and never experienced the slightest ill effects from it. It is, however, clear that there would be danger in swallowing it, were any part of the mouth, the throat, or the csophagus, in a state of ulceration, or having an abraded surface.

It will not perhaps be wholly uninteresting to describe briefly the very beautiful apparatus* by which the poison wounds are inflicted, which render these, and so many other Serpents, so formidable. On each side of the upper jaw, instead of the outer row of teeth which are found in non-venomous Serpents, there exist two or three, or more, long, curved, and tubular teeth, the first of which is larger than the others, and is attached to a small moveable bone, articulated to the maxillary bone, and moved by a muscular apparatus, by which the animal has the porver of erecting it. In a state of rest the fang reclines backwards along the margin of the jaw, and is covered by a fold of skin; " when about to be called into use, it is erected by means of a small muscle, and brought to stand perpendicular to the bone. The tooth itself is as it were perforated by a tube, the mode of formation of which was not understood until it was demonstrated by Mr. Smith in the

* See page 64 . 
Philosophical Transactions for 1818. This tube, although completely enclosed, excepting at its basal and apical orifices, must be considered as formed merely by the closing round of a groove in the external part of the tooth itself, and hence not in any way connected with the inner cavity of the tooth, in which exists the pulp upon which the substance of the tooth is formed. The base of the tooth, and consequently the basal orifice of the tube just described, is embedded in a sac, into which the poison is poured from the ducts of the glandular structure by which it is secreted, and which is believed to represent the parotid gland of the higher vertebrata. The poisonous fluid itself is inodorous, tasteless, and of a yellow colour. It is secreted in greater quantity, and its qualities are more virulent in a high temperature than in cold. Its secretion may be greatly increased by local irritation; as is evidenced by the following fact. Some years since I was dissecting very carefully and minutely the poison apparatus of a large Rattlesnake, which had been dead for some hours; the head had been taken off immediately after death; yet as I continued my dissection the yellow poison continued to be secreted so fast as to require to be occasionally dried off with a bit of rag or sponge; I believe that there could not have been less altogether than six or eight drops at the least.

When the animal inflicts the wound, the pressure on the tooth forces a small drop of the poison through the tube; it passes through the external orifice, which is situated on the concave side of the curved tooth, and is in the form of a slit. The manner in which the blow is inflicted is as follows. The animal generally throws itself in the first place into a coil more or less close, and the anterior part of the body is raised. The neck is bent somewhat abruptly 
backwards, and the head fixed almost horizontally. In an instant the head is, as it were, launched by a sudden effort towards the object of its anger, and the erected tooth struck into it, and withdrawn with the velocity of thought. It is found by experiment that the effect of subsequent wounds is greatly diminished either by the diminution of the quantity of venom, or by some deterioration of its strength; so that if a venomous Serpent be made repeatedly to inflict wounds, withont allowing sufficiently long intervals for it to recover its powers, each successive bite becumes less and less effective. A gentleman of my acquaintance had some years since received a living Rattlesnake from America. Intending to try the effects of its bite upon some rats, he introduced one of these animals into the cage with the Serpent; it immediately struck the rat, which died in two minutes. Another rat was then placed in the cage ; it ran to the part of the cage farthest from the Serpent, uttering cries of distress. The Snake did not immediately attack it; but after about half an hour, and on being irritated, it struck the rat, which did not exhibit any symptoms of being poisoned for several minutes, and died at twenty minutes after the bite. A third, and remarkably large rat, was then introduced into the cage. It exhibited no signs of terror at its dangerous companion, which, on its part, appeared to take no notice of the rat. After watching for the rest of the evening, my friend retired, leaving the Serpent and the rat together; and on rising early the next morning to ascertain the fate of his two heterogeneous prisoners, he found the Snake dead, and the muscular part of its back eaten by the rat. I do not remember at what time of the year this circumstance took place, but I believe it was not during very hot weather. 
Although there is no reason to believe that the Viper employs this powerful means of destruction for the purpose of disabling its prey before it is finally seized; but, on the contrary, all the observations which have been made upon its mode of feeding, tend to shew that, like the Snake, it seizes its prey at once, and immediately begins to swallow it ; yet it is not at all improbable, considering how instantaneously the poison begins to affect small animals s. that even in the act of seizing a mouse or bird, or any other victim, it may instil a sufficient quantity of venom into its system to paralyze and presently destroy it. Still the action by which it takes its prey is very different from that which it employs in its defensive attack, and resembles that employed by the innocuous tribes. Its favourite food consists of the smaller mammalia, field-mice, shrews, and similar little animals, of frogs also, though less commonly, and occasionally of birds. It does not always confine its voracity within the limits of its powers of deglutition; for I have in my possession a specimen of a small Viper which was taken on Poole Heath in Dorsetshire, in a dying state, in the act of attempting to swallow a mouse which was too large for it, the skin of the neck being so distended as to have burst in several places.

The Viper, like many others of the poisonous groups of Serpents, is ovo-viviparous. I have concluded, from the examination of many specimens, both of this species and of the Rattlesnake, that it is in the act of parturition that the membrane of the egg is burst. I have examined several in which the young have appeared ready to be excluded; but have always found the investing membrane entire; although so thin and soft as to be torn by the slightest force. I give a figure of the young Viper in this state, the membrane having been removed. It is coiled up so 
closely as almost to appear like a solid mass; but no sooner is it emancipated than it assumes all the activity and virulence which belong to the species. If a female Viper about to bring forth her young be killed, and the young

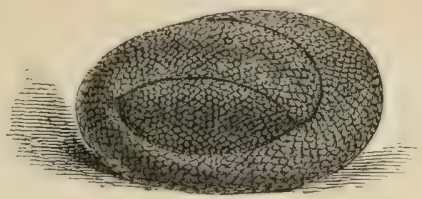

ones set at liberty by opening the abdomen, they will immediately crawl about, and on being irritated will throw themselves into an attitude of defence.

A certain degree of temperature, varying in the different classes, is requisite for the development of the embryo. In the mammalia this temperature is afforded by the standard heat of the body of the parent, within which the young is brought to perfection; in birds it is also, with few exceptions, communicated by the parent, but by means of incubation, or sitting on the eggs after they are excluded from the body; in the reptilia, on the contrary, it is communicated solely by the surrounding atmosphere; and this is equally the case whether the eggs are deposited before the growth of the embryo has commenced, or the young are perfected within the mother, and brought forth alive. In the latter case, as I have already observed, when speaking on the development of the young of the common Viviparous Lizard, Zootoca vivipara, it is by the exposure of the body of the mother to the sun's rays that the necessary degree of heat is obtained; and hence during the period of gestation it is very common to see the pregnant female Tiper lying, as it were, all abroad, with flattened body, basking in the sunshine; and at this time she 
is much less easily disturbed, and more tardy of flight than the male. The number of young produced at each birth varies from twelve to twenty, or even more.

There are on record numerous statements of various degrees of credibility, of the curious fact that the female Viper allows her young ones to retreat into her stomach for safety when alarmed by any sudden danger. These statements generally declare that the mother, on the occurrence of any such emergency, opens her mouth, and that the young immediately enter it, and pass into the stomach, where they remain protected until the danger be passed, or the Viper has gained a place of safety; it is added, in many cases, that, on killing the mother, the young have been found within the stomach, and on being liberated have at once reassumed all their former activity. The question has been reopened of late by the publication of several communications in a most respectable periodical, to which the reader is referred.* It will be observed, that with one exception, the writers have given their statements only on hearsay; and that in the one case which is given from personal observation, the circumstance is stated to have occurred when the writer was a boy. The first impression made on the mind of one accustomed to compare evidence with probability, and to weigh the value of assertions by the rules of analogy, is that the mistake, if it be one, may have arisen from the viviparous character of the animal ; but the opinion is so general, the mass of evidence so considerable, and the details in many cases so minute, as scarcely to allow of the question being thus summarily disposed of; and in this state of doubt upon so interesting a subject, it is perhaps better to await

\footnotetext{
* See several numbers of the Gardeners' Chronicle, in April, 1348, \&c.
} 
the results of direct experiment, which might be readily made in any locality where these reptiles abound.

The Viper, like the other reptilia, seeks a secret and secure place in which to hibernate during the cold months of the year. Here several are found entwined together, and in a very torpid condition; and if at this period a Viper be made to wound an animal with its poison-fang, no injury is likely to result from it; the poison either does not exist at all, or it is inert.

It frequents dry sandy heaths and waste places, not requiring, like the Snake, the neighbourhood of water, nor swimming so readily as that species. In many parts of the country it is even more common than the Snake.

The name Adder, by which it is known in many parts of England and Scotland, is anciently written nedre, and afterwards eddre, the initial $n$ being dropped. It is from the Anglo-Saxon ncedre,-nether, lower,-from its creeping position, and the name was applied to all the Serpent tribe. The word Viper, Latin Vipera, is derived from its viviparous habit.
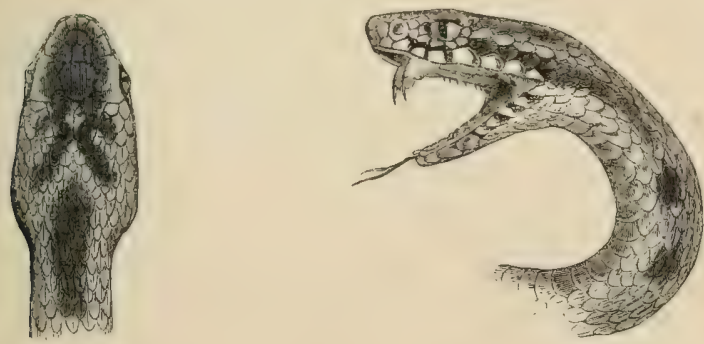

The head is somewhat depressed, almost oval, slightly widening behind the eyes. Gape as long as the head, ascending behind. No teeth in the upper maxillary bones, excepting the poison-fangs; a row of small teeth in the 
palatine bone on each side. Neck rather smaller than the back of the head, from which the body increases to nearly the middle of the entire length; the rest of the body to the vent scarcely diminishing; the tail becoming almost abruptly smaller, and tapering to its extremity, which is pointed; the tail varies in its proportion to the body, but is generally not more than one-eighth of the total length, and in some even less. The head is covered with small squamous plates, which in some specimens are regularly formed and symmetrically placed; but in others they are very irregular. There are three which are larger than the others,-namely, the vertical, and the pair of occipital plates. The scales of the back and sides are semi-oval, or somewhat lanceolate, imbricated, and distinctly carinated; they are disposed in eighteen series. The plates of the abdomen have nothing particular in their form; they vary in number, but usually consist of about one hundred and forty to one hundred and fifty, and those of the tail are about thirty-five pairs.

The general ground-colour varies considerably. In some it is nearly olive, in others a rich deep brown, and in others a dirty brownish yellow; and when in high health, and shortly after having cast the skin, the surface is slightly iridescent in particular lights. A mark between the eyes, a spot on each side the hinder part of the head, and a zigzag line running the whole length of the body and tail, formed by a series of confluent rhombs, as well as a row of small irregular triangular spots on each side, all of a much darker hue than the ground-colour of the borly, and frequently almost black. I have a specimen in my collection which I received alive from Hornsey Wood, the ground of which was almost perfectly white, and all the markings jet black. The under parts are plumbeous in 
some, with lighter or darker spots, in others almost wholly black.

The tendency of this species to vary in its colours has occasioned an erroneous multiplication of species by various authors. Some of the more remarkable and conspicuous varieties I proceed to describe.

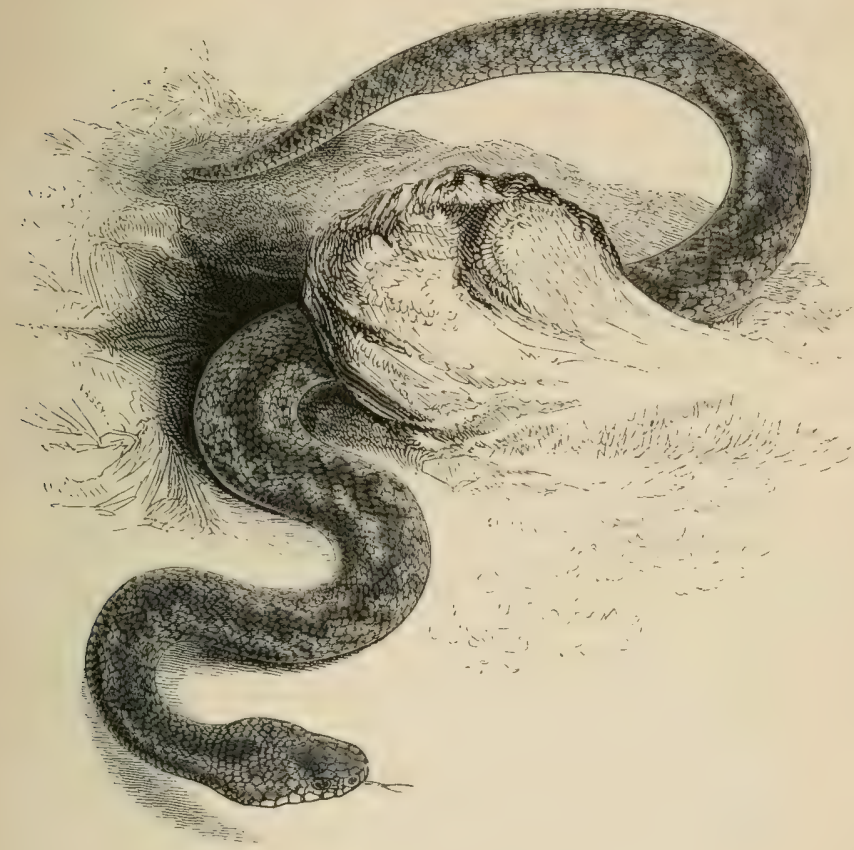

The first is the Red Viper ( $V$. communis, var. $\beta$ of Mr. Jenyns), described by my venerable friend the late Rev. Thomas Rackett, in the twelfth volume of the Linnean Transactions. It was found by him in Cranbourne Chase in Dorsetshire, in which county I have also obtained it from Poole Heatl. It varies much in the brightness and intensity of its colour. 
The specimen which I here figure, and from which I give the following description, was taken in the neighbourhood of Fordingbridge, in Hampshire, and was kindly forwarded to me by Dr. Thackeray, Provost of King's College, Cambridge, by whom I am informed that, of great numbers of Vipers which are annually destroyed in that neighbourhood, about one in ten are of the present variety.

The ground-colour is a dull brick-red, with the usual markings of the Common Viper, of a ferruginous brown, or mahogany colour. The marks on the head are very similar in form; but the $\mathrm{V}$ mark is somewhat more divergent than is usual in the common variety. The throat is white, tinged with ferruginous red, and the belly is ferruginous grey, with minute whitish dots, and a ferv larger dots of reddish brown. The round spots on each side of the back are rather more distinct, and somewhat smaller than in the common sort; there are also a few irregular reddish white spots along the sides of the neck; the upper lip is white, barred with brown. The only striking peculiarity in its form is the greater proportionate breadth of the head behind the eyes, which in this specimen is equal to the length of the gape.

The plates of the abdomen are one liundred and fifty; those of the tail thirty-three pairs. The following are the dimensions of the specimen here figured :-

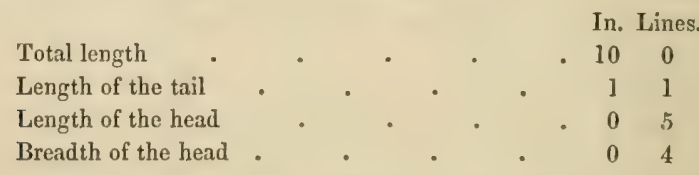

A specimen has been particularly described by $\mathrm{Mr}_{\mathrm{r}}$. Strickland, in the sixth volume of Loudon's Magazine of Natural History, in the following words: — "Of a bright 
ferruginous red, with zigzag markings down the back, resembling in form those of the Common Viper; but instead of being black, or dark brown, they are of a deep mahogany colour; also a series of irregular spots of the same colour along each side; the zigzag line terminates at the back of the head in a heart-shaped spot, placed between two converging dark-coloured bands, which meet on the top of the head, and again diverge towards the eyes; belly ferruginous like the back." Mr. Strickland adds the fact which I have mentioned above, that the head is much broader and shorter than that of the Common Viper. The Prince of Musignano figures, in his Fauna Italica, as the true Chersed, a small Viper, considerably similar to our Red Viper, excepting in its colour, which is a light grey, with darker markings. There is in that figure, also, the greater breadth of head which is observable in our animal, together with a still more obtuse rostrum. The Prince's figure is evidently taken from a young animal, which may possibly belong to a different species. He terms the V.Berus, "marasso palustre," and his V.Chersea, "marasso alpino," - a distinction certainly not sustained by our two varieties. After all, the question whether it be the Coluber Chersed of Linneus, and whether, if not so, this last-mentioned species be distinct from the Common Viper, is one of considerable doubt and obscurity.

The second variety (var. $\gamma$ of Jenyns), is described as a distinct species by the Rev. R. Sheppard in the Linnean Transactions, under the name of Coluber coeruleus, or Bluebellied Viper. It scarcely even deserves to be considered as a distinct variety, as the plumbeous belly by which it is characterized is rather a difference of degree than of hue. 
The Black Viper, of which I give a figure, drawn from a very fine living specimen, now before me, obtained, and obligingly lent me, by Mr. Combe, is the var. $\delta$ of $\mathrm{Mr}$.

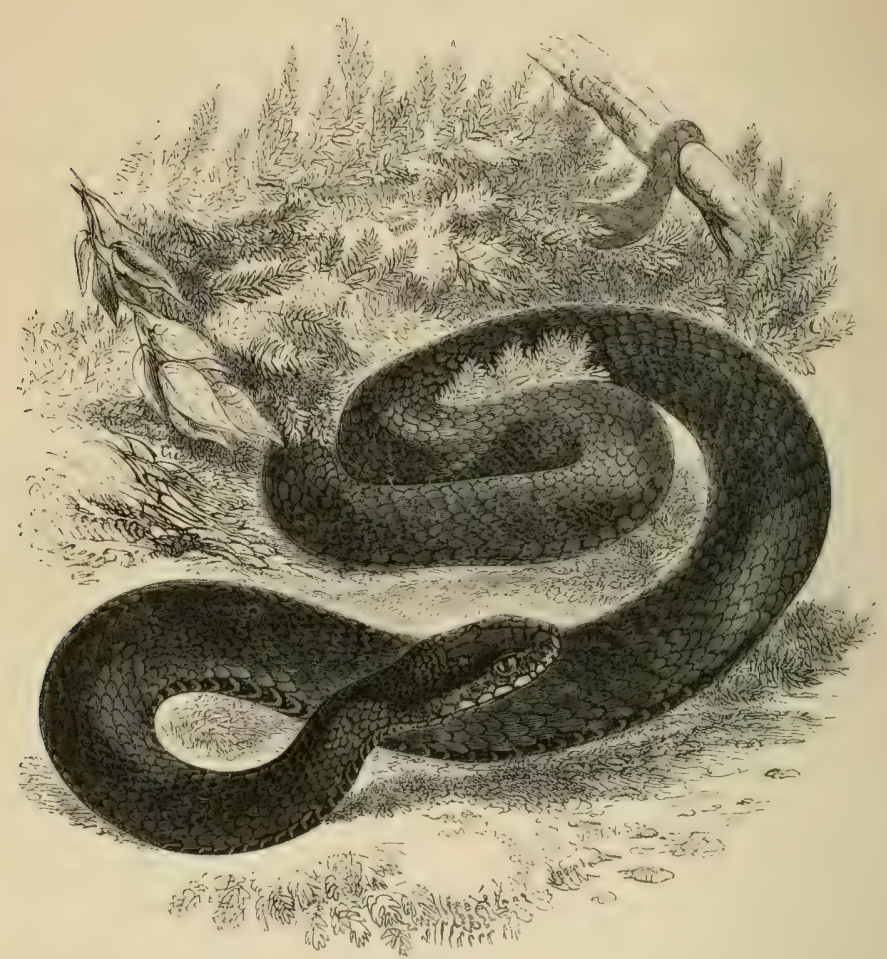

Jenyns. It has been figured, though but badly, and described by Dr. Leach, in his Zoological Miscellany. It is evidently a variety only of the present species, and is of a fine rich black colour, excepting under the jaw and throat, which is of a dirty white; the usual markings of the species may be seen, in particular lights, of a more intense black than the ground colour. 
I have to add a fourth variety, from the specimen in my possession, already mentioned, which I obtained from Hornsey Wood. The ground-colour was of an uniform dirty white, and all the markings were of a deep full black. It was, when living, one of the most beautiful of the species I have ever seen, and offers a remarkable contrast to the black variety.

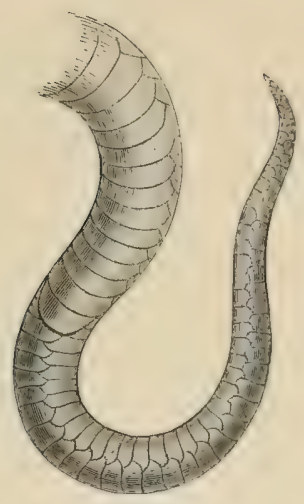

A TAIT, FIECF. 


\section{A MPHIBIA.}

\section{INTRODUCTORY OBSERVATIONS.}

Tre doctrine of continuous affinities could scarcely receive a more striking illustration in the animal kingdom than is afforded by the interesting group constituting the Aмpнiвia of modern authors. Intermediate in their structure, and, in many forms, in their habits and mode of life also, between the fishes and the true reptiles, they bear a still more interesting relation to these classes, in that remarkable change which many of them undergo at a certain period of life, by which they become transformed from the nature and habits of the former, to those of the latter class; and thus exhibit in their own individual life a beautiful and complete example of transition of organizotion; a subject which constitutes one of the most important theories connected with the higher departments of Zoological science. To any person capable of appreciating the interest attached to the study of physiological phenomena, the contemplation of an animal which at one period of its life is endowed exclusively with the organs of aqualic respiration, resembling the gills of fishes, with means of locomotion adapted only to a constant residence in the water, and with a digestive apparatus fitted exclusively for the assimilation of vegetable food, assuming by degrees the function of atmospheric respiration, acquiring limbs which are formed for leaping on land with great strength and agility, and manifesting the most voracious 
carnivorous appetite, will not only excite feelings of the deepest admiration, but necessarily lead to the investigation of the laws by which such extraordinary changes are governed, and of the relations which they bear to the theory of continuous affinity before alluded to, and to that of progressive development through the whole of the animal kingdom. That such phenomena are exhibited by the typical forms of this class will be sufficiently established by the slight sketch of their structure, habits, and development, which will presently be offered.

The Aмpнibia have by many zoologists been considered in the light of an order of the class Reptilia; but the characters by which they are distinguished appear to me to be sufficiently marked and important to justify their separation as a distinct class. They may be characterised as "vertebrated animals with cold blood, naked skin, and oviparous reproduction, and most of them undergoing a metamorphosis, having reference to a change of condition, from an aquatic to an atmospheric medium of respiration." "The class has been variously divided into groups, according to the different views of the naturalists by whom they have been arranged. The division adopted by many zoologists of the present day, according to the mere presence or absence of the tail in the perfect state, is not only liable to the objections which belong to all merely dichotonous arrangements, but appears to be far less natural and less consistent with the physiological characters of the groups than that which is derived from the absence or presence and the duration of the branchix. Thus the Frogs and Toads, which in the adult state have not the vestige of a tail, and the Salamanders and Tritons, which retain that organ through life, all agree in the early possession of branchia, which are subsequently lost and replaced by true 
lungs, and in undergoing consequently a total change in the medium of their respiration; whilst the Proteus and the Siren retain their branchia with lungs, (rudimentary, at least,) and probably throughout life possess synchronously the two-fold function of aquatic and atmospheric respiration. The Amphiuma and Menopoma have not as yet been observed to possess branchiæ at any period of their existence, though further observations are necessary to warrant the conclusion of the absolute non-existence of a metamorphosis in those genera." *

As it appeared to me that no one arrangement hitherto given had sufficiently distinguished the different forms, I proposed, in the article just quoted, the following modifications as more consistent with the diversities of structure in the different groups.

\section{Class AMPHIBIA.}

\section{Order I. AnOura.}

Body short and broad. Feet during the tadpole state wanting; afterwards four, the hinder ones long, and formed for leaping. Tail before the metamorphosis long, compressed; afterwards totally wanting. Ribs wạtirg: Vertebræ few and anchylosed. Tympanum open. Respiration at first aquatic by branchix, afterwards atmospheric by lungs. Branchice at first external, but withdrawn within the chest before the metamorphosis. Impregnation effected externally during the passage of the ova.

Genera. Rana, Hyla, Bufo, \&c.

* See the article "Amphibia," by the author of the present work in Dr. Todd's Cyclopædia of Anatomy and Physiology. 
Order II. unodela.

Body long, slender. Feet always four. Tail long, persistent. Ribs very short. Vertebre numerous and moveable. Respiration at first aquatic by external branchiæ, which are never concealed within the chest; afterwards atmospheric by cellular lungs. Tympanum concealed. Impregnation effected by sexual contact, at least in most instances

Genera. Salamandrina, Salamandra, Molge.

\section{Order III. AMPHIPNEUSTA.}

Body elongate, formed for swimming. Feet either four or two anterior only. Tail compressed, persistent. Respiration aquatic by means of branchiæ throughout life, co-existing with rudimentary lungs. Branchix external, persistent. Eyes with palpebræ.

Genera. Proteus, Siren, Menobranchus, \&c.

\section{Order IV. abranchia.}

Body long, formed for swimming. Feet four. Cranium sclic. Tail compressed. Respiration by means of lungs olily. 'Branchiæ none. No metamorphosis known.

Genera. Menopoma, Amphiuma, \&c.

\section{Order V. APODA.}

Body elongate, slender, angniform. Feet none. Tail very short, almost wanting. Lungs one larger than the other. (The existence of branchix at any period of life 
unknown.) Ribs very short. Sternum wanting. Ear's concealed. Impregnation probably internal.

Genus. Cocilia.

I do not offer this arrangement either as wholly original, nor as absolutely natural ; but it appears to me to be less objectionable than the others which have been proposed.

It is exclusively to the first and second order that the few Amphibia which are indigenous to this country belong; and I shall confine my observations on the general characters of the class, and on their physiological peculiarities, to those points which may be illustrated by a reference to our own native species. The most striking external character by which the whole of these animals are distinguished is the naked skin. Whilst all the true Reptilia are covered by some hard and corneous, or, at least, coriaceous modification of the cuticle, which appears in the form of plates, as in the Crocodiles and Tortoises, and in that of scales, as in the Lizards and Serpents, the Amphibia have no vestige of such a structure; the skin being in all cases soft and smooth, and in many instances always more or less moist. Some of them, as the Salamanders and the Toads, have a number of cutaneous glands which secrete a viscid fluid, which is said to be more or less acrid and irritating. This is most conspicuous in the common Salamander of Europe, which when irritated will often throw out from these glands a quantity of such white and tenacious fluid. Now the acrid quality of this secretion forms the sole ground for the reputed poisonous character of these animals; for it is a well ascertained truth that not one of them possesses any organ by which poison can possibly be communicated. The cuticle is frequently shed, and in various modes, according to the 
habits of these species. Thus the cuticle of the Frog and often of the Water Newt comes off in shreds in the water; whilst that of the Toad is removed at once by the exertions of the animal, comes away whole, and is swallowed at one gulp. Of this very curious fact the details will be found in the description of the common Toad.

But the most interesting circumstance connected with the functions of the integuments of these animals, or indeed with any part of their economy, is their cutaneous respiration; or, in other words, the power which the surface of the skin possesses of effecting those changes in the blood which are usually performed by the lungs or branchix. It was ascertained by Spallanzani, that the skin of the Frog gave out carbonic acid when in contact with the atmosphere; but the subject had never undergone that strict and philosophical investigation by which all its important bearings should be ascertained, until Dr. William Edwards of Paris entered upon the inquiry, the results of which he published in his admirable work "On the Influence of Physical Agents on Life;" than which there does not exist in the whole range of physiological literature a more perfect example of the manner in which a physiological inquiry ought to be imagined, planned, and conducted, and its results reasoned upon, and described. As I have endeavoured, in the article already quoted, to give a short sketch of the principal results of Dr. Edwards's experiments, I shall now merely offer a somewhat modified quotation from that article, rather than enter at length into the detail, which, however interesting the subject may be to the physiologist, would be out of place in the present work, and would be unnecessary to those who alone could appreciate it: for where is the physiologist who has not read and admired the original work itself? 
The existence of cutaneous respiration in the Frog was proved by the simple experiment of tying a piece of bladder over the head so tightly as to prevent the possibility of communication with the lungs, so as indeed to produce complete strangulation. The Frogs were then placed under water; and on examining the air contained in the vessel after an hour or two, a sensible quantity of carbonic acid was detected.

On placing Frogs in vessels filled respectively with river water, and with water which had been deprived of air by boiling, and inverted over the apertures contained in the shelf of a pneumatic trough, containing about ninety-eight pints, those in the latter lived on the average little more than half as long as those in the aërated water. On trying the effects of submersion under stagnant water frequently renewed they lived two months and a half, and then died from accidental neglect of changing the water. The results of placing them under running water were similar: in this case they were confined in a sort of cage, and sunk in a river. The effects of temperature in all these experiments were amongst the most curious and interesting circumstances connected with the inquiry. These results prove that the duration of life under water is in an inverse proportion to the elevation of the temperature from 32 degrees to about 107, at which point the animals die almost instantly. But these effects of temperature were found to be modified by an increase of respiration, whether by their rising to the surface and breathing the atmosphere, or by the quantity of aërated water being increased.

Such is a slight glance at the results obtained with reference to the cutaneous respiration carried on through the medium of aërated water; and those connected with the atmospheric respiration of the same surface are no less 
conclusive. Six Frogs were taken for one of the experiments, and a ligature tied with the most rigid compression round the neck, so as to exclude any possible passage of air. One of these lived twenty days in a damp atmosphere, whilst those which were placed in five ounces and a half of water, died as soon as all the air contained in that water was respired, which was in from one to three days. Another experiment of corresponding tenour was performed by the total excision of the lungs; and of three Frogs thus treated, two died on the thirty-third, and one on the fortieth day.

The results of other experiments proved that pulmonary respiration alone is not sufficient to support life without the aid of that of the cutaneous surface.

It is very clear that this important function cannot be carried on unless the surface be constantly kept in a moist state. The branchix of fishes and of crustacea, and the lungs of all pulmoniferous animals, equally require that the respiratory surface in every modification should be humid; for as soon as it becomes dry, its function ceases, and the animal speedily dies. But as the Frog, for instance, is frequently exposed to a dry atmosphere, it is essential that there should be some provision made for a constant supply of moisture to the skin, which has just been shewn to be a respiratory surface. This is effected precisely as in other surfaces which perform this function,-namely, by a secretion of fluid from the surface itself. The extent of the skin is, however, so great that the whole internal moisture of the animal would speedily be exhausted, unless a reservoir were provided for an extraordinary demand; and I now proceed to shew what this reservoir is, and by what means it is replenished. Every one knows that when a Frog is hastily seized, or even quickly pursued, it voids a consi- 
derable quantity of water, which is generally, but erroneously, supposed to be the urine. This water is limpid and pure, containing no traces of the usual component elements of the urinary secretion. It is contained in a sac, which has also been mistakenly believed to be the urinary bladder. This is the reservoir to which I have alluded. When, therefore, the Frog is happily placed in a damp atmosphere, or in water, the skin absorbs a quantity of water, which there is every reason to believe is secreted into the bladder just mentioned, where it is kept in store until the dryness of the skin requires a supply for the purpose of respiration, when it is again taken up, and restored to the surface by which it had been first absorbed.

There can be no doubt that this cutaneous respiration is of much more frequent occurrence in animals having naked and moist skin than has hitherto been ascertained; and it is exceedingly probable that it will be found to take place, not only in all the aquatic amplibia, but in the mollusca, and many others, having integuments of a similar character.

Allusion having already been made to the metamorphosis of the typical Amphibia, I shall here offer a few general remarlis upon this most remarkable phenomenon. In the whole of the tribes of Frogs, Toads, and Newts, or, in other words, in the two orders Anoura and Urodela, the young animal, as it emerges from the egg;, and for a considerable time afterwards, exhibits a form and structure essentially similar to those of fishes. The organs of respiration and of circulation differ in no important point from those which exist in that class, and their mode of aquatic progression is absolutely identical. At a certain period of their growth a gradual change takes place in the structure and function of each of these systems, during which 
the little pisciform creature is gradually assuming the general characters of the reptile type. I shall here offer a few illustrations of the changes which take place in each of these systems, giving the detail of the various morlifications which take place in the different groups, when describing each form.

The swimming of fishes is effected by the powerful lateral motions of the tail and posterior part of the trunk, and the numerous short oblique masses of muscle, which constitute the greater proportion of the bulk of those parts, are admirably adapted for the performance of these powerful and rapid movements. Such is the use, too, to which the long and powerful tail which belongs to the Tadpole is applied; and the wriggling motion given to this organ, by which the little animal is propelled through the water, by successive lateral impulses, is similar to that by which fishes are propelled. In the Anoura this is totally removed by absorption, and gives place to the extensive and interesting development of the anterior and posterior limbs, particularly of the latter, which are equally adapted for leaping with great force on the land, or for a rapid and equal propulsion through the water. In the Urodela, as the Newts, for instance, this original mode of progression contimues throughout life, and the feet which are ultimately added to the animal's organization, are extremely small and feeble, serving only for awkward and imperfect progression on land, or along the bottom of the water.

The organs of circulation undergo a no less striking and far more important change. In the first instance the heart is single, but the circulation is complete. The blood, after its systemic circulation, is received from the veins by a single auricle, and is immediately propelled by a fleshy ventricle to the branchial arteries, of which one goes to 
each leaf of the gills or branchiæ. From the branchial capillaries, the aërated blood is received by the branchial veins, which unite to form an aorta without the intervention of a second ventricle. Every tyro in comparative anatomy will at once perceive that this is an exact description of the circulation in fishes; and yet it is taken from that of the Tadpole of the Newt. I shall not enter here into a detail of the changes which take place in the various vessels, by which the branchial vessels become obliterated or altered in their course, and minute branches are augmented in volume, and enter upon new functions; such details could only be understood by the experienced anatomist, and would be out of place. It is sufficient to say, that by the dilatation of one vessel a second auricle is produced; that from the last branchial artery a small branch passes to the air-sac or rudimentary lung, which ultimately becomes the pulmonary artery; and that by other no less astonishing alterations, the transformation of the branchial into the pulmonary circulation is effected, and the heart assumes its new character of a trilocular cavity; possessing, that is to say, two auricles and a single ventricle, by which the blood which is sent to the lungs, and that which is distributed to the system at large, is alike of a mixed character, as in the true Reptilia.

The respiratory organs are no less surprisingly modified during the progress of the changes just described in those of circulation. The total loss of the branchix, which are removed by absorption, and the development of the little rudimentary air-sac, so exactly analogous to the air-bag of fishes, into the most beautiful cellular lungs, are changes which, but for the ocular demonstration to which they are yearly submitted, could scarcely be believed. Into the 
anatomical details of the steps by which these changes take place, it is not my intention to enter; but the general development of the new organs, both of these functions and of that of progression, will be given in the account of each different form.

We find then that these typical forms of the Amphibia become essentially altered during the progress of their growth in all their principal systems of organization; in the nervous, the circulating, the respiratory, the digestive, and the reproductive organs: nor does reproduction ever take place in these animals until the other changes have been perfected. But in the perennibranchiate forms, as the Siren, the Proteus, \&c. it seems as if the metamorphosis were stopped suddenly at that period when the lungs begin to be developed, before the branchiæ have at all diminished in size or in activity of function. The reproductive organs, however, go on to their full development, and the animals never undergo any further change of form or habit, but continue throughout life to breathe both the atmosphere by their air-cells, and water by their branchiæ, as well as either medium indifferently by means of their skin. In a word, the pulmonary, the branchial, and the cutaneous modes of respiration are in these curious animals going on simultaneously, although there can be no doubt that the branchial is the most essential to their well-being, and the pulmonary the least so.

Enough has probably been said on the general physiology of these animals; for it would not consist with the object of this work to enter more minutely into the details of this part of the subject; but to the physiological inquirer, few classes of animals present a more extensive or interesting field of investigation. After all that has been done, much remains yet to be ascertained, in the functions 
both of the earlier and the adult state of their existence, and in the phenomena of their transformation.

The species which belong to the British Fauna are more numerous than they were formerly supposed to be. Of the true Frogs we have two, of the Toads two, and of the Newts four, even excluding the Triton vittatus of Mr. Gray, which is probably a variety of Lissotritor palmipes, and the British habitat of which appears to be doubtful.

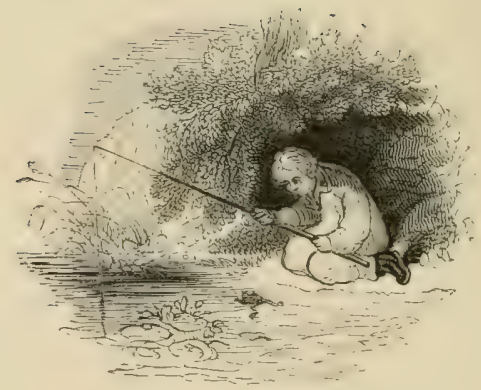




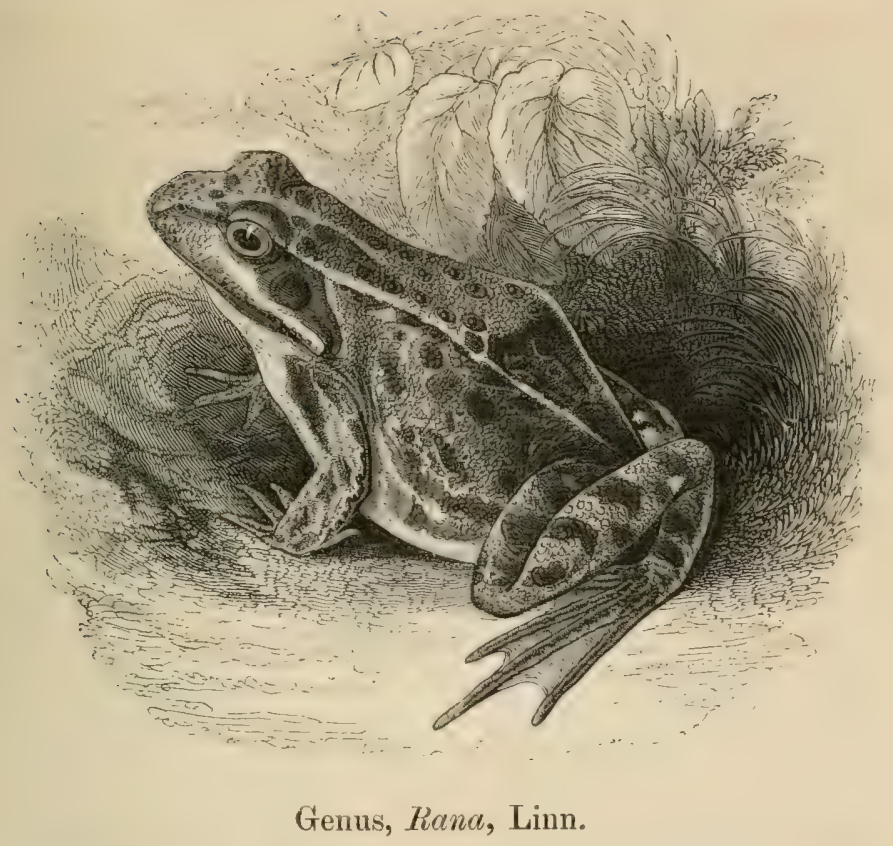

Generic Character.-Skin smooth, hinder legs very long, formed for leaping; the toes palmated. Teeth on the upper jaw, and on the palate.

\section{COMMON FROG.}

\section{Rana temporaria. Linn.}

Specific Character.-Reddish, or yellowish, or greenish brown, with an oblong brown spot behind the eyes; the legs with brown fasciæ.

Rana temporaria, Linn. Syst. Nat. I. p. 357. Flenr. Brit. An. p. 158. JENYNS, Brit. Vert. p. 300.

" aquatica, RAv, Syn. Quad. p. 247.

"fusca, Rosel. Hist. Nat. Ran.

Common Frog, Penn. Brit. Zool, III. p. 9. Shaw, Gen. Zool. III. p. 96. t. xxix.

Grenouille rousse, Cuv. Reg. Anim.

Var. Rana Scotica, BeLl, Brit. Rept. Ed. 1, p. 102.

IF in the natural system of animals we must look for the typical representative of any group in that form in which 
the distinctive characters of the whole group are most obviously and unequivocally developed, $-\mathrm{a}$ test insisted upon, I believe, by all who have even professed to believe in the existence of such types of form,-it is in the family Ranada that we may expect to find the typical character of the present class of animals; and the truth of this test is not invalidated by the absurd and even ludicrous instances of its breach, of which some of the most strenuous asserters of the principle have been guilty. To apply to this test only one or two of the structural or physiological peculiarities of the class. The most remarkable and important of all is the change, which has already been mentioned, from the condition of a fish to that of a reptile; and in this respect, whilst we must consider the permanent pisciform condition of the Proteus, the Siren, and others, which retain their branchial respiration throughout life, as an abnormal form leading towards the fishes, and the Cacilia, on the other hand, as probably approximating the Ophidian Reptilia; the caducibranchiate groups - and especially the present family-exhibit the phenomena of this metamorphosis to the greatest extent, the change which they undergo being certainly more complete than that of any of the other forms. The cutaneous respiration is another peculiar characteristic of the class; and there is no doubt that this function also is enjoyed by the Frogs in the highest degree.

The innocent and very useful species about to be described, is one of the most common of our vertebrated animals. It is found in almost all parts of this island, wherever there is a river or a pool, or even sufficient shade to maintain the degree of moisture necessary to preserve the respirable condition of the skin ; for the presence of a considerable quantity of water, although requisite for the 
development of the young, is not so for the existence and health of the perfect animal.

Of the existence of the Frog in Ireland very erroneous opinions have been entertained. I need not again allude to the legend of St. Patrick's extirpatory malediction against the whole race of reptiles; but it is worthy of observation, that even of late years, the belief that Frogs, in common with Snakes, could not live in that favoured island was very general. The truth, however, is, that this species is not only now an inhabitant of that place, but, as will appear by the following extract, has been so since the very beginning of the eighteenth century. I owe the knowledge of this passage to my friend W. Ogilby, Esq., who communicated it to me in the following letter;-

"The following is the extract from Swift's work of which I some time since spoke to you, concerning the introduction of Frogs into Ireland. It occurs in a tract styled, 'Considerations about Maintaining the Poor,' which, though without date, I fancy from the context, and other collateral evidence, must have been written about the year 1726. Among the public grievances of which he complains, he rather singularly mentions the practice of insuring houses in English offices; which, it appears, was then becoming common in Ireland. 'A third,' [absurdity] says he, 'is the Insurance Office against fire, by which several thousand pounds are yearly remitted to England (a trifle, it seems, we can easily spare), and will gradually increase till it comes to a good national tax; for, the society-marks upon our houses (under which might be properly written, 'The Lord have mercy upon us'), spread faster and farther than the colony of Frogs.' To this passage, one of Swift's editors, I believe Sheridan, adds the following note:'This similitude, which is certainly the finest that could 
possibly have been used upon the occasion, seems to require a short explanation. About the beginning of the eighteenth century, Dr. Gwythers, a physician, and fellow of the University of Dublin, brought over with him a parcel of Frogs from England to Ireland, in order to propagate the species in that kingdom, and threw them into the ditches of the University Park, but they all perished. Whereupon he sent to England for some bottles of the Frog spawn, which he threw into those ditches, by which means the species of Frogs was propagated in that lingdom. However, their number was so small in the year 1720, that a Frog was nowhere to be seen in Ireland except in the neighbourhood of the University Park; but within six or seven years after they spread thirty, forty, or fifty miles over the country, and so at last by degrees over the whole nation.' What credit may be due to the note I will not take upon me to determine, though it appears perfectly circumstantial, and given upon the editor's personal knowledge; but Swift's own notice proves indisputably the fact of the introduction, and the period about which it took place."

The respiration in this animal is, as has already been stated, both pulmonary and cutaneous. The former function, that of breathing by lungs, is effected not by successive alternations of contraction and dilatation of the chest, -a movement, which, as the Frog possesses no ribs, is impossible, - but by the act of swallowing air, as in the case of the Testudinata before described. The mechanism by which this act is performed is precisely the same in both cases; the air is inhaled through the nostrils by the dilatation of the pharynx, the csophagus being closed to prevent its passing into the stomach; then the posterior openings of the nostrils being also closed by the application of the 
tongue, the pharynx is contracted, and the air forced into the lungs. These organs are of considerable size, lying on each side of the anterior part of the vertebral column; they consist of large cells separated by the most beautifully delicate diaphanous parietes. From this peculiarity in the respiration, it follows that it can only be performed when the mouth is closed; and that if the mouth be gagged open, the animal soon perishes from the cessation of pulmonary respiration.

The ordinary voice of the Frog is too well known to require particular description. It is termed croaking, and is principally heard during the season of sexual excitement. In the spring every one has heard the neighbourhood of ponds and ditches, where these animals abound, resounding with their loud yet not disagreeable notes. When great numbers are congregated together, the noise heard at a considerable distance is far from being unmusical, and, when associated with the return of the genial season, and the calm of a still mild evening, is far more pleasant and soothing than many a more fashionable and dearly-bought musical entertainment.

The food of the Frog usually consists of various kinds of insects, and of the small species of slug. So voracious are its habits during the whole of the season at which it feeds, -for, like other cold-blooded terrestrial animals, it passes the cold part of the year in entire abstinence,-that it might become a most important assistant to the gardener or the farmer in the destruction of those pests of the respective objects of their culture which I have just named. It will swallow large coleopterous and other insects whole, and will take several of them at a meal. The quantity of insects and of slugs, indeed, which would be destroyed by encomraging these animals, instead of wantonly and un- 
necessarily persecuting and killing them, would be advantageous to a much greater extent than could at first sight be believed. This consideration ought surely to weigh even with those who are inaccessible to the appeals of humanity, in favour of this innocent and much-persecuted race.

The manner in which the Frog takes its food is very interesting. As in the Toad, the posterior part of the tongue is free, and being imbued with a viscous secretion at the extremity, it is suddenly thrown forwards upon the insect, which, being caught by the adhesive matter upon it, is instantly drawn into the mouth by the sudden return of the tongue to its former position, and is then swallowed. This is but the work of an instant; and, indeed, is performed with such rapidity, as scarcely to be detecterl without careful watching.

Like the rest of the Amplibia and the Reptilia, the Frogs retire, on the approach of winter, to their hibernating retreats, where they pass the dreary season in a state of absolute torpidity. This is generally in the mud at the bottom of the water, where they are not only preserved in a nearly equal temperature, though at a low degree, but also secured from external injury. Here they congregate in multitudes, embracing each other so closely as to appear almost as one continuous mass. On the return of spring they separate from each other, emerge from their places of retirement, and recommence their active life by exercising the important function of the reproduction of their species. Here we enter upon the most interesting scene in the history of these animals; for it is here that the peculiar characters which distinguish them from all other forms, are most strikingly shewn; and I shall, therefore, enter somewhat in detail into the different steps of the development of the embryo, and of the changes which take place in the 
structure and habits of the young animal as it advances towards its perfect condition.

The impregnation of the female Frog is effected in a peculiar and very remarkable manner. Whilst in the reptilia, as in most of the superior vertebrate animals, as well as in many of the lower classes, the application of the vivifying fluid to the ova, is rendered certain by actual insertion within the body previously to their expulsion,-and in the fishes, this is effected after their actual depositions, -in the Frog it takes place during the passage of the eggs from the body of the parent. As the season of spring advances, the renewal of active existence after its temporary suspension is evinced by the most energetic action of the procreative orgasm. The male Frog leaps on the back of the female, and grasps her behind the arm-pits with his fore legs, for which purpose a temporary development of a warty protuberance takes place on the thumbs, by means of which his hold is rendered more firm and secure. So powerful is this instinct of adhesion, that instances are not unfrequent of male Frogs seizing upon and remaining firmly attached to the surface of large fishes, from which they have not been detached without considerable force. Izaak Walton quotes a passage from an ancient writer which appears to refer to a fact of this kind. "But before I proceed further," says honest Izaak, "I am to tell you that there is a great antipathy betwixt the pike and some Frogs; and this may appear to the reader of Dubravius (a Bishop in Bohemia), who, in his book of Fish and Fishponds, relates what, he says, he saw with his own eyes, and could not forbear to tell the reader, which was-'As he and the Bishop of Thurgo were walking by a large pond in Bohemia, they saw a Frog, when the pike lay very sleepily and quiet by the shore side, leap upon his head; 
and the Frog having expressed malice or anger by his swoln cheeks and staring eyes, did stretch out his legs, and embraced the pike's head, and presently reached them to his eyes, tearing with them and his teeth those tender parts." It appear's by the sequel that the bishop's fisherman assured him that "pikes were often so served." Now, although there is evidently here much of the exaggeration which may naturally be expected from the astonishment of ignorance, yet there is no reason to doubt that the main facts are true. It happens, too, that the sex of the Frog is incidentally and unwittingly furnished by the writer by his mention of the "swoln cheeks," which he attributes to the creature's malice against his formidable enemy.

I have often heard my father relate an instance of a similar fact, though with somewhat more adherence to the simple truth of the case. As he was walking in the spring on the banks of a large piece of water at Wimpole, the seat of Lord Hardwicke, he observed a large pike swimming in a very sluggish manner near the surface of the water, having two dark-coloured patches on the side, which he thought must be occasioned by disease. A few days afterwards he saw the same pilie floating dead upon the surface of the water, and having drawn it to land by means of a stick, he found that the dark-coloured masses, which he had observed on the former occasion, were two living Frogs, still attached to the fish, and that so firmly, that it required some force to push them off with the stick. There can be no doubt that the diseased state of the pike facilitated the approach and adhesion of the Frogs, to which they were primarily impelled by the sexual instinct before mentioned.

During the cohesion of the two sexes, then, the female commences the deposition of the spawn, which is fecundated 
during its passage. When first expelled it consists of numerous small opake globular bodies, enveloped in a small glairy, or glutinous mass. This latter substance soon absorbs a large quantity of water, and, in the course of an hour or two, each becomes not less than a quarter of an inch in diameter. The consequence of this augmentation in the bulk of the transparent mass, surrounding each embryo, is, that all the latter are removed from each other by a whole diameter of each globe; and they appear like black dots regularly distributed throughout a large mass of transparent jelly.

The deposit of the eggs takes place at the bottom of the water, notwithstanding the assertion of some naturalists, and of Rösel amongst them, that they are expelled at the surface. The mistake, probably, arose from the mass of eggs being generally found at the surface; but this arises merely from the disengagement of gas in the sulstance of the glairy envelope, in consequence of partial decomposition.

The changes which now begin to take place in the embryo are most interesting. They have been detailed in a very minute and satisfactory manner by Rusconi in his work, already alluded to; and I have taken considerable pains during the last spring to follow out his investigations, and by actual observation to correct or confirm his account. I may here observe, once for all, that, with the exception of a few of the details in the earliest periods, I have been able to satisfy myself of his correctness; and in those points, I believe that I only failed to do so, partly by my not having obtained the ova immediately after their expulsion, and partly by the want of time to enter into all the necessary minutix of the investigation.

I have also to observe that the developement of the young 
is more or less rapid, according to the temperature of the atmosphere; and that I was enabled to retard or hasten it by regulating this circumstance. I therefore kept my reservoir of eggs in a very cold situation, and occasionally brought a few of them into my drawing-room for the purpose of observation; in which place, being in an elevated temperature, the developement became very rapid. As my object, therefore, was to ascertain positive facts, rather than the periods of the changes, which were dependent upon variable circumstances, I kept no register of the temperature or of the periods; and I shall, in both these particulars, give some of the statements of the accurate Rusconi.

The embryo is found, in the first place, to consist of a small globular body, one side, or hemisphere, of which is of a dark brown colour, the other being much paler. In a very short period after the egg is deposited,-four hours, according to Rusconi, - a deep furrow across the dark hemisphere divides it into two equal parts, and this is soon afterwards crossed by another at right angles; a third and a fourth furrow are produced, and so on, until the whole surface of this side of the sphere is, as it were, granulated. This appearance, however, is but transitory, the surface soon becoming almost smooth. In the course of the second day, the sphere begins to elongate, and a groove, which had previously divided the upper part of it into two equal parts, begins to close up. The head becomes prominent, the tail begins to shew itself, the little hooks by which it subsequently lays hold of objects and supports itself, begin to appear. At this period the examination becomes more easy, and more interesting. At somewhat more than fifty hours in an elevated temperature, the heal is very well marked, the tail somewhat elongated, and even the rudi- 
ment of the membrane, or web, which is destined to form its fin, is visible. About this time, also, a small projection takes place on each side of the head, which is the earliest indication of the branchir, and the muscles of the spine may just be seen. In figure 2 of the woodcut, I have

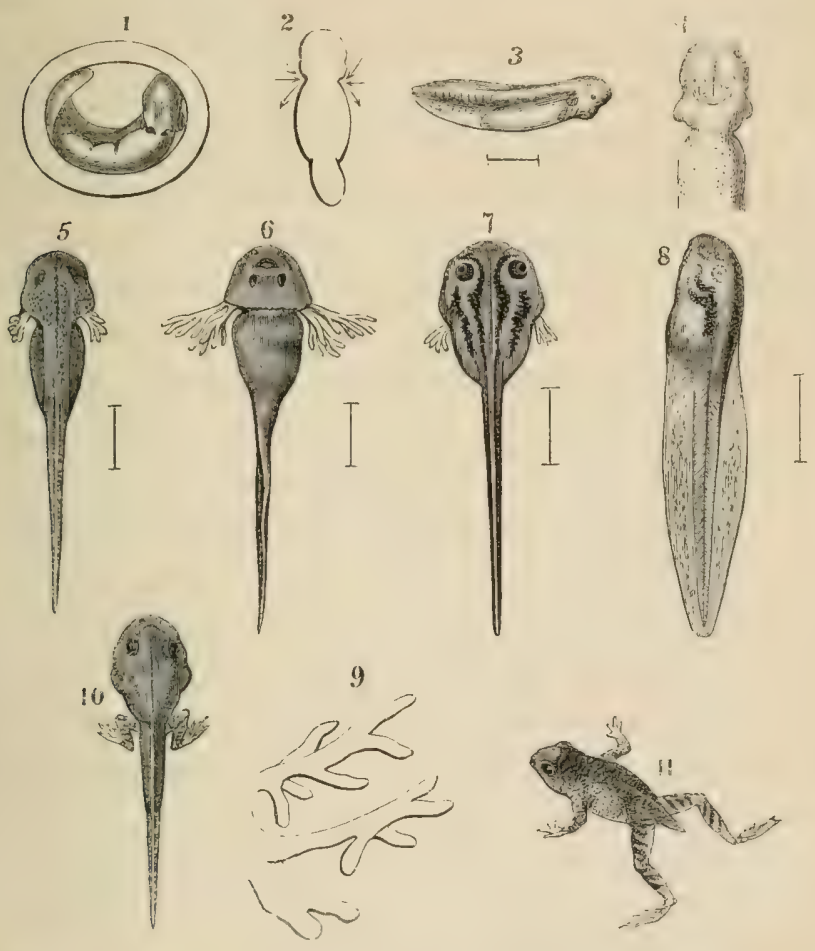

given an outline of the embryo in this condition. At this time the water is seen to flow in a distinct and rapid current to the branchial orifice over the rudiments of the branchiæ, which are now just visible, the course of which current I have indicated by arrows. These parts gradually become more developed; the body is more elongated, the branchiæ more distinct; the fin extends round the tail and 
partly over the back; and the head is distinguished from the body by a slight contraction at the neck; and a short period more suffices to bring it to the condition represented in figures 3,4 , of the woodcut, in which the branchix are seen to consist of two tubercles on each side, as yet simple and undivided; the holders, which are small simple organs placed near the situation of the future mouth, and which serve to enable the little animal to attach itself by means of a viscid secretion at their extremities, have become longer, the web, or fin, is also enlarged. By this time the first voluntary motion of the embryo is discovered on the application of any means of excitement or disturbance; but it consists only of a slight movement of the head or tail. The nostrils are seen more distinctly, but the mouth is scarcely yet observable, and shortly afterwards the eye, in a rudimentary state, may be just discerned. The next step in the developement is a slight division of the branchiæ into lobes, and the appearance of that beautiful and interesting phenomenon, the circulation of the blood through these organs. The embryo, which is still confined to a curved position by the envelopes (fig. 1), is now seen frequently to extend itself by sudden jerks, as if to emancipate itself from its confinement, which it eventually does by tearing the membrane of the egg. The Tadpoles, we see, are now hatched (fig. 5). According to Rusconi, this takes place within four days after the deposit of the eggs, in a temperature varying only from $23^{\circ}$ to $27^{\circ}$ Centigr. ( $73^{\circ} \cdot 4$ to $80^{\circ} 6$ Fahr.); but certainly in our own climate, in the ordinary temperature of our spring, it does not talie place until at least a month. As I before observed, the developement may be greatly hastened by a constant elevation of temperature, and I was often surprised at the degree to which this was the case in the course of my own obser- 
vations; but the comparatively low temperature of our spring, and the cold frosty nights which occur in March and April, may well account for such a discrepancy. If the eggs be deposited at the middle or latter end of March, it is generally, with us, the latter end of April before they are hatched. The situation of the mouth is now distinctly visible, though the opening is but small; and even when it becomes considerably enlarged it has no power of movement, and there are no distinct lips. The branchiæ now speedily enlarge, and each of the two branches on either side is seen to consist of about four leaves (figs. 6. 9); these are sessile upon the body or stem of the branchia; they are somewhat granular on the surface, and slightly irregular in their form; there is also frequently a short additional branch at the base of the posterior one, as is shewn in the outline, figure 9 . The present state of these organs, which have now arrived at their maximum of development, constitutes one of the most charming objects for microscopic observation which can be conceived, and to view which a very high power is not necessary, nor even desirable. The current of the blood poured in regular pulsations at each contraction of the heart, passes up each stem or main branch of the branchiæ, and a distinct stream is given off to each leaf; it is propelled to the extremity, and then returns down the opposite sides in the most regular manner, and the parts are so transparent that every globule of blood is distinctly and beautifully visible.

This state of things, however, is destined to last but a short time. No sooner have these interesting organs attained their greatest developement than they begin to diminish in size; they become obtuse (fig. 7), and are gradually so reduced as to be withdrawn within the branchial 
cavity, and concealed by a little operculum of the integument. The eyes are now perfectly formed. The holders have become much diminished in size; the mouth has acquired moveable lips, and has changed its position from the inferior part of the head to near the extremity, and the little creature which has hitherto derived its sustenance either from its own resources or by absorption, now seeks its food amid softened and decomposing vegetable matter. The caudal web (fig. 8) has, therefore, become considerably developed, and serves for very rapid as well as varied locomotion. The colour of the body, too, has undergone a considerable change, having become of a soft olive green, the abdomen being dotted with golden yellow.

The Tadpole now undergoes but little change in its external form for a considerable time, but increases rapidly in bulk, and by and by a little tubercle appears on each side of the vent, which is the rudiment of the posterior extremity; this soon acquires somewhat the form of the perfect limb, the toes budding, as it were, at the extremity, but it still continues very short, even in proportion to the diminutive size of the animal (fig. 10). Meanwhile the anterior extremities are also budding forth in the same manner, and gradually assume their distinct and final form.

As the hinder extremities become developed, the tail, the former organ of progression, is removed by absorption, not thrown off; as has been erroneously stated. This is a gradual process, the absorption beginning at the apex, and progressing onwards to the base, until the whole is removed; so that the posterior part of the body becomes rounded, and the cloacal opening, instead of being placed beneath, is directed somewhat upwards. Fig. 11 exhibits the young Frog with a small portion of the tail still remaining unabsorbed. 
Rusconi complains of having had considerable difficulty in ascertaining the proper food for the Tadpoles, so as to preserve them in health during his observations on their developement. He found, however, by accident, that they would thrive upon the green sediment which results from the agitation of decayed vegetable matter in water; and I have succeeded completely in keeping them on the decaying vegetable matter without any artificial preparation. In their more advanced period, but still before the growth of the extremities, they fed indifferently upon animal or vegetable substances, actually gnawing away the substance of almost any kind of leaf that was placed in the vessel, as soon as it became softened. I have reason to believe, also, that they often killed their own companions, as soon as these, by the acquisition of their limbs, had nearly assumed their ultimate form. Suspecting this, I placed in a large glass globe of water, several Tadpoles, more or less nearly approaching their final change, and I observed that almost as soon as one had acquired its limbs it was found dead at the bottom of the water, and the remaining Tadpoles feeding upon it. This took place with all of them successively excepting the last, which lived on to complete its change, and for a considerable time afterwards.

The little animal has now undergone its complete developement; and having become capable of respiring air by true lungs, and of progressing with great freedom on land by means of its hinder legs, it comes on shore to feed on small insects and worms. Such multitudes of these newly perfected little beings are often found in damp weather enjoying their new scene of existence, as to have given rise to many a story of its having rained Frogs; - a fable which is still devoutly believed in many parts of the country. They now grow with great rapidity during the remainder of the 
year, until the approach of winter warns them to betake themselves to their places of hibernation. But, in the mean time, thousands of them have fallen a prey to their numerous enemies; even in the Tadpole state they are devoured in hosts by the different species of newts, and small fishes; and when adult, by pikes, and others of the larger species of fish, many by the smaller carnivora, such as the weasel and the polecat, and many by almost every species of water-fowl, as well as by the Common Snake, of which they constitute, the principal food. Such is the destruction which thus takes place amongst them at different periods of their growth, that probably not one in a thousand that had emerged from the egg in the spring, ever reaches its winter retreat.

That the Frog is susceptible of being tamed to almostas great a degree as the Toad, is proved by the following anecdote, for which I am indebted to my friend, Dr. William Roots, of Kingston, who informs me that he was in possession for several years of a Frog in a perfect state of domestication. It appears that the lower offices of his house were what is commonly called underground, on the banks of the Thames. That this little reptile accidentally appeared to his servants, occasionally issuing from a hole in the skirting of the kitchen, and that during the first year of his sojourn, he constantly withdrew upon their approach; but from their shewing him kindness, and offering him such food as they thought he could partake of, he gradually acquired habits of familiarity and friendship; and during the following three years he regularly came out every day, and particularly at the hour of meal-time, and partook of the food which the servants gave him. But one of the most remarkable features in his artificial state of existence, was his strong partiality for warmth, as, lluring the winter seasons, 
he regularly (and, contrary to the cold-blooder tendency of his nature) came out of his hole in the evening, and directly made for the hearth in front of a good kitchen-fire, where he would continue to bask, and enjoy himself until the family retired to rest.

There happened to be at the same time a favourite old domestic cat, and a sort of intimacy or attachment existed between these two incongruous inmates; the Frog frequently nestling under the warm fur of the cat, whilst the cat appeared extremely jealous of interrupting the comforts and convenience of the Frog. This curious scene was often witnessed by many besides the family.

In its general form it is more slender than the Toad, though less so than many species of true Frog. The head forming half an oval, or nearly so; the snout rounded; the mouth horizontal, linear; the gape very wide, extending as far as the posterior margin of the orbit; teeth placed in a single row in the upper jaw and on the palate, very minute; none in the lower; tongue soft, fleshy, spatula-shaped and notched, the anterior portion folded back upon the posterior when not in use; eyes elevated above the forehead. The back is generally flat, excepting at the setting on of the pelvis, where it is sometimes a little raised. The fore-feet are of moderate size and length, with four toes, of which the third is slightly the longest, the second notably the shortest, as is probably the case in all the true Frogs; hinder legs very long, and very muscular, extending to more than half as long again as the body; hinder toes five in number, long, slender, palmated, the fourth toe being by much the longest. Skin naked, smooth. The male is smaller and more slender than the female.

The changes which the colour of the Frog undergoes both in intensity and in hue, from the variation of tempe- 
rature, the presence or absence of light, and the influence of fear, and perhaps of other causes of mental excitement, although certainly much less striking and considerable, are scarcely less varied than those exhibited by the chameleon. The causes of these changes have not, I believe, been examined, but the subject well deserves a careful and minute investigation.

The whole of the family to which this species belongs are liable to great variety of colour, and even of marking; but there are certain limits beyond which these variations do not extend, which although not always easily expressed in the few words which are convenient for a specific diagnostic phrase, are yet easily recognised by the eye, when once well and sufficiently observed.

It is generally brown, inclining more or less to yellowish or reddish brown on the upper side, spotted irregularly with black, brown, or brownish grey, with transverse fascix, which vary in number, of the same colour on the legs; beneath, yellowish white, sometimes with spots similar to those on the back, but smaller and fewer. "The most constant mark," as Mr. Jenyns well observes, " is an elongated patch of brown, or brownish black, behind the eyes, on each side of the occiput: there is also generally more or less indication of a whitish line running longitudinally down each side of the back, and enclosing a space paler than the adjoining regions."

Inch. Lines.

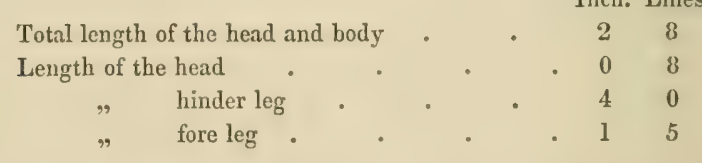

It has been long observed by sereral naturalists that a Frog exists in Scotland, of a much larger size than the 
common one, and it has generally been referred to the Ranc esculenta, or Edible Frog of the continent of Europe. Thus Mr. Don, in his account of the Plants and Animals found in Forfarshire, mentions the Edible Frog as to be met with in the lakes of that neighbourhood, although rather rare; and both Shaw and Pennant allude to it, the former as being "rare in England," the latter simply incorporating it amongst his British Reptiles, but without mentioning its locality; and Dr. Fleming merely observes that it is "not so common as the preceding." In July 1833, Dr. Stark exhibited at the Zoological Society a skeleton of the Scottish species, the following meagre account of which, occurring in the Proceedings of the Society, is all that remains of that gentleman's observations. "Dr. Stark exhibited the skeleton of the Edible Frog, Rance esculenta (Linn.), and stated that this species is found in the neighbourhood of Edinburgh, whence his specimen was obtained. He pointed out some of the differences between its osseous structure and that of the Common Frog, Rana temporaria, Linn."

Thus one observer after another has gone on, each copying the error of his predecessor, until Mr. Jenyns suggested the probability that the species described as $R$. esculenta, by the only two persons who have assigned any locality for it, may possibly be a new one. Pennant describes a Frog under the name of the "Great Frog," as a native of the roods near Loch Ransa in the Isle of Arran; but he does not give any authority, and from his description, which, however, is very slight, there is no doubt that the animal was nothing more than the Common Toad.

Being naturally anxious to ascertain so interesting a point, I determined upon procuring all the information in 
my power respecting it; and on writing to Sir William Jardine upon the subject, I obtained from him, with his accustomed kindness and liberality, the opportunity of examining the identical skeleton upon which Dr. Stark's notices were made. My excellent friend Bibron also kindly sent me several specimens of the true $R$. esculenta, and from these data I came to the conclusion that the Scottish Frog is a new species, to which, from its only known locality I gave the name of $R$. Scotica. During the last spring, however, I received, from Mr. Wolley of Edinburgh, numerous specimens of both sexes, and of various ages of the Scottish Frog, and the result of the most careful examination and comparison which I am able to make, is the conviction that it is nothing more than a very large variety of the Common Frog, R. temporaria. My friend, Mr. Gray, whose accurate and extensive knowledge of these subjects, gives great weight to his opinion, and Mr. Wing, also of the British Museum, a most acute and intelligent observer, have confirmed this opinion; and it appears to us that the slight differences which I observed in the osteology, might have been sexual or even merely accidental. I am much indebted to Mr. Wolley for his great kindness in enabling me, by a plentiful supply of specimens, to determine this point, as well as for other similar attentions which I shall have another opportunity of acknowledging.*

The specimens were obtained on the Braid Hills, where these large Frogs are very numerous.

I give in a vignette the crania of the two varieties of R. temporaria, and of the $R$. esculenta; and the great

* M. Bibron has expressed his doubts whether the $R$. Scolica may not be considered as identical with the common species. Hist. Nat. des Rept. t. viii. p. 362 . 
similarity of the two former, excepting in size, and the remarkable distinctness of the latter, will be at once detected. The left-hand figure belongs to $R$. esculenta, the middle one to the Scotch Frog, and the right-hand one to the ordinary form of $R$. temporaria.
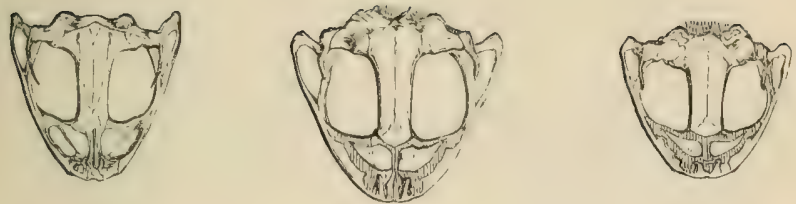


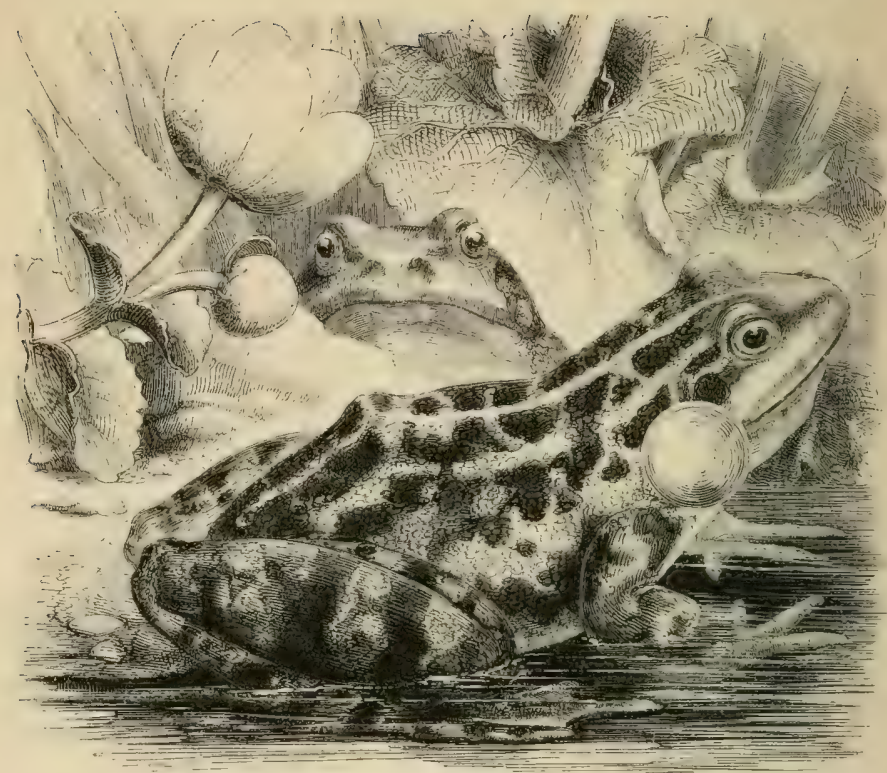

EDIBLE FROG.

\section{Rana esculenta. Linn.}

Specific character.-Thumb with two tubercles; vomerine teeth forming two small groups ; vocal sacs in the male large and globular; upper parts of the body variously marbled; a yellow or whitish mesial line rumning the whole length of the back.

Rana esculenta, Linn. Syst. Nat. ed. 12, I. p. 376, No. 15. Daud. Hist. des Rept. VIII. p. 90. Сi. Bonap. Non. Faun. Ital.

"viridis, Linn. Faun. Suecix, p. 94 . Roesel, Hist. Ran. p. 53, t. xiii. -xvi. Bibr. Hist. Nat. Rept. VIII. p. 343.

Green froy, SHaw, Gen. Zool. III. p. 103. t. xxxi.

The fact that the true Rana esculenta, so well known in some parts of the Continent as an article of food, is an inhabitant of this country, is now perfectly established. 
Its existence as a British species was first recorded in the "Zoologist," in the following notice from Mr. Bond, dated November, 1843:*_- I have the pleasure of recording in the 'Zoologist' the capture of the Edible Frog (Rane esculenta, Linn.) for the first time, I believe, in this country. Two specimens were taken by my friend, C. Thurnall, Esq., of Duxford, in Foulmire Fen, Cambridgeshire, in September last." Shortly afterwards a characteristic figure was published in the same work; and subsequently I received some specimens myself from Mr. Bond, which I had an opportunity of comparing and identifying with the continental species, having then in $\mathrm{my}$ possession many living ones, which I had received from France. Mr. Bond relates, in a farther notice in the same work, that they were very abundant in that locality, and expresses his surprise "that they were never seen before, their croaking being so very different from that of the common frog; the sound is more of a loud snore, exactly like that of the barn owl (Strix flammea). The whole fen was quite in a charm with their song." Mr. Bond proceeds to say, that "this Frog is a very timid animal, disappearing on the least alarm, and it is not very easy to catch. It seems to be entirely a water reptile, never coming on the land; at least, I never could find one out of the water, like the common species." The very remarkable and sonorous croak belonging to this species had procured for the Frogs of this neighbourhood the names of "Cambridgeshire nightingales," and of "Whaddon organs;" and I have often heard my father, who was a native of those parts, say that the croak of the frogs there was so different from that of others, that he thought they must be 
of a different kind. It is somewhat remarkable that my father, who was no systematic naturalist, but a very accurate observer, should have detecterl, when a boy, now more than eighty years since, the distinction of the harvest mouse and of this species of Frog. The peculiarity in the croak of the male is accounted for by the existence of the large vocal sacs, to which farther allusion will be made.

The Rana esculenta may be at once distinguished from $R$. temporaria by the absence of the large distinct black mark, which in the latter species occupies the space extending from the eye to the shoulder, and by the existence, in the present species, of a light line running the whole length of the middle of the back; the marbling also in R. esculenta is much more distinct, varied, and beautiful, and consists partly of circumscribed round spots. The vocal sacs, which are peculiar to the males, become, when filled with air in the act of croaking, large globular, bladder-like sacs, standing out one on each side of the head,

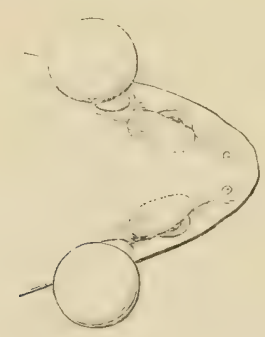

which do not exist at all in $R$. temporaria: the vomerine tecth are placed rather farther back in the common species. I have observed in $R$. esculenta a pair of lumbar glands, which, although less conspicuous, occupy the same position as in the genus Pleurodema of Tehudi. 
I gave a figure of this species in the former edition of the present work, taken from a foreign specimen, but I have thought it better to have the present illustration taken from an individual which is a native of the British locality before referred to. The figure above referred to is repeated below: it will enable the reader to compare the English with the foreign variety.

The following notice, in a recent number of the "Zoologist," * shews that the extension of this fine species may be easily effected. "Mr. Henry Doubleday having received from Foulmire Fen, some living specimens of this truly beautiful Frog, turned them loose near a pond not far from his residence. They soon migrated to another pond, and there have made themselves perfectly at home."

The peculiarities both in habits and appearance which characterize this species in England, agree, as far as they have been observed, with those mentioned by Dumeril and Bibron, and other continental authors. "It is," say these eminent naturalists, "essentially aquatic. It inhabits indiscriminately running or still waters, the borders of rivers, rivulets or streams, lakes or ponds, salt or fresh marshes, or even ditches and simple pools of water. Sometimes they are seen on the leaves of water-lilies, or on the herbage of the banks, where they love to bask in the warm sunshine; but at the slightest noise they strike into the water, and do not again expose themselves until certain that all danger is past.

The croaking of the male is exceedingly powerful, and is produced by means of the air which it forces into the globular vocal sacs, which are situated near the corners of the mouth, and causes to vibrate in them; they croak 
by day as well as by night. The female, being without these organs, produces only a slight groaning noise.

The eggs are deposited in France from the end of March until the beginning of May. It would be interesting to observe exactly the period when this function begins and ends in this country, and to ascertain how far it is hastened or retarded by the temperature of the atmosphere.

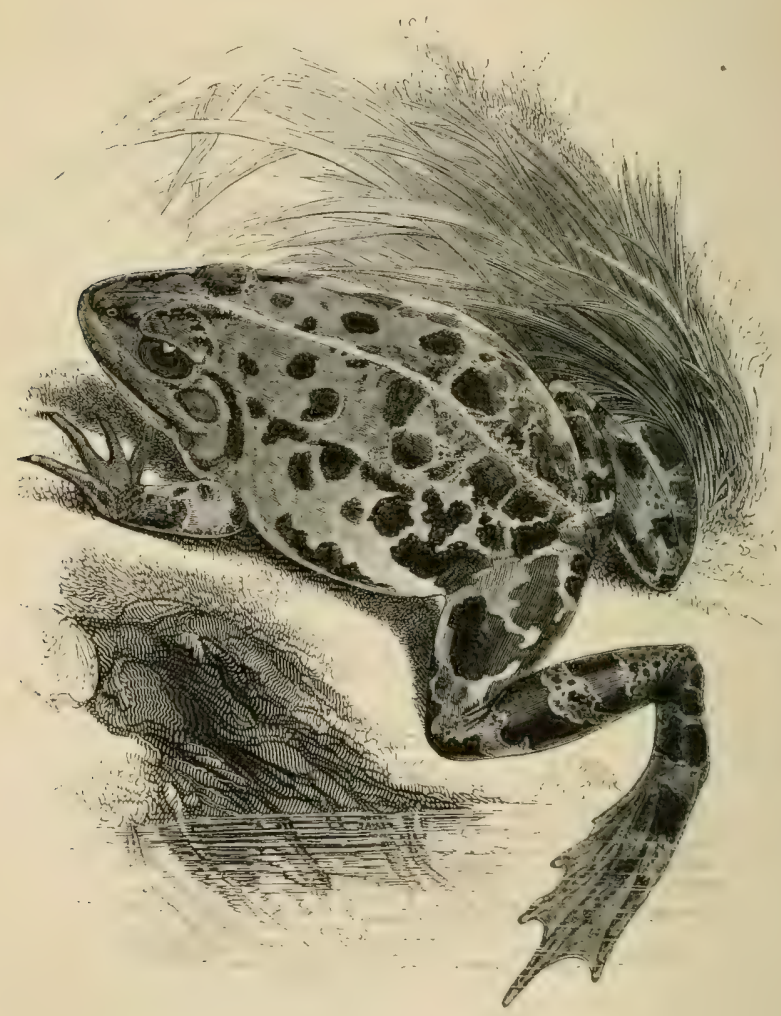




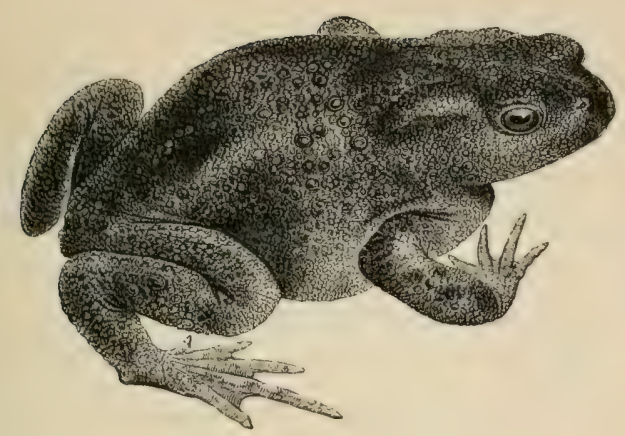

Genus, Bufo. Toad.

Generic character.-Body inflated; skin warty; parotids porous; hind feet of moderate length, toes not webbed; jaws without teeth; nose rounded.

\section{COMMON TOAD.}

PADDOCK.

\section{Bufo vulgaris. Laurent.}

Specific character.-Lurid brownish grey, with reddish brown tubercles; body much inflated.

Bufo,

Rana Bufo,

Bufo terrestris,

, vulgaris,

Toad,

Common Toad,

Crapaud commun, Cuv. Règ. Anira. II. p. 109.

RAY, Syn. Quad. p. 252.

LinN. Syst. Nat. I. p. 354.

Rosel, Ran. t. xx. p. 301.
Laurent. Flem. Brit. Anim. p. 159. Jenyns, Brit. Vert.

Pennant, Brit. Zool. III. p. 14.

SнAw, Gen. Zool. 11I. p. 138, t. xl.

$F_{\text {Ew }}$ animals have ever suffered more undeserved persecution as the victims of an absurd and ignorant prejudice than the Toad. Condemned by common consent as a disgusting, odious, and venomous reptile, the proverbial 
emblem of all that is malicious and hateful in the human character, it is placed under universal ban, and treated as an outlaw both by man and boy throughout the country. Should I be able, by the following history of its habits and manners, to shew that it is, on the contrary, highly useful, perfectly harmless, inoffensive, and even timid, and susceptible of no inconsiderable degree of discriminating attachment to those who treat it with kindness, it is hoped that some few individuals may be thus rescued from those barbarous acts of cruelty to which the species is almost everywhere subjected. The mistaken notions to which I have alluded are indeed pardonable in the ignorant and uneducated; but that one professing to be an observer and an admirer of the works of nature, should have suffered his prejudices to dictate such a violent and false philippic against this harmless creature, as the following passage from Pennant, is not easily to be accounted for, and scarcely to be forgiven :-

He calls it "the most deformed and hideous of all animals; the body broad; the back flat, and covered with a pimply dusky hide ; the belly large, swagging, and swelling out; the legs short; its pace laborious and crawling; its retreat gloomy and filthy: in short, its general appearance such as to strike with disgust and horror." The whole of his account teems with expressions of the same kind; and it would be difficult to find a more striking instance of the influence of prejudice in the mind of any professed admirer of nature, or a more unpleasing example of partial misrepresentation. The true lover of Nature, on the contrary, who, in the simplicity and singleness of heart which always belongs to that character, seeks even in the less attractive of her works for those proofs of wisdom and beneficence by which they are all characterised, will rather find in the 
very peculiarities which excited the spleen and disgust of our celebrated drawing-room zoologist, only fresh indications of the same discriminating wisdom, and the same never-failing, though often, to the superficial observer, mysterious and veiled beneficence.

The Toad belongs to a family, the sluggish habits of which are remarkably distinct from those of the lithe and active animals of which the Frog is the type. Terrestrial in its general abode, it requires not the powerful paddles of the latter to propel it rapidly through the water, and its safety consists rather in concealment than in the power of escaping from its enemies. It bears, in fact, the same relation to the Frog that the terrestrial Salamander does to the Water Newt. Like the rest of the amphibia, it becomes torpid during the winter, and chooses for its retreat some retired and sheltered hole, a hollow tree, or a space amongst large stones, or some such place, and there remains until the return of spring calls it again into a state of life and activity. Its food consists of insects and worms, of almost every kind. It refuses food which is not living, and, indeed, will only take it at the moment when it is in motion: such at least is the result of my own observations upon the habits of this animal, which have been neither few nor brief. The Toad, when about to feed, remains motionless, with its eyes turned directly forwards upon the object, and the head a little inclined towards it, and in this attitude it remains until the insect moves; when, by a stroke like lightning, the tongue is thrown forward upon the victim, which is instantly drawn into the mouth. So rapid is this movement that it requires some little practice as well as close observation to distinguish the different motions of the tongue. This organ is constructed as in the Frog, and the surface being embued with a viscid mucous secretion, the 
insect is secured by its adhesive quality. When the prey is taken it is slightly pressed by the margins of the jaw; but as this seldom kills it, uniess it be a soft tender larva, it is generally swallowed alive; and I have often seen the muscles of the Toad's sides twitch in a very curious manner, from the tickling movements of a hard coleopterous insect in the stomach. It will also take earth-worms of considerable size, and it is a very curious sight to watch the manner in which the powerful and writhing worm is secured. If the Toad happen to take it by the middle, the extremities of the worm are twined with great force and activity around the muzzle in every direction, in its attempts to escape; but the Toad pushes one portion after another into its mouth, by means of the fore feet, until it all disappears, when it is swallowed whole.

For the following very curious and almost marvellous statement, I am indebted to the Rev. J. Sladen, of Ninfield, who kindly communicated it to me in the following letter, which I give verbatim and entire, and without attempting to account for the extraordinary fact :-

"Sir,

Ninfield, Sussex, Feb. 14, 1836.

"As you are now engaged in writing a history of British Reptiles, I am induced to send you an account of a fact that has lately come to my linowledge, thinking it may be thought by you worth recording.

"The fact I have to relate was witnessed in the month of August 1814, and the scene of it was the Fairlight Dowus, near Hastings; the exact spot being part of an open and bald height facing the sea, and looking down upon a glen covered with brambles, \&c. The hour was about noon, and the sun was shining powerfully at the time.

"A gentleman was taling a walk with two companions, 
when on arriving at the spot above described, they saw what was to them a totally unprecedented sight. A Toad was squatted on the ground, with its front elevated, holding the head of a viper in its mouth. The viper writhed its body occasionally, as if trying to escape, but its exertions were to no purpose. After watching the two animals for a short time, one of the party attempted to separate the victim from its enemy with a stick; but failing in this, he threw both together into the glen below. The countenance of the toad evinced much ferocity, and its eyes glared. The entire head of the viper was in the Toad's mouth, which seemed completely filled in consequence, and its jaws were perfectly closed; and yet it did not appear at all inconvenienced by the mouthful, respiring apparently without effort.

"The gentleman who, with his two companions, witnessed this, and who has related it to me, is the Rev. Joln Phillips, Vicar of Ninfield, near Battle, and I am his curate.

"Should this relation be as curious as it appears to me, it will doubtless be worth your notice; but should it be nothing unusual, I must beg you will pardon my thus troubling you, and I may be permitted to remain,

$$
\text { "Sir, }
$$

"Your humble servant,

"And well-wisher in the cause of Natural History,

(Signed) "Edward H. M. Sladen."

"Further to authenticate this account, I have requested Mr. Phillips to ard his signature.

(Signed) "John Phillips."

Like the other Amphibia, and the Reptilia generally, the Toad sheds its skin at certain intervals, the old cuticle coming off, and leaving a new one which had been formed underneath in its stead. There are some very remarkable 
circumstances connected with this process, which I detailed many years ago to the Zoological Club of the Linnean Society, and of which the following is the substance. Having often found, amongst several Toads which I was then keeping for the purpose of observing their habits, some of brighter colours than usual, and with the surface moist and very smooth, I had supposed that this appearance might have depended upon the state of the animal's health, or the influence of some peculiarity in one or other of its functions: on watching carefully, however, I one day observed a large one, the skin of which was particularly dry and dull in its colours, with a bright streak down the mesial line of the back; and on examining further I discovered a corresponding line along the belly. This proved to arise from an entire slit in the old cuticle which exposed to view the new and brighter skin underneath. Finding, therefore, what was about to happen, I watched the whole detail of this curious process. I soon observed that the two halves of the skin, thus completely divided, continued to recede further and further from the centre, and become folded and rugose; and after a short space, by means of the continued twitching of the animal's body, it was brought down in folds on the sides. The hinder leg, first on one side and then on the other, was brought forward under the arm, which was pressed down upon it, and on the hinder limb being withdrawn, its cuticle was left inverted under the arm; and that of the anterior extremity was now loosened, and at length drawn off by the assistance of the mouth. The whole cuticle was thus detached, and was now pushed by the two hands into the mouth in a little ball, and swallowed at a single gulp. I afterwards had repeated opportunities of watching this curious process, which did not materially vary in any instance. 
The reproduction of the Toad is in all essential points similar to that of the Frog. The ova are in a similar manner impregnated during their passage, and their immersion in water is equally necessary for the developement of the embryo. But instead of being expelled in a mass, they are arranged in a double series, placed alternately, and perfectly regular. The jelly-like mass in which the embryos are enveloped, forms a continuous line about the eighth or sixth of an inch in thickness, and extending to the length of three or four feet. The ova are deposited in the spring, about a fortnight later than those of the Frog, and it is not until the approach of autumn that the young ones, having cast off their Tadpole form, come to seek their food on the land. The Tadpole is smaller and blacker in all the stages of its growth than that of the Frog; but there are no other peculiarities which are at all popularly interesting.

The stories of Toads having been found in the very substance of the wood of a tree, and in the midst of a solid and hard rock, are too numerous, and too generally asserted and believed, to be passed over here, although I have to regret that, after many and urgent inquiries, and the examination of several asserted cases of that kind, I am unable to throw any light upon this doubtful and mysterious question. Some years since I had a Toad sent me by a person of the highest credit, with the assurance that it had been taken alive out of a mass of indurated clay, of great depth, and that it had died immediately after being exposed to the air. But this case, like most, if not all, others of the same kind, is liable to the objection that the Toad most probably fell into the hollow where the men were at work, and was taken up by them in ignorance of the mode in which it had come there. Numerous experiments have 
been made in order to try whether the Toads would die on being artificially embedded in masses of clay, of plaster of Paris, in wooden boxes surrounded by plaster, and in other similar circumstances; but hitherto all have failed, although in some of them the animals have certainly lived for a much longer period than could have been expected, prolonged sometimes to many months, or even to between one and two years. Upon the whole, it appears to me that whilst the many concurrent assertions of credible persons, who declare themselves to have been witnesses of the emancipation of imprisoned Toads, forbids us hastily to refuse our assent, or at least to deny the possibility of such a circumstance, it must be confessed that we still want better and more cautious evidence, to authorize our implicit belief in these asserted facts. The truth probably is, that a Toad may have lain hid in the hollow of a tree, during perhaps a whole autumn and winter, and found itself on the return of spring so far enclosed within its liding place as to be unable to escape. As this animal requires but little respiration, and consequently but little food to support life, especially when in a state of entire inactivity, the smallest opening would be sufficient to admit the requisite passage of air, and even the occasional ingress of a small insect; and afterwards, when the tree was cut up, the Toad may have been found enclosed, and the opening may have escaped detection. To believe that a Toad enclosed within a mass of clay, or other similar substance, shall exist wholly without air or food, for hundreds of years, and at length be liberated alive, and capable of crawling, on the breaking up of the matrix, now become a solid rock, is certainly a demand upon our credulity which few would be ready to answer.

That Toads may be rendered very tame, and be made to 
distinguish those who feed and are kind to them, there are abundant facts to testify. I have possessed a very large one which would sit on one of my hands, and eat from the other ; and the story of Mr. Arscott's Toad in Devonshire, related in Pennant's British Zoology, is too well known to need repetition.

The opinions formerly entertained of the properties of the Toad, were pre-eminently absurd. It was highly poisonous, and this not only from its bite; its breath, and even its glance were fraught with mischief or death. The water which it expels from the reservoir communicating with the cloaca, and the object of which I have already explained in speaking of the Frog, was supposed to be the urine, as it is generally, indeed, up to the present time, and was believed to be highly poisonous. It is almost umnecessary to add, that this water is pure and limpid, and wholly without any deleterious qualities. The only circumstance which can be said at all to favour the barl character which attaches to this animal is, that there are situated upon the back and sides numerous secreting follicular glands, the secreted matter from which is somewhat fetid and of an acrid quality. Dr. John Davy was, I believe, the first who ever minutely examined into its true nature. The following is an abstract of Dr. Davy's observations on this subject. "After adverting to the correctness of the popular opinion respecting the poisonous nature of the Toad, which the professed naturalist has generally rejected, the author proceeds to describe the seat of the poison, which is chiefly in follicles in the skin, and which on pressure exudes from it in the form of a thick yellowish fluid, which on evaporation yields a transparent residue, very acrid, and acting on the tongue like extract of aconite. It is neither acid nor allialine; and since a 
chicken inoculated with it received no injury, it does not appear to be noxious when absorbed, and carried into the circulation.

"Dr. Davy thinks that the principal use of this poison is to defend the reptile against the attacks of carnivorous animals; he also remarks, that as it contains an inflammable substance, it may be excrementitious; it may serve to carry off a portion of carbon from the blood, and thus be auxiliary to the function of the lungs. In support of this idea, the author observes that he finds each of the pulmonary arteries of the Toad divided into two branches, one of which goes to the lungs, and the other to the cutis, ramifying most abundantly where the largest follicles are situated, and where there is a large venous plexus, seeming to indicate that the subcutaneous distribution of the second branch of the pulmonary artery may further aid the office of the lungs, by bringing the blood to the surface to be acted upon by the air." *

I have extracted the latter part of this passage to shew how beautifully the independent observations of two physiologists, so eminent as Dr. Davy and Dr. William Edwards, bear upon and illustrate each other; as will be obvious to every one who recollects the account I have already given of the cutaneous respiration of the amphibia, as discovered and explained by the last-named philosopher.

The usual pace of the Toad is neither leaping nor running, it is rather a kind of crawl; and on being alarmed, or threatened with danger, it stops, swells its body, and, on its being handled, a portion of the cutaneous secretion which I have just mentioned exudes from the follicles, and a discharge of the limpid water, which has been before

* Abstracts of the Phil. Trans. Part II. p. 263. For the whole paper see the Phil. Trans. for 1826, Part II. p. 127. 
alluded to, immediately takes place. Its quickest movement is an imperfect leap.

The general form of the Toad is certainly far from prepossessing. The body is puffed out and swollen; the head large, flat on the top ; the muzzle rounded, and very obtuse. There are no teeth either in the jaw bones, or on the palate. There is above the eyes a slight protuberance, studded with pores; and the parotids are large, thick, prominent, and porous, secreting an acrid fluid. Body covered with warts, which are larger above, and more numerous beneath. Fore feet with four toes, not at all palmated; hind legs of moderate length; the toes five in number, and slightly palmated. The colours are liable to some variation, but are always much lighter and brighter immediately after the removal of the old cuticle; the upper parts are of a dirty, lurid, or blackish grey, with sometimes a slight greenish tinge; tubercles more or less brown; beneath, dirty yellowishwhite, sometimes spotted with black.

Dimensions of a large specimen :-

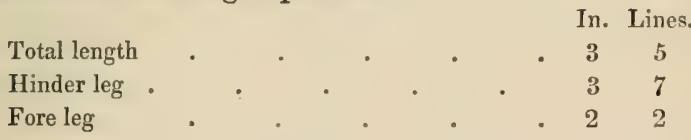

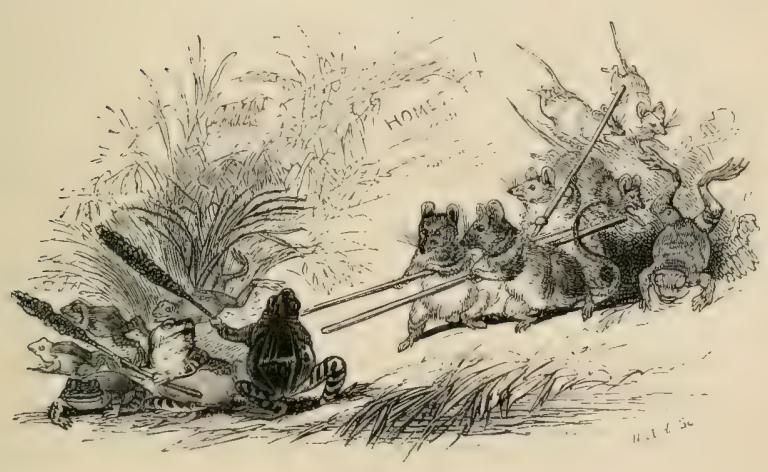




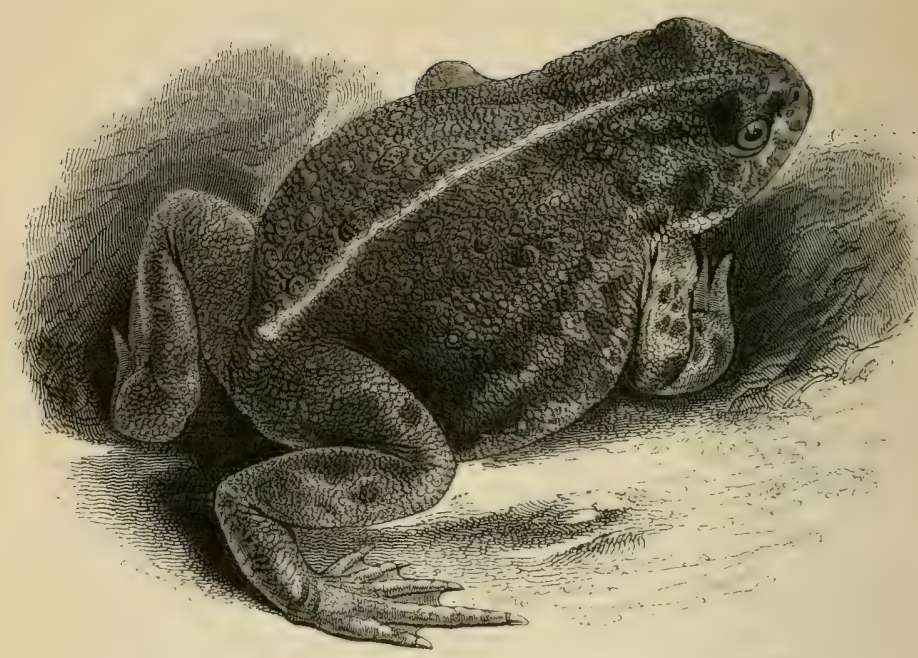

\section{NATTER-JACK TOAD.}

\section{Bufo calamita. Laur.}

Specific character. - Light yellowish brown, clouded with dull olive; a bright yellow line along the middle of the back.

Rana Bufo, var. B. Gare. Syst. Nat. Lin. I. pt. iii. p. 1047.

, Rubeta, Turton, Brit. An. p. 80.

Bufo Rubeta, Flem. Brit. Anim. p. 159.

" terrestris foetidus, Rosel, Hist. Ran. p. 107, t. xxiv.

" Calamita, Laur. Amph. 27. Jenyns, Brit. Vert. p. 302. Natter Jack, Pennant, Brit. Zool. III. p. 19.

Bufa mephitica, var? ShaW, Gen. Zool. p. 152.

Thrs species, although found in considerable numbers in certain localities, is far from being commonly met with. Pemnant, who appears to have been the first to publish it 
as a British reptile, obtained his knowledge of it from Sir Joseph Banks; and we find from his account that it had been observed both " on Putney Common, and near Reverby Abbey, Lincolnshire, where it is called the Natter Jack." It is common on Blackheath, and in several other places in the neighbourhood of London; I have found it in considerable numbers near ponds and ditches not far from Deptford, where they appear to have congregated for the purpose of breeding. Mr. Jenyns mentions Gamlingay Heath in Cambridgeshire, and two or three localities in Norfolk. It would appear that Dr. Fleming was not aware of its being an inhabitant of Scotland, as he does not add this to the formerly known localities; but Sir W. Jardine has favoured me with the following account of its habitat in that part of the kingdom:- "The Natter-Jack Toad is taken in a marsh on the coasts of the Solway Frith, almost brackish (certainly so in winter), and within a hundred yards of spring-tide high-water mark. It lies between the village of Carse and Saturness (Southerness) point, where I have found them for six or seven miles along the coast. They are very abundant." Sir William has sent me some specimens, which are in every respect the same as those found in the neighbourhood of London. The greatest number which I have ever known, however, is in my own garden at Selborne, where the species is far more frequent than the Common Toad. Dr. Broomfield has also found it in numbers on Short Heath near that place.

The habits of this species differ in some respects from those of the Common Toad. It is less sluggish in its movements, and its pace is ordinarily quickened to a sort of run, its body being raised considerably above the ground during its progress. It is most probable that its reproduction, and all the stages of its development resemble those of the 
Common Toad; but on these subjects some additional information is required. It is far more capable of sustaining: drought than the common species, and is frequently found in dry situations, resorting to the water only for the purpose of breeding. Thus I have often found several of them lying under the shallow layer of turf covering the top of the wall of a ha-ha at Selborne, exposed to the powerful rays of the summer's sun, in the hottest and driest situation in the garden; and this, in fact, appears to be their favourite resort.

The general form of this animal is similar to that of the last-named species; it is, however, less tumid; the eyes are much more prominent,- - and are, in fact, elevated above the upper surface of the head. The porous protuberances behind the head are also less developed; but the warts on the surface of the skin are even more prominent than in the True Toad. The hinder legs are scarcely so long as the body; the toes are less palmated than even in the Common Toad; - a structure in accordance with its still more terrestrial habits; and the rudimentary sixth toea tubercle which has been so considered, which we find in the Common Toad-is here absent. The general colour is a light yellowish-brown, or olivaceous, clouded with a darker hue, and a distinct yellow or whitish line along the middle of the back. The warts, or glands, on the body, and the large glands behind the head of a reddish hue. The under parts yellowish, with black spots; the legs marked with black bands.

Dimensions:-

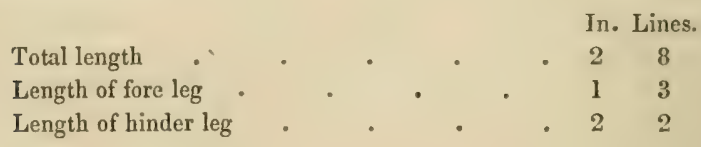



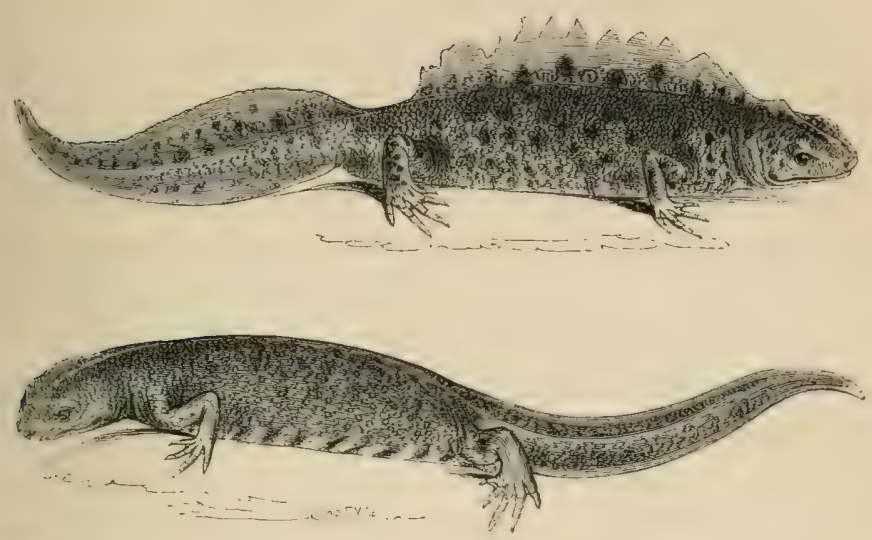

\section{Genus, Triton. Laur.}

Generic Character. - Tongue semi-globular, slightly free at each side, free and pointed behind. Palate with a double longitudinal series of teeth. No parotids nor glans along the back. Body covered with warty tubercles; glandular pores behind, and over the eyes, and a longitudinal series of distant similar pores along each side. Toes without nails; four on the anterior, and five on the posterior feet. Dorsal and caudal crests (in the male) separate.

\section{COMMON WARTY-NEWT.}

\section{GREAT WATER-NEWT.}

\section{Triton cristatus. Laur.}

Specific Character.-Upper lip overhanging the lower, but without any distinct lobe.

Lacerta palustris, Linn. Syst. Nat. I. p. 370. Shaw, Gen. Zool. III. p. 298, t. lxxxii.

Salamandra aquatica, RAy, Syn. Quad. p. 273.

" cristata, Daud. Hist. Rept. VIII. p. 233. Cuv. Règ. Anim. (edit. 2.) II. p. 116.

Triton cristatus, Laur. Spec. Med. p. 39, et 146, sp. 44. Fitz. Class. Rept. p. 66, sp. 5. BonAp. Icon. Faun. Ital.

, palustris,

Flem. Brit. An. p. 157. Jenyns, Brit. Vert. p. 303.

Molge ,

Merrett, Syst. Amph. p. 187, sp. 8.

Warty Lizard,

Penn. Brit. Zool. III, p. 23, t. iii. 
IF an instance were wanting to exemplify the obvious fallacy of the opinion that external form is alone sufficient to indicate the relations of animals, it would be impossible to select one more striking and remarkable than that of the tailed Amphibia; and it is certainly not a little extraordinary that Linnæus himself, notwithstanding the acuteness which generally enabled him to pierce through the fallacious indications offered by external appearance, and to seize upon the true relations of individuals and groups without being misled, like most others of his day, by form alone, should in this instance have failed to detect the latent affinities of the group, and to appreciate the relative value of its characters. A want of more accurate knowledge, or, perhaps, a degree of timidity arising from the novelty of the position which he took, prevented this great man from always following out the principles which his genius impelled him to adopt, and doubtless led him to the inconsistencies with which he has been too severely and indiscriminately charged. Be that as it may, he certainly, in the present instance, not only searched not below the surface, but failer even to appreciate the importance of the character of the skin itself; a reference to which, and to several peculiarities in external structure, might have led him to suspect, at least, the relations which this part bears to that of the tailless Amphibia, and especially of the Frogs.

The generic form to which the present species belongs, exhibits all the characters of the Amphibia in as striking a point of view as either of those which have been already mentioned. The naked and respirable skin, and the completeness of the transformation, are not less obvious in the present than in the former group. The whole of them are characterised also by an elongated body, by the existence of four legs, and by an aquatic life. 
The separation of the present animals from the genus $S a$ lamandra was an essential step, for which we are indebted to Laurenti, although there may be some objection to the name Triton, which he applied to them, on account of its having been already assigned by Linnæus to the inhabitants of certain shells. As, however, the principle upon which he did this-namely, the adoption of a distinct nomenclature for the animals and their shells-has long since been very properly exploded, and as the application of the name Triton to a genus of Buccinoid Mollusca, although universally adopted, is of later date than its application to the animals now under consideration, it must be retained by these.

This species, which grows to the length of six inches, is the largest found in this country. It is not at all uncommon in ponds and large ditches, where it lives upon aquatic insects, and upon any other small living animals. It feeds during the spring upon the Tadpole of the Common Frog, which it devours with great voracity, and thus doubtless co-operates with the smaller fishes to keep under the immense increase of Frogs, which, but for this, and similar means of destruction, would necessarily take place, and almost realize amongst us a repetition of the Egyptian plague. They will also devour the smaller species of Newt, Tr. punctatus, which they seize with great apparent ferocity, and hold fast in spite of all the efforts made by the victim to escape. I have taken them more than once in the act of swallowing an individual of the smaller species, which was so large as to occasion great difficulty and delay in the act of deglutition. The following fact in their habits is also worthy of remark :- " It is," says the Prince of Musignano, " a wonderful circumstance, that an animal so tenacious of life, should die with the most violent convulsions on having a little salt sprinkled upon it." 
The aquatic progression of these animals is effected principally by means of the tail ; and during the act of swimming, the legs are turned backwards, so as to admit of the smallest possible degree of resistance; when floating quite still on the surface of the water, which they frequently do, the feet are stretched out at right angles to the body, and the toes spread as widely as possible; and at the bottom of the pond they creep by means of their little weak feet, which also serve for their progression on land.

In the early spring the distinction between the males and the females in external form, which during the winter had been slight and inconspicuous, becomes more decided. The dorsal crest, which in this species is high and deeply incised, and the superior and inferior membrane of the tail, become developed to a remarkable degree. The male seeks and follows the other sex; and the tail of the former is vibrated, and, as it were, smacked, by a motion similar to that of smacking a whip, several times duriug only a few moments. Rusconi asserts, and he has been followed by most subsequent writers, that impregnation is effected without contact; but I have reasons, which it is unnecessary for me to detail here, for believing this to be a mistake, at least in some species. It is sufficient for me to state that those reasons are the result of my own repeated observations. The manner in which the egg's are deposited is very interesting and curious. The female, selecting some leaf of an aquatic plant, sits, as it were, upon its edge ; and folding it by means of her two hinder feet, deposits a single egg in the duplicature of the folded part of the leaf, which is thereby glued most securely together, and the egg is thus effectually protected from injury. The manner in which this is effected is highly interesting, and may be readily observed by any one, as the animals are sufficiently 
common in many ponds and ditches, and may generally be easily obtained by means of a minnow net. In the neighbourhood of London, especially, they are to be found in numbers every spring; and I have had no difficulty in procuring as many as I wished for the purposes of observation.

From this facility of obtaining them, the number of eggs which each produces, and the time which is occupied in the act of deposition, it is astonishing that the mode above described was never observed until of late years, and that many excellent naturalists have given most erroneous accounts of the process. Spallanzani, for instance, declares that the eggs fall at once to the bottom of the water when deposited; and Cuvier asserts that they are produced by several at a time, attached to each other like beads. These mistakes have arisen from the fact that the precaution was not taken of placing aquatic plants in the vessel with the Newts, the consequence of which has been that, in the first place, the eggs of course fell to the bottom of the vessel; and, in the next place, as they fell into contact with each other, they became united by the mass of tenacious matter by which they are surrounded. This shews how important it is, in all observations on the habits of animals, made on individuals in confinement, to place them in circumstances as nearly natural as possible, and never to rest satisfied by any results obtained under artificial restraints. Rusconi has the merit of first publishing an accurate account of the process in question, and I have observed it many times, and long before I was acquainted with Rusconi's book.

As soon as the female has in this way deposited a single egg, she quits the leaf; and after the lapse of a short time seeks another, there to place another egg.

I now proceed to describe briefly the developement of the embryo in this species, which, as it is the largest, is the 
most easily observed. The period when the deposit of the eggs commences depends upon the season; but the time when the greater number are produced, is during the months of May and June; and it is worthy of notice, that the different species of Newt are found depositing their eggs during a much longer period of the summer than the ecaudate Amphibia, such as the Frog and Toad. At the time I have mentioned, if the leaves of various species of aquatic plants be observed, many of them will be found folded together, and within the fold a single egg of the Newt will be discovered. It is, however, necessary for accurate observation from the commencement, that the female Newt be taken and placed in a vessel of water with the plants in question, that she may deposit the egg under the eye of the observer. The best plant for the purpose is the Polygonum persicaria, which is ordinarily chosen by the animal in its natural habitat. A large glass globe is a good vessel for the purpose of observation; but if it be wished to employ a larger one, I may be allowed to recommend the largest sized foot-bath made of white ware. This vessel I have often used for keeping many aquatic animals; and if a layer of Roman cement be placed at the bottom, and a few pebbles, or a stone of sufficient size be fixed by the cement at one end, the objection to the slipperiness of the vessel will be obviated, and the animal will also have the opportunity of coming above the surface at pleasure.

The egg, when first deposited (fig. 1 of the woodeut), is very lightly tinged with buff; it is surrounded by a glairy envelope, to which it is not attached, but rotates unrestrainedly within it. The first obvious change which takes place is the elongation of the white embryo, which in a few days exhibits somewhat of a division into a cephalic, an 
abdominal, and a caudal portion ; and shortly afterwards, as at figure 2, the developement has advanced so far as to afford indications of the branchir on each side of the neck, and even a slight enlargement at the part where the anterior feet will hereafter make their appearance. In the space of a few days more, the state of the embryo is such

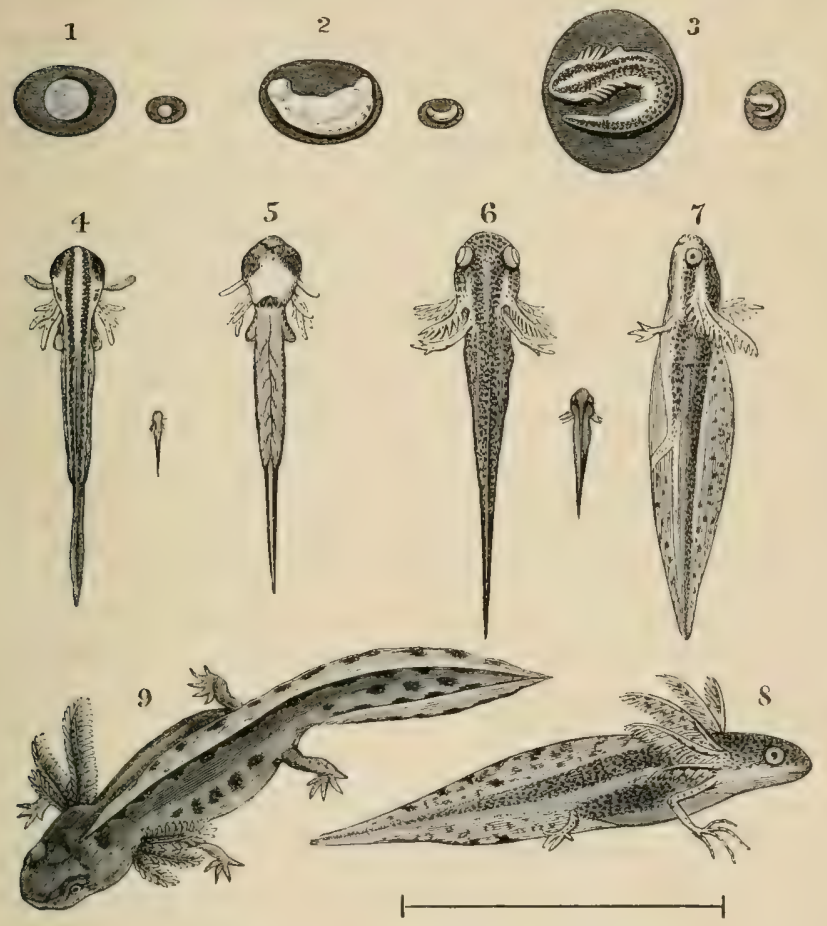

as we observe at figure 3 . The different lobes of the branchiæ are now distinctly seen, though still simple; the anterior pair of lobes are the holders, by which the little animal afterwards attaches itself to leaves, or other bodies; and behind the branchiæ may be observed a slight eminence on each side, which is the rudiment of the anterior 
foot. At this stage a double dorsal line of minute brown spots may be seen. All these characters continue to be hourly developed; and in the state which is represented at figures 4,5 , it quits its envelope, which has been continually becoming elongated to accord with the changing form of the embryo. On first issuing from the egg, it swims about, says Rusconi, without apparent consciousness of any impediments, striking against a leaf, or the sides of the vessel, and immediately adhering by its holders to the substance against which it happens to strike, and remains thus suspended for a time, as if asleep; and then, without any apparent excitement, swims off to another part. The developement of the young Tadpole, for such it must now be considered, progresses with considerable rapidity after its exclusion from the egg. In a fortnight, or three weeks, according to the temperature, it has acquired the condition exhibited in figures 6,7 . The branchiæ now offer one of the most beautiful and elegant objects in nature, as well as one of the most interesting. Observed even with the naked eye, the leaf-like division of these organs present a most pleasing subject of contemplation; but viewed in the microscope, the branchial circulation excites the greatest delight and surprise. The blood, which has now become red, ascends by the branchial arteries, and returns by the veins after having undergone the necessary change of decarbonization; and the globules of the blood are seen accelerated by momentary jerks through the vessels. The transparent tail affords a beautiful example of the systemic circulation, as the former organs do of the respiratory; and in both instances the transparency of the parts is such as to present no obstacle to the view. The eyes have now acquired their permanent character; the mouth has become terminal, and the anterior feet have acquired distinct digi- 
tations. In consonance with this latter change, the holders, which had been the only previous means of station, being now unnecessary, have become almost entirely absorbed. At figure 8, the further developement of the anterior feet, which have acquired four toes, and the rudimentary existence of the posterior pair, have considerably approximated the little animal to its permanent condition; but the branchix have acquired a still more extensive developement, and the leaflets of which they are composed are much more distinct. In figure 9 , which is of the natural size, we see the animal much changed. The body is now bulky, the colours are nearly those of the perfect condition, and the transparency of the body, which has previously been such as to afford the most agreeable opportunity to examine the internal structure, and to watch the functions which were going on, has given place to the opacity of the adult animal. The branchir, however, still remain, and have assumed a firmer consistence, a more opaque appearance, and a deeper colour. From this period the branchix become gradually absorbed, and the lungs are in the same proportion developed, until at length, towards the close of autumn, the young animal has acquired its perfect condition, and has quitted its aquatic for an atmospheric mode of respiration. In fact, like the Tadpole of the Frog, the metamorphosis of which we have already traced, it has passed from the state of a fish to that of a reptile.*

- In the perennibranchiate forms of the Amphibia, such as the Siren, the Proteus, and others, the developement of the sanguiferous and respiratory systems is arrested at that point of their growth which we have just been observing in the present animal, at figure 9 , at the point where the lungs have just begun to assume their functions, and before the branchix have undergone any diminution in their volume. Here they permanently remain; and exhibit the extraordinary phenomenon of co-existent pulmonary and branchial respiration. 
This species is much more durably aquatic in its habits than the common smaller one, Lissotriton punctatus. It occasionally, indeed, leaves the water, and I have found it hibernating under stones; but I believe this is not usual; it commonly remains torpid at the bottom of ponds and ditches, until the warmth of spring recalls it into activity. During this season of retirement the male loses his fine dorsal crest, and the web of the tail also becomes considerably diminished; but even before the return of the warm season this characteristic sexual ornament becomes developed, to be again lost in the following winter. It does not fall off; but, like the tail of the Tadpole, is gradually absorbed. The Newts ordinarily shed their skin in the same way as other aquatic amphibia; it comes off in shreds, and is washed awray as it becomes loose, but in Lissotriton it has been observed on some occasions to come arway entire.

The head of this species is flattened; the muzzle obtuse and rounded; the gape nearly straight, and extending a little beyond the eyes; teeth numerous, minute; the upper lip slightly pendulous, covering the margin of the under jaw when the mouth is closed, but not forming a distinct lobe. The trunk is continuous with the head, the neck being only distinguished by a small fold of integument beneath. The body is thick, but not ventricose; round, corrugated, and covered with small warts or tubercles. There are no parotids; but there are two patches of simple pores on each side of the head, and a line of similar pores running along each side, and somewhat distant from each other.

The tail is about two-fifths of the entire length, considerably compressed, the upper and under margins sharply and abruptly carinated. The anterior feet, when brought forwards, extend a little beyond the snout, each having four 
flattened toes, of which the third is the longest, then the second, then the fourth, and the first is the shortest. Hinder feet longer and thicker than the fore, each with five toes, of which the first is the shortest, the fifth longer, then the second, the third and fourth being equal, and the longest. The upper parts of the animal are blackish brown, or yellowish brown, with darker round spots; under parts bright reddish orange, with round black spots; sides dotted with white; sides of the tail, particularly in the male sex, of a beautiful shining pearly white, which, like the rest of the colours, becomes brighter in the spring.

In the breeding-season the male acquires a deep, flexible, indented crest, which extends the whole length of the back, along the mesial line. It is separated from the corresponding crest of the tail by a ristinct hiatus. The crest is of a lighter colour than the back. It is confined to the male, and disappears during the winter.

\section{Dimensions :-}
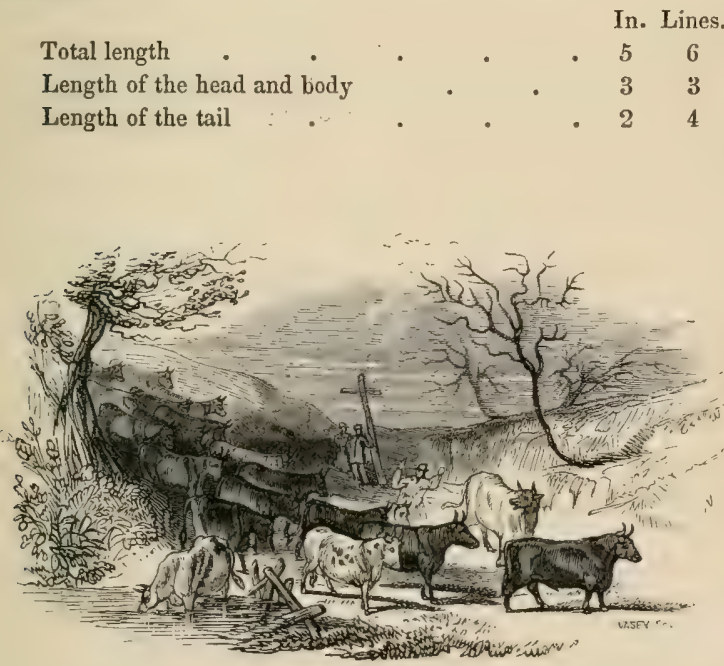


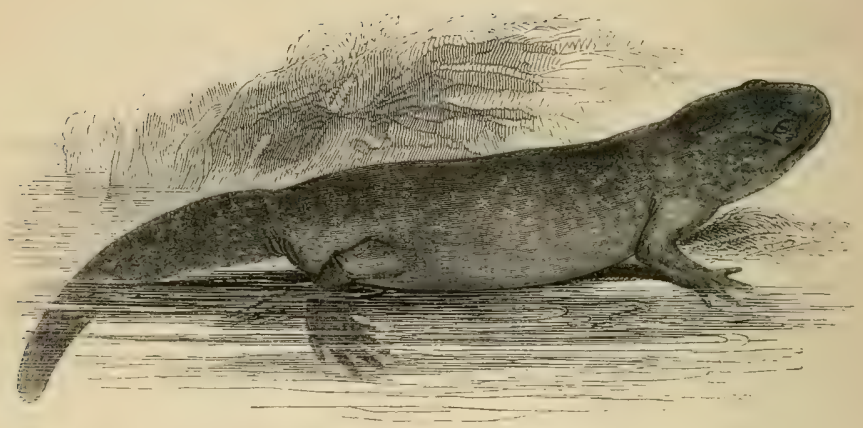

\section{STRAIT-LIPPED WARTY-NEWT.}

\section{Triton Bibronii. Mihi.}

Specific Character.-The same as $T r$. cristatus, excepting that the upper lip is perfectly straight, meeting the lower, and not overhanging it. The skin, and particularly that of the head, much more rugous and more strongly tuberculated. Colour darker.

Triton marmoratus, BiBron, in Proc. Zool. Soc. non Latr.

OF the existence of this second species of tuberculated Triton we were ignorant, until my friend, the late $\mathbf{M}$. Bibron, detected it in the collection of the Zoological Society, and from the character of the lip believed it to be the Tr. marmoratus of Latreille. In the course of the last spring I had several, both of this species and of Tr. cristatus, living; and have now before me the specimen belonging to the Society upon which M. Bibron's opinion was founded, as well as one of the true marmoratus, which he has lindly sent me from Paris. I have also examined 
several in the British Museum, where they were confounded with the Tr. cristatus. Upon a careful comparison of the whole, I am induced to consider that the new English species is distinct from $T r$. marmoratus, and that it is not only new to the British Fauna, but a hitherto undescribed species. I have, therefore, ventured to assign to it a specific name, and I have chosen that at the head of this article, as a proper compliment to the first of Erpetologists, and one of the most amiable of men.*

The principal distinctions between the species are the following:-In Triton Bibronii the skin is remarkably rugous, and the tubercles are more numerous and more elevated than in Tr. cristatus. The tubercle at the base of the inner toe on each foot is much smaller, and in some cases scarcely perceptible. The most tangible peculiarity, however, is in the form of the upper lip, which in the present species is perfectly straight, whereas in Tr. cristatus it considerably overhangs the margin of the lower jaw. By this character the two species may be at once distinguished. With regard to coloration and markings there is but little difference; I have thought, however, that the present species is somewhat darker, and the spots on the sides less distinct.

The structural characters which distinguish Tr. Bibronii from $T r$. marmoratus, are also comparative and slight. In the latter, the rugosity of the skin is less considerable, and the upper lip, instead of being absolutely straight as in our

* This talented and amiable man has, during the passing of this edition through the press, fallen a victim to consumption, which had for years been making its secret inroads upon his constitution. In the midst of the awful scenes of the late Revolution in France, surrounded by the fury of faction and the horrors of civil war, his gentle spirit passed into its rest, happier than those who survived him in having been spared the later scenes of that sanguinary and most disgusting conflict. 
species, has a slight enlargement towards the junction of the lips. But the markings and coloration are widely different; the upper parts being beautifully marbled with grey, with a white line along the mesial line of the back, and the belly irregularly mottled.

I give a comparative view of the head of $T r$. cristatus and of Tr. Bibronii, by a reference to which any one may readily determine the species.
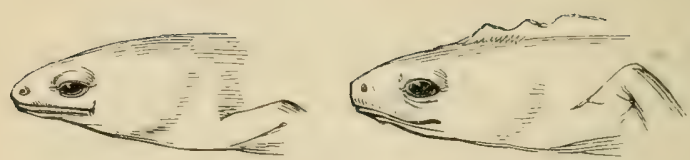


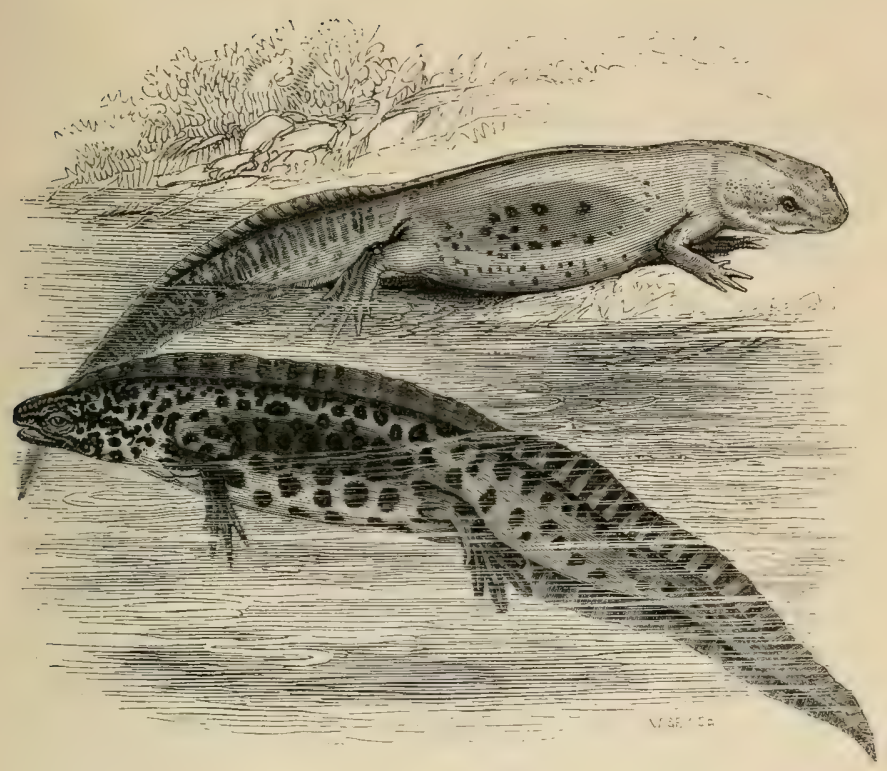

Genus, Lissotriton. Mihi.

\section{SMOOTH-NEWT.}

Generic Character.-Tongue, teeth, and feet, as in the genus Triton. Skin smooth; two patches of pores on the head ; none on the back or sides. Dorsocaudal crest continuous.

\section{COMMON SMOOTH-NEWT.}

\section{SMALL NEWT, EFT, OR EVET.}

\section{Lissotriton punctatus.}

Specifu Character.-Dorso-caudal crest of the male festooned, very deep ; tail tapering gradually to a point, without any appendage; hinder feet with the toes free.

Lacerta aquatica, Linn. Syst. Nat. I. p. 370 (\%) Shaw, Gen. Zool. III. p. 298, t. Ixxxiii. 
Lacerta maculata, Shepp. in Linn. Trans. VII. p. 53. Turton, Brit. Fåun. p. 79.

Salamandra punctatu, DaUd. Rept. VIII. p. 267. LAtr. Salam. de France, p. 53 , sp. 6 , t. vi. f. 6 .

2. Triton Palustris, LAUR. Spec. Med.pp. 39, 145, t. iv. f. 2.

" aquaticus, Flem. Brit. Anim. p. 158, sp. 7.

$"$ punctatus, Fitzing. Nat. Class. Rept. p. 66, sp. 8. Bonap. Icon.

Faun. Ital. JENyns, Brit. Vert. p. 304.

Molge punctata, MERr. Syst. Amph.p. 186, sp. 4.

Brown Lizard, PenN. Brit. Zool. 1II. p. 23, t. ii.

THe size of this small and common species would distinguish it at once from the former in its adult state, and from younger individuals it may be readily known by the difference of colour, and the absence of all warts and tubercles on the skin, which is, indeed, almost as smooth as that of the Frog. This latter character has led me to believe that the two forms might with great propriety be considered as generically distinct, upon the same principle as that which has led to the separation of the Toads from the Frogs; although it must be confessed that, in the latter case, the habits of the two groups offer a much greater discrepancy, the relations between the Frogs and Toads presenting rather an analogy with that between the smooth Newts and the true or terrestial Salamanders. Thus a tolerably continuous chain of affinity may be traced from the smooth Newts, through the tuberculated Newts, and the Geotritons of the Prince of Canino, to the true terrestrial form of the Salamanders, which last are even more strikingly characterized by a tuberculated and porous skin than either of the other forms.

The Common, or Small Newt, is found in almost every ditch and pond, especially in those in which the waters are clean, in considerable numbers; and affords food to the larger species just described, as well as to different kinds of fish. Its own food consists of small aquatic insects, 
both in their perfect and, especially, in their larva state, and of small aquatic worms and Mollusca; they also rise to take gnats, \&c. which settle on the surface of the water.

The reproduction and metamorphosis of this species differ very little from those of the former. I have observed that in depositing their eggs, they do not so constantly place them within a folded leaf, but frequently in the axillæ of the leaves; in which situation I have very often observed the females in the act of placing them, and sometimes by two, three, or four together. The pursuit of the male after the female differs also in some respects. He follows her in swimming for a considerable time; they do not, as in the former instance, necessarily rest upon the ground; and the tail of the male is doubled forwards in a sort of loop, and vibrated with a rapid tremulous motion. The changes which take place in the developement of the embryo are similar to those already described in the former species. The seasonal changes, however, are still more curious and varied than in the two species of Triton, and deserve a more detailed description, especially as these differences have led to much misunderstanding by the establishment of erroneous specific names, and consequent confusion of synonyms.

In the month of June the young animals have in many cases lost their branchiæ by absorption, and very soon afterwards a great number of them at least quit the water, and remain on land. Many of the adults also become terrestrial soon after this period, creeping about amongst the herbage in the neighbourhood of the water, or in damp places, frequently concealing themselves amongst the roots of shrubs and plants, and sometimes even venturing into damp cellars. The males about this time begin to lose the 
membranous crest and enlargement of the caudal web, which had distinguished them during the spring. The colours also of both sexes become more dull, and the male especially loses in a measure the bright and pleasing tints

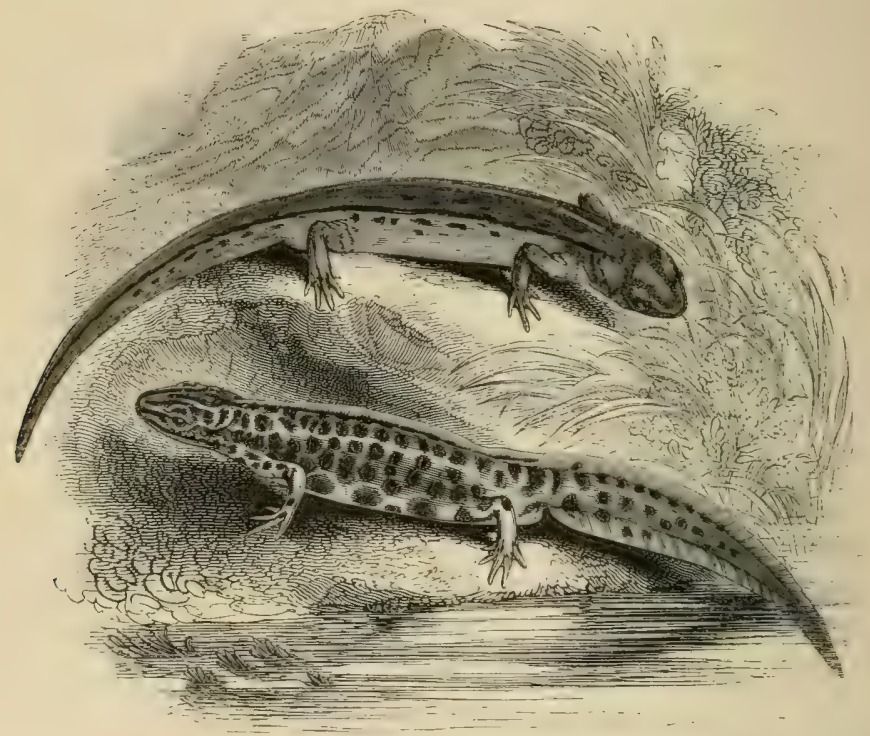

which characterize him during that season. The red tips to the crenations of the crest and tail are of course no longer seen as these parts become absorbed; but the colour of the body is also more obscure, and the spots less distinct; the belly, which has been of a bright orange passing into red, is now paler and less vivid.

It is probable that the period at which the young lose their branchia varies in some degree according to circumstances connected with temperature, food, and other causes; as they are sometimes taken with the branchia still remaining on them, when conspicuously larger than other 
individuals, which have lost these organs.* The growth of the young animals during the summer and autumn is very rapid; so that they attain nearly their adult size the first year. Very early in the winter the crest of the male begins to make its appearance, and by the beginning of the year it is conspicuous.

The result of a partial and hasty observation of these circumstances has been that naturalists have described the same species, in different conditions, as being specifically distinct. Shaw, in his General Zoology, asserts that the Common Nervt is "altogether a terrestial species," and contests even the statement of Linnæus, that it inhabits water during its larva state. "I can," proceeds Dr. Shaw, "safely affirm that I have more than once met with specimens in perfectly dry situations, so extremely minute as scarcely to equal half an inch in length, which appeared to differ in no respect, except in magnitude, from the fullgrown animal." Now it is here evident that he liad met with the young and the adult of this species when they had left the water for their autumnal visit to the land, and the branchiæ of the one, and the dorsal crest of the other were both lost. The Rev. Revett Sheppard has still farther confused the question; but, as these mistakes arose altogether from the want of a proper consideration of the characters of the group, and of closer observation of the habits of the animals, and as both these points are now cleared up, it is unnecessary to enter farther into the subject.

For the following interesting observations on the mode in which the change of skin is effected by this species I am indebted to Mr. James Salter :-

* There is in the Museum of the Zoological Society an interesting Series of Specimens exhibiting these facts. They were collected by Mr. Blyth, and the bottles are furnished with his observations. 
"During the latter part of the month of August of the present year (1848) I kept a little male newt-Lissotriton punctatus-in a basin of clear water, quite alone.

"The markings of the skin of the newt at this time were bright and distinct, and the dorsal crest was deep. At eight o'clock, on the morning of the $30 \mathrm{th}$, I noticed that it was particularly dull and would scarcely move on being touched, and I feared that it was going to die from its confinement and want of food: it was very thin, but its epidermic covering had undergone no change, and its summer dress was as bright as ever. Upon again looking at the little animal at eleven o'clock, I found that it had assumed the colours and form of the newt in the winter, approximating those of the female, and in the water its entire exuvium was floating about so thin and translucent as to look a mere film, but still quite perfect, excepting the fissure by which the body had emerged.

"The newt was now of a brown colour and the black spots on its surface less distinct; the dorsal crest, which before was deep, was merely represented by a ridge, and the tail had diminished by one-third of its vertical depth, this decrease being principally on its dorsal surface. The integument was very thin, the cutaneous blood-vessels being quite apparent through it. It was very active and swam about the basin with renewed life and vigour. The slough was a perfect cast of the whole body, limbs and tail; it was quite entire and not torn or broken in any part, excepting that it had been split straight down the middle line on the ventral surface, from the symphysis of the lower jaw to the point of the tail, and had thus simply peeled off the body, beginning from the belly and passing oft the sides and then from the back taking away the dorsal crest. It is remarkable that there was no fissure or 
crack in the cuticle from the legs and feet, but it had slipped off the limbs exactly as a glove would if pulled by the extremities of the fingers, and was not inverted; in this respect resembling the slough from the tail of the snake and slow-worm,- the tail in them being said to slip out of its covering ' like a sword out of its scabbard.'

"The little sheaths of the legs, feet, and toes, were very beautiful, they were almost transparent, excepting the points corresponding to the black markings of the skin; here they were blackish, and their integrity was so complete that when removed from the basin the water did not run through them, but distended them like tiny gloves.

"It is singular that the colour of the newt should have been so much altered by merely removing an almost colourless cuticle, but I think that this most probably arose from the partial washing off of the soft rete mucosum on the removal of the harder cuticle; for certain it is, that the colour of the newt, as I saw it, after it had thrown off the slough, ardded to the colour of the slough itself would not give the same hue as it exhibited prior to the change.

"The manner of shedding the epidermis by shreds, which I have repeatedly seen during the spring and summer, never appears to affect for any length of time the colour and general aspect of the newt, simply making the part from which it has come rather lighter for a few hours; and pieces of epidermis may be seen to peel off the dorsal crest without in any degree altering its form. May not this partial casting off of the cuticle-this desquamation-during the summer be connected with the very abundant growth of epidermis which occurs at this season? And may not the entire shedding of the slough with the 
dorsal crest, as I have just described it, be the normal manner in which the animal makes its seasonal change of dress?"

It was on this species principally that Spallanzani tried his well known experiments on the reproduction of portions of the extremities and of the tail ; and he found that the same member will be reproduced several times in succession of being cut off, and this with the bones, muscles, vessels, and nerves belonging to its original state. Its tenacity of life, like that of most other cold-blooded vertebrate animals, is a remarkable feature in its functional character. It has been frozen in a solid block of ice, and when slowly thawed, it has appeared scarcely injured.

The food of this species is similar to that of the larger species. Like them, it not only eats aquatic insects and small Mollusca and worms, but swallows the tadpoles of the Frog and Toad with great avidity.

It is almost unnecessary to say that the accusation of being poisonous, so generally believed by the lower classes in most parts of the country, is wholly unfounded.

The word Eft, or Evet, by which the whole of these animals are designated in many parts of the country, is Anglo-Saxon; "Efete,-an Eft, a Newt, a Lizard," says Somner. "I know not," says Skinner, "whether from Ef-an, equalis, from the smoothness and evenness of the skin." Junius suggests that Newt is corrupted from an evet, a nevet, a newt.

The whole of the skin in this species is quite smooth; there are no tubercles, but on the head are two rows of pores. Tail terminating in a sharp point. The lip of the male is slightly lobed in the spring, but becomes straighter when it loses its crest towards winter. The crest of the back and tail in the male are, during the season of repro- 
duction, very much developed, and are continuous; the margin is crenate throughout its length, and posteriorly deeply festooned. The colour varies very much in the course of the year, and even in different individuals at the same period. That of the male is also very different from that of the female. The former is brownish grey above, passing into yellow beneath, which in the spring becomes a rich bright orange; marked everywhere with round dark spots of unequal size. On the head are two or more longitudinal streaks. The crenations of the crest, in the
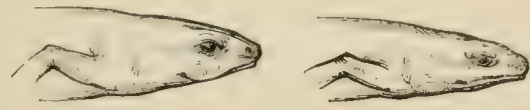

spring season, are often tipped with bright red or violet. The female is usually light yellowish brown, or even buff with scattered brown dots, and the belly often quite plain.

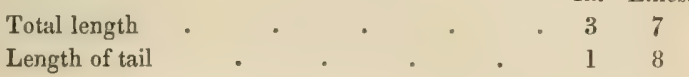

This species appears to be liable to considerable variation in colour and markings. I possess a female specimen which is of a very dark brown above, and the belly minutely punctated with black; and there is a space or band running along the side almost bare of spots. But the most remarkable variety is that which has been described by Mr. Gray and after him by Mr. Jenyns as a species, under the name of Triton vittatus, the ground colour of which is white, "with unequal black spots; tail black; belly, under sides of the legs and tail, and a broad streak along each side of the body and tail, white." I have carefully examined the specimens in the British Museum, and am 
convinced that it is to be considered as a variety only of the present species; there is not the slightest structural difference between them, they are the same in size and form. It is also, in all probability, the Salamandre ceinturêe of Latreille. Its claim to a British locality rests, as Mr. Gray informs me, upon its having been found in the British Museum in a bottle containing other British specimens, and marked "England." There is no reason, therefore, to doubt that they are British, and there is ground for believing that they were taken at no great distance from London.

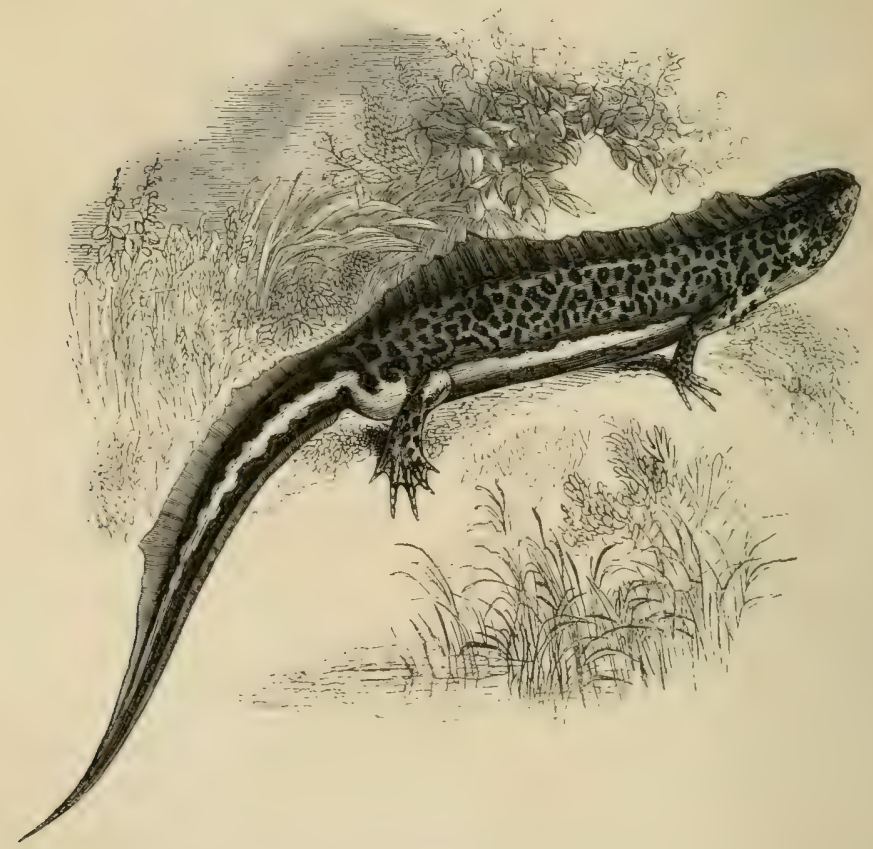

Having given my own reasons for my entire conviction that Triton vittatus of Gray is a variety only of the present species, I think it right, in justice to Mr. Gray, to add 
the following extract of a note which I have received from him on this subject:-

"My Salamandra vittata, which has been figured by Guerin, who has adopted my name, belongs to the same group as the former [Triton cristatus]. It agrees with it in having the crest interrupted over the loins, and chiefly differs from it in having smaller tubercles, and in colour. It is easily known both from $S$. palustris [Tr. cristatus], and from Triton punctatus, by the wide black-edged white streak along the lower part of each side of the body, \&c. The head is much larger and more depressed than that of any of the varieties of Tr. punctatus."

I have only to add that I differ entirely from these opinions of Mr. Gray, and that the last-named character was only found in one specimen of those of the British Museum, the others having the head of the same proportional size as in Lissotriton punctatus. The exception was probably accidental.

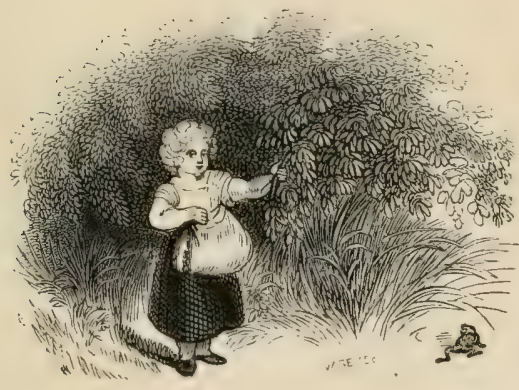




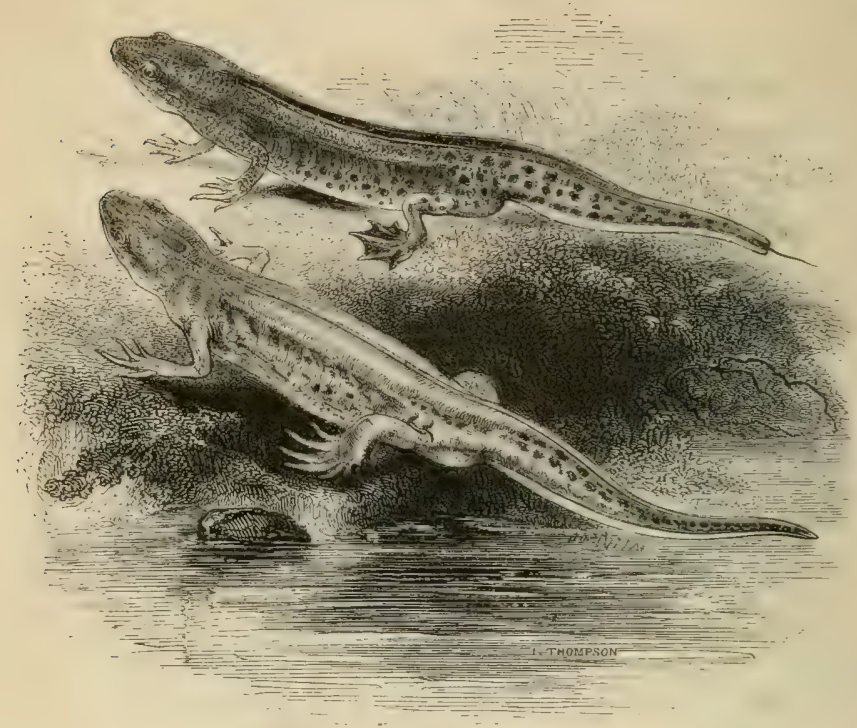

\section{PALMATED SMOOTH-NEWT.}

\section{Lissotriton palmipes.}

Specific Character.-Hind feet, in the male, perfectly palmate; tail truncate, terminating in a short slender filament; back flattened, with a raised line on each side, extending from above the eyes to the base of the tail; dorsal crest with the margin even.

Salamandre Suisse, Razovmowsiri, Hist. Nat. du Jorat, p. 111. " palmipède, Latreille, Hist. Nat. des Salam. de France, t. vi. f. 7. p. 55. SonNini, Rept. II. p. 248.

Salamandra palmipes, Daud. Hist. Nat. des Rept. VIII. t. xcriii. f. 2, p. 253. Trilon palmipes, DEBV, in Zoologist, p. 2233.

As the error which I committed in the former edition of this work-in considering a remarkably developed form of L. punctatus as the L.palmipes of continental authors, 
into which error I was led by trusting that the accuracy of my lamented friend Bibron, so generally to be depended on, was absolutely infallible, - has been subsequently corrected from various quarters, and as the true $L$. palmipes has been found extensively distributed in this country,I think it right to state the history of this discovery somewhat in detail.

It was at the end of April 1843, that I received, through the present Dean of Westminster, a communication from Mr. Baker of Bridgewater, respecting a new species of Nerwt which he had discovered in that neighbourhood; and on the 6th of May, that gentleman kindly forwarded to me several specimens of what has since proved to be the true L.palmipes. The prominent characters of the perfectly palmated feet, and the filamentary appendage to the tail, as well as the differences in the markings, are particularly alluded to in this, the earliest notice of the species as a native of Britain. I liept several specimens for some time in a glass globe, where they throve well; but as, during the autumn, they lost the caudal appendage, whether from absorption or from its being nibbled off, I waited for further opportunities of describing the species from specimens in their full spring-dress. Meanwhile I gave it the provisional name of $L$. appendiculatus. Circumstances occasioned my intention to be postponed from time to time; until Mr. Wolley discovered the same species in the neighbourhood of Edinburgh, and communicated the discovery to the Zoologist, in a short but satisfactory notice,-and to myself in a letter accompanied by numerous living specimens. It is not necessary for me to quote the observations of $\mathrm{Mr}$. Wolley, as they may be referred to in the Zoologist; in which publication there subsequently appeared further communications from Mr. Balier and Mr. 
Wolley, some excellent observations on the nomenclature of the Newts by Mr. Newman, and finally, a short but most clear and decisive note from M. Julian Deby, who at once set the question at rest, by giving a comparative view of the tails of this and of the common species, with notes of their distinctive characters, and a short account of the Continental authorities on the subject. The figure in Dandin of his Salamandra palmipes is indeed so characteristic, that had I consulted, as on any other occasion I should have done, this excellent author, I could not have committed the mistake into which I was led by implicit reliance upon an authority which never, on any other occasion, failed me.

The first intimation we have of this species as distinct, is in the "Histoire Naturelle du Jorat," of M. Razoumowski, who there terms it "Salamandre Suisse." Latreille, with great propriety, changed this name to that of "S. palmipede;" in which he was followed by Sonnini. It inhabits the midland countries of Europe, having been found, as M. Deby observes, "by Fournelle in the department de la Moselle, by Sturm in Germany, by Razoumowski in Switzerland, by Latreille in France, and by De Selys, Van Haesendonck, and myself in Belgium."

I now proceed to detail the principal distinctions which exist between this and the common British species, L. punctatus.

The whole animal is smaller; the head flatter, broader in proportion, and beautifully marbled; the body has two distinct lateral carinæ above, and two less conspicuous ones beneath, giving to it somewhat of a quadrate form. The crest is straight, and much less elevated than in the other species, and begins further back on the neck. The hinder feet of the male are palmate; entirely so in the summer, less so in the autumn, and towards winter the web is 
scarcely broader than in L. punctatus in the full season; the tail is not much more than half the depth, and terminating rather abruptly, and is furnished at its extremity with a small filament, which varies in length from two to four lines; and in the female dwindles to a mere mucronation. The colours of the back and sides are more clear and bright, although generally darker. The spots are more numerous and often confluent; and the tail has two distinct longitudinal fascix of spots, with occasionally a few between them; but the inferior margin is invariably and distinctly pale and immediate. The female is ordinarily paler than the male; but the spots on the tail are in general more numerous, smaller, and disposed to become confluent.

This interesting species has now been found in very various localities. Mr. Wolley has the following interesting note in the Zoologist, of its extreme northern habitat:- " I have to report the existence of our recently ascertained Newt, in the extreme north of the island. On the 1st of August I found several females and one male in a little fresh-water peaty pool, a few hundred yards from high-water mark, on the side of the hills which rise from Loch Eribol, and on the west side of the loch. It is an inlet of the sea, about sixteen miles to the east of Cape Wrath, in the north coast of Sutherland." The same gentleman had previously recorded its existence in the neighbourhood of Edinburgh. In England, in addition to the first recorded locality in which it was discovered by Mr. Baker; my relative, Mr. James Salter, found it plentiful in a pond near Ryde, in the Isle of Wight, from whence I have since received numerous specimens from Dr. Bell Salter, of that place, who obtained them from a pond at Brading; and the former gentleman has informed me that he has found it in tolerable plenty "in a pond 
within three miles of Poole, in Dorsetshire, on the heath between Constitution Hill and Kinson." It is extremely probable that it will be found to be much more generally distributed than has hitherto appeared. Mr. James Salter has communicated the following facts respecting those found in the latter locality, which appear to me too interesting to be lost. This letter is dated December 13, 1848:- " I took from this pond eight or ten males and several females. The males were brighter coloured than those I took in the Isle of Wight, but in other respects the same. I scraped from the bottom of the pond, out of the mud, a male L. punctatus, and its semitorpid state contrasted greatly with the vigour and activity of the other species. A female $L$. palmipes had in its stomach a good-sized, whole, recently taken eartl-worm.

"It is worthy of remark, that in no ponds where there were hundreds of $L$. punctatus in the summer, have I been able to find any now in the adult state, excepting the single individual before referred to. I have, however, found hosts of very young ones, some just above the tadpole state, with only two legs, and others with four legs and large branchiæ. Is not this very remarkable for the 13 th of December?

"In the pond where I took $L$. palmipes, there were young ones about as far advanced, and these were palmipes, as the appendiculate tail was already conspicuous. In this latter pond there were also thousands of very small tarlpoles, not above a week old, if so much; these were doubtless palmipes also.

"I have thus had an opportunity of observing its winter, and comparing it with its summer, dress. The differences are these: In winter the dorsal crest is diminished by about one-third, although it is never very deep, and the 
tail is also lessened by about one-fourth of its vertical deptl. The palmation of the hinder feet of the male is completely altered; instead of being webbed like a duck's foot, it has now each toe simply fringed with skin, and the fringes are joined at the bases of the contiguous toes. The ridges on the back do not alter, and the caudal filament remains undiminished."

The palmation does, however, in some instances remain, with scarcely any change, up to the commencement of winter.

The colour of the male and its markings are somewhat duller in the winter than in the summer, but this change is much less considerable in the present species than in $L$. punctatus. The female, as in the other species, undergoes no seasonal change.

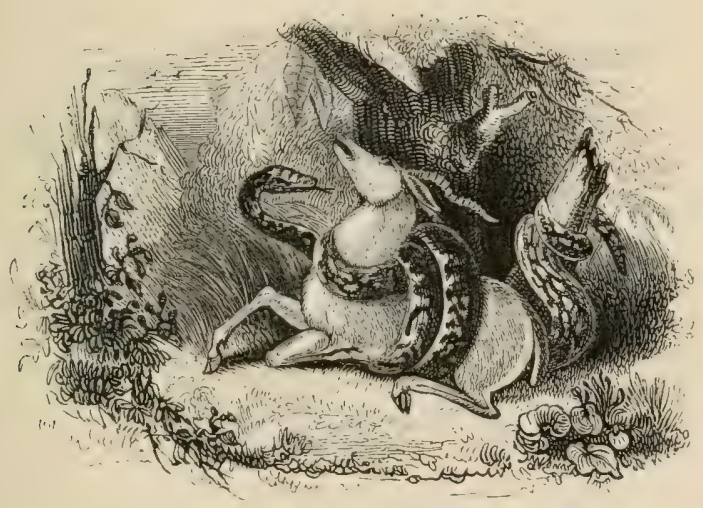


LUNDUN:

Printed by S. \& J. BentLeY and Henry Fley, Bangor House, Shoe Lane. 
THE FOLLOWING SERIES,

Published by Mr. VAN VOORST, is uniform with

"The History of Britisi Reptiles."

THE NATURAL HISTORY OF GREAT BRITAIN. This Series of

Works is Illustrated by many Hundred Engravings; every Species has been

Drawn and Engraved under the immediate inspection of the Authors; the best Artists have been employed, and no care or expense has been spared.

A few copies on larger paper, royal $8 \mathrm{vo}$.

THE QUADRUPEDS, by Professor Bell. $1 l .8 s$.

THE BIRDS, by Mr. Yarrell. Second Edition, 3 vols. $4 l .14 s .6 d$.

COLOURED ILLUSTRATIONS OF THE EGGS OF BIRDS, by

Mr. Heivitson. 2 vols. 4l. 10s.

THE Reptiles, by Professor Bell. Second Edition, $12 s$.

THE FISHES, by Mr. Yarkell. Second Edition, 2 vols. $3 l_{\text {.* }}$

THE CRUStACEA, by Professor Bell. Now in course of Publication, in Parts at $2 s .6 d$.

THE STAR-Fishes, by Professor Edward Forbes. $15 s$.

THE ZOOPHYTES, by Dr. Johnston. Second Edition, 2 vols. $2 l .2 s$.

THE MOLLUSCOUS ANIMALS AND THEIR SHELLS, by Professor

EdWARd Forbes and Mr. HANley. Now in course of Publication, in Parts at $2 s .6 d_{\text {. }}$; or Large Paper, with the Plates Coloured, $5 s$.

THE FOREST TREES, by Mr. SELBY. $28 s$.

THE FERNS AND ALLIED PLANTS, by Mr. NEWMAN. 25.

THE FOSSIL MAMMALS AND BIRDS, by Professor OWen, 1l.11s. 6d.

A GeNeral OUTLINE OF THE ANIMAL KINGDOM, by Professor

T. RYMER JoNes, 8 vo. $1 l$. $18 s$.

* "This book ought to be largely circulated, not only on account of its scientific meritsthough these, as we have in part shown, are great and signal-but because it is popularly written throughout, and therefore likely to excite general attention to a subject which ought to be held as one of primary importance. Every one is interested about fishes-the political economist, the epicure, the merchant, the man of science, the angler, the poor, the rich. W'e hail the appearance of this book as the dawn of a new era in the Natural History of England."-Quarterly Review, No. 116. 


\section{AN ALPHABETICAL LIST OF BOOKS PUBLISHED BY MR. VAN VOORST.}

Many of the works are freely illustrated, and of some a few large-paper copies have been printed.

ACCENTUATED LIST OF BRITISH LEPIDOPTERA 8vo, วัs.

ADAMS, BATKIE, AND BARRON. MANUAL OF NATURAL IMSTORY, for the Use of Travellers. Post Svo, 12s.

ADAMS, H. AxD A. GENERA OF RECENT MOLLUSCA. 3 vols. 8ro, Plates plain, $£ 410$ s. Royal 8 ro, the figures of the Animals Coloured, $£ 9$.

AIKIN. ILLUSTRATIONS OF ARTS AND MANUFACTURES. Foolscap 8ro, 8s.

ANSTED. ELEMENTARY COURSE OF GEOLOGL, MNERALOGY, and Physical Geography. Second Edition, post 8ro, $12 s$.

- SCENERY, SCIENCE, AND ART. 8vo, 10s.6 .

THE ANCIENT WORLD. Second Edition, post 8vo, 10s。 6d.

THE GEOLOGIST'S TEXTBOOK. Foolscap 8 ro, $3 s, 6 d$.

THE GOLD-SEEKER'S MANUAL. Foolscap 8ro, 3s. $6 d$.

ATTFIELD. AN INTRODUCTION TO PIARMACEUTICAL CHEMISTRY. Post 8ro, 10s. $6 d$.

BABINGTON. FLORA OF CAMBRIDGESHIRE. 12mo, with a Map, 7 s. 10s. 6 i. MANUAL OF BRITISH BOTANY. Sixth Edition, 12mo,

BAILY. CHARACTERISTIC FIGURES OF BRITISH FOSSILS. Part 1, 8ro, plain, 5s.; Coloured, $7 s$.

BAPTISMAL FONTS. 4 Series of 125 Engrarings, with Descriptions. 8vo, $£ 11$ s.

BATE AND WESTWOOD. BRITISII SESSILE-EIED CRUSTACEA. Parts 1-20, 8vo, 2s. 6d.; Royal, 5s. each.

BEALE. NATURAL HISTORY OF TIIE SPERM-WHALE. Post 8 ro, 12.

BECK. THE ACHROMATIC MICROSCOPE. Royal 8vo, $21 s$. 
BEDDOME. FERNS OF BRITISH INDTA. 4to, vol. i., $\mathfrak{\& 4}$. . FERNS OF SOUTHERN INDIA. 4to, in Parts, £6 10s.

BELL. BRITISH REPTILES. Second Edition, 8 ro, $12 s$.

-. BRITISH STALK-TYED CRUSTACEA. 8vo, 25s.

- AND TOMES. BRITISH QUADRUPEDS. In the press.

BENNETT. GATHERINGS OF A NATURALIST IN AUSTRALASIA. 8 ro, $21 s$.

BLOOMFIELD'S FARMER'S BOY, AND OTHER POEMS. With Tlustrations, foolscap $8 \mathrm{ro}, 7 \mathrm{~s}, 6 \mathrm{~d}$; ; large paper, $15 \mathrm{~s}$.

BOCCIUS. PRODUCTION AND MANAGEMENT OF FISH IN FRESIT Waters. 8ro, 5 s.

BONAPARTE. GEOGRAPIICAL AND COMPARATIVE LIST OF THE Birds of Europe and North America. 8vo, $5 s$.

BOWDITCH. ON COAL-GAS. 8vo, 2s, $6 d$.

BREWER. FLORA OF SURREY. 12mo, with Two Maps, 7s. $6 d$.

BRIGHTWELL. LIFE OF LINNEUS. Foolscap 8ro, 3s.6d.

BRODRICK. FALCONERS' FAVOURITES. Folio, $\mathfrak{L}_{2} \mathrm{2s}$.

BULLER. LETTERS FROM ABROAD. Post 8vo, 7 .

BURTON. FALCONRY IN THE VALLEY OF THE INDUS. Post8ro, 6 s. CATAIOGUE OF BRITISII TERTEBRATE ANTMALS. 8ro, sewed, $2 s$ 6 . CHURCH. LABORATORY-GUIDE FOR STUDENTS OF AGRICULtural Chemistry. Post 8 ro, $4 s, 6 d$.

CLARK. BRITISH MARINE TESTACEOUS MOLLUSCA. Sro, 1.s.

- LETTERS HOME, FROM SPAIN, ALGERIA, AND BRAZIL. 8 ro, $7 s .6 d$.

CLAUSIUS. TIIE MIECIIANICAL THEORY OF IIEAT. Translated by Hirst. 8 ro, 15 s.

CLERIIONT, LORD. GUTDE TO TIIE QUADRLPEDS AND REPtiles of Europe. Post 8vo, $7 s$.

COUCH. ILLUSTRATIONS OF INSTINCT. Post 8vo, 8 s. $6 d$.

CRICHTON. A NATURALIST'S RAMBLE TO TILE ORCADES. Foolscap 8vo, $4 s$.

CUMMING. THE ISLE OF MAN. Post 8ro, 12s, $6 d$.

CUPS AND THEIR CUSTOMS. Post 8 ro, $2 s, 6 d$.

CURRENCY (THE) UNDER THE ACT OF 1844. 8vo, 6.

DALLAS. ELEMENTS OF ENTOMOLOGY. Post 8 ro, 8s. 6 d.

DICKSON. THE UNITY OF THE PHISTCAL SCTENCES. Post 8 ro, 4 .

DODSLEY. ECONOMY OF HUMAN LIFE. 12 Plates, 18mo, js. 
DOMESTIC SCENES IN GREENLAND AND ICELAND. Second Edition, 16 mo, $2 s$.

DOUGLAS. THE WORLD OF INSECTS. 12mo, sewed, $3 \varepsilon .6 d$. DOWDEN. WALKS AFTER WILD FLOWERS. Foolscap 8ro, 4s. $6 d$. DREW. PRACTICAI METEOROLOGY. Second Edition, foolscap 8ro, 5 s. DRUMMOND. FIRST STEPS TO ANATOMY. 12mo, $5 \mathrm{~s}$.

ELEMENTS OF PRACTICAT KNOWLEDGE. Second Edition, 18mo, 3 . ELIOT AND STORER. A MANUAL OF INORGANIC CHEMISTRY. Crown 8ro, 10s. $6 d$.

ENGLAND BEFORE 'THE NORMAN CONQUEST. 16mo, $2 s .6 d$. ENTOMOLOGISTS' ANNUAL, 1855-1868. Foolscap, 2s.6d. each. ENTOMOLOGISTS' MONTILI MAGAZINE. Nos. 1-48, 6c. each. EVENING THOUGIITS, BY A PHYSICIAN. Third Edition, 4s. 6c. EYTON. HISTORY OF THE OYSTER AND TIE OYSTER-FISHERIES. 8 ro, 5 s.

FIRST PRINCIPLES OF RELIGION. $18 \mathrm{mo}, 2 s$.

FLY-FISHING IN SALT AND FRESH WATER. 8ro, 7s.6d.

FORBES. HISTORY OF BRITISH STARFISHES. 8vo, 158.

FORBES AND AUSTEN. NATURAL HISTORY OF THE EUROPEAN Seas. Foolscap 8ro, 5 s.

FORBES AND HANLEY. IIISTORY OF BRITISH MOLLUSCA AND their Shells. 4 vols. 8 ro, $£ 610$ s. Royal 8vo, with the Plates Coloured, $£ 13$.

FRANKLAND. LECTLRE-NOTES FOR CHEMICAL STUDENTS. Post 8vo, 12 s.

GARNER. FIGURES OF INVERTEBRATE ANIMIALS. Royal sro, $5 \%$ . NATURAL HISTORY OF THE COUNTY OF STAFFORD (with Sipplement). 8vo, 10 s.

GISSING. MATERIALS FOR A FLORA OF WAKEFIELD. Sro, $1 s, 6 d$. GOLDSMTTH. VICAR OF IVAKEFIELD. Illustrated by MulREAy. Second Edition, square 8 vo, $10 s .6 d$.

GOODSIR. AN ARCTIC VOYAGE. Post 8ro, 5s. $6 d$.

GOSSE. AQUARIUM. Post 8vo, $17 \mathrm{~s}$.

- HANDBOOK TO MARINE AQUARIUM. Foolscap 8vo, 2s.6 $d$. BIRDS OF JAMAICA. Post 8vo, 10s.

BRITISH SEA-ANEMONES. 8vo, $21 s$.

CANADIAN NATURALIST. Post $8 \mathrm{ro}, 12 s$.

DEVONSIIIRE COAST. Post 8ro, 21 s.

- MANUAL OF MARINE ZOOLOGY. 2 rols. feap 8 ro, 7 s. $6 d$. each. 
GOSSE. OMPHALOS. Post 8 ro, 10s, 6 d.

TENBY. Post 8 ro, $21 s$.

GRAY'S BARD. With Illustrations; uniform with the Elegy, post 8vo, $7 \mathrm{~s}$.

- ELEGY IN A COUNTRY CHURCHYARD. With 33 Engravings, post $8 v o, 9 s$, ; Polyglot Edition, 12s.; a small edition, foolscap 8vo, 2s. $6 d$.

GRAY. SYNOPSIS OF THE SPECIES OF STARFISH IN THE British Museum. 4to, sewed, $7 s, 6 d$.

GREG AND LETTSOM. MANUAL OF BRITISH MINERALOGY. 8ro, $15 \mathrm{~s}$.

GRIFFITH AND IIENFREY. MICROGRAPHIC DICTIONARY. Second Edition, 8vo, £2 5s.

GRIFFITIT. AN ELEMENTARY TEXT-BOOK OF THE MICROSCOPE. Post 8 vo, 7 s. 6 .

GROTIUS. INTRODUCTION TO DUTCH JURISPRUDENCE. Translated by Herbert. Royal 8 ro, $31 s, 6 d$.

GURner. CATALOGUE OF RAPTORIAL BIRDs. Part 1, Imp.8vo, 5 s. - ON THE GREY PHALAROPE. 8vo, sewed, $6 d$.

HARDING. UNIVERSAL STENOGRAPHY. Foolscap Sro, sewed, is.; bound, $3 s .6 d$.

HARTING. THE BIRDS OF MIDDLESEX. Post 8 ro, $7 s, 6 d$.

HARVEY. BRITISH MARINE ALGE. Sro, 21s.; Coloured, 31s. 6d.

-. FLORA CAPENSIS. 8vo, vols. i. \& ii., 12s. each; vol. iii., 18s.

-.. THESAURUS CAPENSIS. Vols. i. \& ii., 21s, each.

- - INDEX GENERUM ALGARUM. Svo, sewed, $2 s .6 d$.

- - - NEREIS BOREALI AIIERICANA. Royal 4to, sewed, £:3 3 .

- SEASIDE BOOK. Fourth Edition, foolscap 8vo, 5 s.

IIASLAM. PERRAN-ZABULOE. THE CHURCH OF S. PIRAN. Foolscap 8 ro, $4 s .6 d$.

HENFREY. ELEMENTARY COURSE OF BOTANY. Post sro, $12 s .6 d$. RUDIMENTS OF BOTANY. Foolscap 8ro, 3s, $6 \mathrm{~d}$.

SIX BOTANICAL DIAGRAMS FOR ILLUSTRATING Lectures, $15 \mathrm{~s}$.

- THE VEGETATION OF EUROPE. Foolscap 8ro, 5 s.

HEWITSON. COLOURED ILLUSTRATIONS OF THE EGGS OF British Birds. Third Edition, 2 vols. 8 ro, $£ 414$ s. $6 d$.

- DESCRIPTION OF $100 \mathrm{NEW}$ SPECTES OF HESPEridæ. Parts $1 \& 2,8$ ro, sewed, $6 d$. each.

EXOTIC BUTTERFLIES. Vols, i.-iii., 4to, £5 5s. each; continued in Quarterly 5s. Parts (66 published).

1-3, 4to, sewed, 25s, each. 
HINCKS. CATALOGUE OF THE ZOOPHYTES OF THE SOUTH OF Deron and Cornwall. 8ro, sewed, $3 s$.

HOLMESDALE NATURAL-HISTORY CLUB PROCEEDINGS. 8ro, $1 s$. annually.

HUNTER, ESSAYS AND OBSERVATIONS. Edited by OWEN. 2 vols. 8 ro, $31 s, 6 d$.

IBIS. A QUARTERLY JOURNAL OF ORYITHOLOGY. 6s. each.

INSECTA. SAUNDERSTANA. Parts 1-8, 8vo, sewed, $3 s$. each.

INSTRUMENTA ECCLESIASTICA. First and Second Series, 4to, sheep, $£ 111 s, 6 d$, each.

JEFFREYS. BRTTISII CONCHOLOGY. Fols. i.-iv., post 8vo, 12.s. each. (An Atlas containing Coloured Figures of all the Species is preparing.)

JENYNS. MEMOIR OF PROFESSOR IIENSLOW. Post 8 vo, 7 s. $6 d$.

- OBSERVATIONS IN METEOROLOGY. Post 8ro, 10s. $6 \mathrm{~d}$.

- OBSERVATIONS IN NATURAL HISTORY. Post 8vo, 10s,6d. JESSE. AN ANGLER'S RAMBLES. Post 8 ro, 10s, $6 d$.

JOHNSTON. HISTORY OF BRITISH ZOOPHYTES. 2 vols. 8ro, £2 2. INTRODUCTION TO CONCHOLOGY. 8ro, 21 s.

- NATURAL HISTORY OF THE EASTERN BORDERS. Vol, i. (Botany), 8vo, 10s. 6d.

JONES. GENERAL OUTLINE OF THE ORGANIZATION OF THE Animal Kingdom. Third Edition, 8ro, £1 11s. 6d.

- LECTURES ON THE NATURAL IITSTORY OF ANIMIALS. Vols. i. \& ii., post 8ro, 12s, each.

- THE AQUARIAN NATURALIST. Post 8ro, $18 s$.

TELAART. FLORA CALPENSIS. 8vo, 10s. $6 d$.

- PRODROMUS FAUNE ZEYLANICA. 8vo, 10s.6d.

KNOX. GREAT ARTISTS AND GREIT ANATOMISTS. Post Sro, 6s. 6d. ORNITHOLOGIC.IL RAMIBLES IN SLSSEX. Post Sro, Third Edition, 7s. 6d.

LATHAM. DESCRIPTIVE ETHNOLOGY. 2 vols. 8ro, $2112 s$.

ETHNOLOGY OF BRITISH COLONIES. Foolscap 8 ro, 5 . ETHNOLOGY OF BRITISH ISLANDS. -Foolscap 8ro, 5 s.

ETHNOLOGY OF EUROPE. Foolscap 8vo, $5 \mathrm{~s}$.

ETHNOLOGY OF INDIA. 8ro, $16 s$.

MAN AND HIS MIGRATIONS. Foolscap 8ro, 5 .

VARTETIES OF MAN. 8ro, 21s.

LEACH. STYOPSIS OF TIIE MOLLUSCA OF GREAT BRITAIN. Post 8ro, 14 . 
IJETERS FROMI THE VIRGIN ISLANDS. Post 8 ro, 9s. $6 d$. LETTERS OF RUSTICUS ON NATURAL HISTORY. 8vo, $8 s .6 d$. LOWE. FISHES OF MADEIRA. Parts 1-5, Royal 8 vo, Coloured, 5s,; Demy 4to, Coloured, 7s, 6 d. each.

MANUAL FLORA OF MADEIRA. Foolscip Sro, sewed, Parts $1-4,3 s .6 d$. each.

- TWO MEMOIRS ON FERNS, LAND-SHELLS, ETC. OF MAdeira, $12 \mathrm{mo}, 6 s .6 d$.

LYNN. PRINCIPLES OF NATURAL PHILOSOPHY. Foolseap 8ro, 3 .

MLALAN, SYSTEMATIC CATALOGUE OF EGGS OF BRITISH BIRDS. 8 ro, $8 s, 6 d$.

MARTIN. CATALOGUE OF PRIVATELY PRINTED BOOKS. 8vo, 21s. MEXRICK. HOUSE-DOGS AND SPORTING-DOGS. Feap 8ro, $3 s .6 d$.

MOHL. ANATONY AND PHYSIOLOGY OF THE VEGETABLE CELL. 8 ro, $7 s, 6 d$.

MOORE and MORE. CYBELE HIBERNICA. Post 8 ro, 10s. 6 .

MOSLEY. NATURAL HISTORY OF TUTBURY. Ropal 8ro, $21 s$.

MOULE. HERALDRY OF FISII. Sro, 21 s.; Royal Sro, for Colouring, $\mathfrak{2}_{2} 2 \mathrm{~s}$.

NEWMAN. DICTIONARY OF BRITISH BIRDS. 8vo, $12 s$.

School Edition, foolscap 8 ro, 58 ,

. HISTORY OF INSECTS. 8vo, 12s.

TIIE INSECT-IILNTERS AND OTHER POEMS. Fonls$\operatorname{cap} 8 \mathrm{ro}, 2 s .6 d$.

NEWTON. OOTHECA WOLLEIANA. Part 1, royal sro, $£ 111 s .6 d$.

NORTHCOTE AND CHURCH. QUALITATIVE CHEMICAL ATALYSIS. Post 8vo, 10s, $6 d$.

OWEN. BRITISII FOSSIL MAMMALS AND BIRDS. 8ro, $£ 111 s, 6 d$.

2.-. ON PARTHENOGENESIS. 8vo, $5 s$.

ON THE MYLODON. Royal 4to, $£ 112 s .6$.

PALEY. MANUAL OF GOTHIC ARCHITECTURE. Feap 8ro, 6s. 6 .

MANUAL OF GOTHIC MOLDINGS. Third Ed., 8 ro, $7 s, 6 d$.

- THE CIIURCH RESTORERS. Foolscap Sra, 4 s. $6 d$.

PENNELL. THE ANGLER-NATURALIST'. Post $8 \mathrm{ro}, 10 \mathrm{~s}, 6 d$.

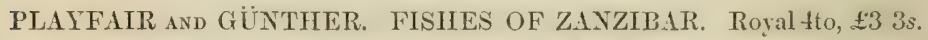

POOR ARTIST, OR SEVEN EYESIGHTS AND ONE OBJECT, Foolscap 8 ro, 5 s. 
PRESCOTT. TOBACCO AND ITS ADULTERATIONS. 8ro, 12s.6 $d$. PRESTON. FLORA OF MARLBOROUGH. 12mo, 3s. $6 d$.

PRESTWICH. GEOLOGICAL INQUIRY RESPECTING THE WATERbearing Strata of the Country around London. 8 ro, $8 s .6 d$. - THE GROUND BENEATH US. 8ro, sewed, 3s. $6 d$.

RECORD OF ZOOLOGICAL LITERATURE. 8vo, 30s. annually (186t-66 published).

REFUGTUM BOTANICUM; FIGURES AND DESCRIPTIONS OF Little-known or New Plants. Royal 8vo, Part 1, 7s.6d.

SALISBURY. GENERA PLANTARUM. A FRAGMENT, CONTAINING part of Liriogame. $8 \mathrm{ro}, 5 \mathrm{~s}$.

SAMUELSON. HUIBLE CREATURES. THE EARTIIWORM AND Housefly. Second Edition, post 8 ro, $3 s .6 d$.

8vo, 6s.

SEEMIAN. BRITISH FERNS AT ONE VIEW. 8vo, Coloured, 6 s.

SELBY. BRITISH FOREST-TREES. 8ro, $28 \mathrm{~s}$.

SHAKSPEARE'S SEVEN AGES OF MAN. Illustrated, square 8 ro, $6 s$.

SHARPE. DECORATED WINDOWs. Sro, Plates, 21s.; Text, 10s. 6d.

SHIELD. HINTS RESPECTING MOTHS AND BUTTERFLIES. 12mo, serred, $3 s$.

SIEBOLD. PARTHENOGENESIS IN MIOTHS AND BEES. 8Vo, $5 s$.

SMITH. BRITISH DIATOMACE E. 2 vols, royal 8vo, £2 11 s.

SOWERBY AND JOINNSON. BRITISH POISONOUS PLANTS. Post 8ro, $9 s .6 d$.

$£ 33 s$.

BRITISH WILD FLOWERS. Coloured, 8vo,

SOWERBY. KEY TO TIE NATURAL ORDERS OF BRITISH WTLD Flowers. 8ro, $7 s .6 d$.

$£ 15$ s, each.

SPRATT AND FORBES. TRAVELS IN LYCIA. 2 vols. 8ro, £1 16 s.

SPRATT. TRAVELS AND RESEARCHES IN CRETE, 2 rols. 8 ro, 2 .

STAINTON. MANUAL OF BRITISH BUTTERFLIES AND MOTHS. 2 vols, $12 \mathrm{mo}, 10 \mathrm{~s}$.

10 vols. 8vo, $12 \mathrm{~s}, 6 d$. each.

- TINEINA OF SYRIA AND ASIA MINOR. 8ro, $4 s$.

STRICKLAND AND MELTILLE. THE DODO AND ITS KINDRED. 4to, £1 $1 s$. 
STRICKLAND. ORNITHOLOGICAL SYNONYMS. Vol. i. (Accipitres) 8 ro, 12 s. $6 d$.

SUNDAY BOOK FOR THE YOUNG. $16 \mathrm{mo}, 2 s .6 d$.

THOUGHTS BY A PIISICTAN: BEING A SECOND SERIES OF Evening Thoughts. Post 8ro.

TUGWELL. MANUAL OF SEA-ANEMIONES. Post 8 ro, $7 \&, 6 d$.

TULK AND HENFREY. ANATOMICAL MANIPULATION. Frap 8to, 9s. WARD. HEALTHY RESPIRATION. Second Edition, foolscap, sewed, $1 s$. WATTS. DIFINE AND MORAL SONGS. Illustrated, square 8ro, 7s.6c. WHITE. NATURAL HISTORY OF SELBORNE. Edited by Jexrs. Foolscap 8 vo, $7 \mathrm{~s} .6 d$.

IVILINSON. BRITISH TORTRICES. 8ro, 25s.

WILKINSON, LADY. WEEDS AND WILD FLOWERS. Post 8 ro, 10s. $6 d$. WILLTAMS. HANDBOOK OF CIIEMICAL MANIPULATION. Post 8ro, $15 s$.

WOLLASTON. COLEOPTERA ATLANTIDUM. 8ro, 21s.

—_. COLEOPTERA HESPERIDUM. 8ro, 10s. 6 .

- INSECTA MADERENSTA. Royal 4to, $£ 22 s$.

- ON THE VARIATION OF SPECIES. Post 8 ro, 5 s.

WOODWARD. ON POLARIZED LIGIT. Second Edition, Sro, $3 s$.

YARRELL. IIISTORY OF BRITISII BIRDS. 3 rols. 8ro, Third Edition, $£ 414$ s. 6 d.

$£ 33$ s.

HISTORY OF BRITISII FISHES. 2vols.8ro, Third Edition, . ON THE SALMON. Oblong folio, sewed, $12 s$.

ZOOLOGIST. A JOURNAL OF NATLRAL HISTORY. 1s. montlily.

\section{In the press.}

THE MOCKING-BIRD AND OTHER POEMS, by Frinmick Fiely, F.R.S. ELEMENTS OF HEAT, by Friderick Guturie, Profeseor of Chemistry and Physics at the Royal College, Mauritius.

A HISTORY OF BRITISII IIYDROID ZOOPHYTES, ly the Rer. THoms Hincks, B.A. 2 rols. 8 ro.

ON THE ARCIITTETURAL HISTORI OF ELY CATIEETRAL, by the Rev. D. J. Stewart, M.A.

JOHN VAN TOOLST, 1 PATERXOSTER ROW. 


\section{.}





.

. 



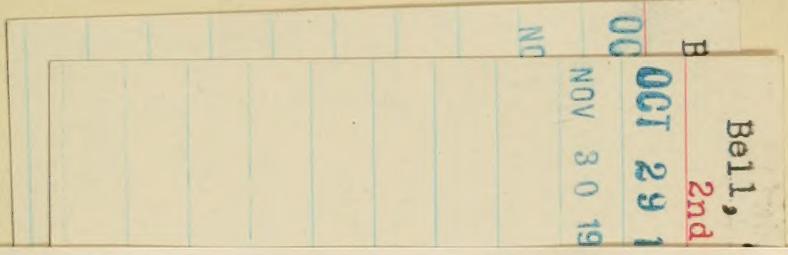


